\title{
Group physical therapy in ankylosing spondylitis
}

Citation for published version (APA):

Hidding, A. (1993). Group physical therapy in ankylosing spondylitis. [Doctoral Thesis, Maastricht University]. Rijksuniversiteit Limburg. https://doi.org/10.26481/dis.19931217ah

Document status and date:

Published: 01/01/1993

DOI:

10.26481/dis.19931217ah

Document Version:

Publisher's PDF, also known as Version of record

\section{Please check the document version of this publication:}

- A submitted manuscript is the version of the article upon submission and before peer-review. There can be important differences between the submitted version and the official published version of record.

People interested in the research are advised to contact the author for the final version of the publication, or visit the DOI to the publisher's website.

- The final author version and the galley proof are versions of the publication after peer review.

- The final published version features the final layout of the paper including the volume, issue and page numbers.

Link to publication

\footnotetext{
General rights rights.

- You may freely distribute the URL identifying the publication in the public portal. please follow below link for the End User Agreement:

www.umlib.nl/taverne-license

Take down policy

If you believe that this document breaches copyright please contact us at:

repository@maastrichtuniversity.nl

providing details and we will investigate your claim.
}

Copyright and moral rights for the publications made accessible in the public portal are retained by the authors and/or other copyright owners and it is a condition of accessing publications that users recognise and abide by the legal requirements associated with these

- Users may download and print one copy of any publication from the public portal for the purpose of private study or research.

- You may not further distribute the material or use it for any profit-making activity or commercial gain

If the publication is distributed under the terms of Article $25 \mathrm{fa}$ of the Dutch Copyright Act, indicated by the "Taverne" license above, 
GROUP PHYSICAL THERAPY IN ANKYLOSING SPONDYLITIS 


\section{CIP-GEGEVENS KONINKLIJKE BIBLIOTHEEK, DEN HAAG}

Hidding, Alita

Group physical therapy in ankylosing spondylitis / Alita

Hidding. - [S.I. : s.n.]. - Ill.

Proefschrift Maastricht. - Met lit. opg. - Met

samenvatting in het Nederlands.

ISBN 90-9006693-4

Trefw.: gewrichtsziekten en groepsoefentherapie;

effectiviteit.

Logo: Stan Heynen

Layout: Tammo Delhaas

Printing: Krips Repro, Meppel 


\section{GROUP PHYSICAL THERAPY IN ANKYLOSING SPONDYLITIS}

\section{PROEFSCHRIFT}

ter verkrijging van de graad van doctor

aan de Rijksuniversiteit Limburg te Maastricht,

op gezag van de Rector Magnificus, prof. dr H. Philipsen, volgens het besluit van het College van Dekanen, in het openbaar te verdedigen op vrijdag 17 december 1993 om 14.00 uur

door

Alita Hidding

geboren te Groningen in 1960 
Beoordelingscommissie: Prof. dr P. Knipschild (voorzitter)

Prof. dr L. Bouter

Prof. dr H. Kuipers

Prof. dr R.M. Leidl

Prof. dr H. van Praag

This thesis comprises studies carried out in the Divisions or Departments of Rheumatology of the Maastricht University Hospital, the Leiden University Hospital, and the Alkmaar Medical Centre. The studies described were funded by the Health Insurance Executive Board (Investigation on Medicine grant Nr. OG90-018) and the 'Nationaal Rheumafonds' of the Netherlands. Financial support for the printing of this thesis came from the 'National Rheumafonds', Kabi Pharmacia, Bartlett Division of Pfizer, Jaeger Benelux, and Support. 
The support of all who have made it possible to complete this thesis is hereby gratefully acknowledged. 
Chapter 1

Chapter 2

Chapter 3

Chapter 4

Chapter 5

Chapter 6

Chapter 7

Chapter 8

Chapter 9

Chapter 10

Summary

Samenvatting

Curriculum Vitae

General introduction.

Group physical therapy in Ankylosing Spondylitis in the Netherlands.

Therapeutic effects of individualized physical therapy in Ankylosing Spondylitis related to duration of disease.

Is group physical therapy superior to individualized therapy in Ankylosing Spondylitis? A randomized controlled trial.

Continuation of group physical therapy is necessary in Ankylosing Spondylitis. Results of a randomized controlled trial.

Cost-effectiveness of group physical therapy added to individualized therapy for Ankylosing Spondylitis. A randomized controlled trial.

Factors related to changes in global health after group physical therapy in Ankylosing Spondylitis.

Determinants of self-reported health status in Ankylosing Spondylitis.

Discordance between self-report measures and clinical observations of functional disability in Ankylosing Spondylitis, Fibromyalgia and Rheumatoid Arthritis.

General discussion. 


\section{CHAPTER 1}

\section{GENERAL INTRODUCTION}


Ankylosing Spondylitis (AS) is a chronic systemic inflammatory disorder of unknown etiology, affecting mainly the axial skeleton. Sacroiliac joint involvement (sacroiliitis) is its hallmark. The diagnosis of AS is based on clinical features. The most recent criteria for AS are the modified. New York criteria $[1,2]$.

The prevalence of AS in the Netherlands is about $0.1 \%$ [3]. This means that at least 15000 persons in the Netherlands have AS. The disease is common among HLA-B27 positive first-degree relatives of AS-patients. Indeed, $11 \%$ to $21 \%$ of them may have signs or symptoms of AS. Clinically, the disease is two to three times more common in men than women $[1,3,4]$.

AS is largely diagnosed on clinical aspects. The most common early complaints are chronic low back pain and stiffness. Patients also frequently report musculotendinous tender spots and bony tenderness. The hips and shoulders are involved at some stage of disease in onethird of patients. Involvement of other peripheral joints is relatively infrequent, but it may be a presenting feature in $10 \%$ to $15 \%$ of the patients [1,5]. Extraskeletal manifestations of AS are acute anterior uveitis and cardio-vascular and pulmonary involvement $[1,6,7]$.

There is currently no cure for AS, but most patients can be adequately managed. The aim of treatment of AS is maintaining or improving general functioning and quality of life. Nonsteroidal anti-inflammatory drugs can reduce pain and inflammation, while regular exercises and physical therapy of AS patients are thought to improve mobility, strength and fitness $[1,8,9]$.

Three kinds of physical therapy for AS can be distinguished: supervised individualized therapy, unsupervised self-administered individualized therapy or exercises at home, and supervised group therapy. In the Netherlands, patients diagnosed as having AS usually first receive a course of supervised individualized therapy. Afterwards, the patients are expected to exercise daily without supervision. Some patients add group physical therapy to their individualized therapy in supervised gym classes and pool sessions with the intention to enhance the effects of the individual exercises. Frequently, the patients initiate group physical therapy themselves.

Group physical therapy has existed for several years in the Netherlands. The effects of group physical therapy are as yet unknown. Some studies of the effects of group physical therapy show promising results, but these studies have serious methodological flaws, which makes it difficult to draw firm conclusions about the efficacy of group therapy [10]. Altogether, 12 studies of physical therapy in AS were published between 1966 and 1991 [11 21]. These studies have been reviewed by Schlumpf [22]. Only 5 studies were controlled trials $[14-17,21]$, and only 1 of the 5 studies reported on group physical therapy [17] (Table). However, the control group in this study was not a randomized control group. We decided to study the efficacy of group physical therapy in a randomized controlled trial in 
Table. Trials on the efficacy of physical therapy in AS.

\begin{tabular}{lllll}
\hline Author & $\begin{array}{l}\text { Year of } \\
\text { publication }\end{array}$ & Therapy & RCT & $\begin{array}{c}\text { Conclusion } \\
\text { of author }\end{array}$ \\
\hline Wynn-Parry [1]] & 1966 & supervised/individualized & no & positive \\
Dixon [12] & 1977 & supervised/individualized & no & positive \\
Tomlinson [13] & 1986 & supervised/individualized & no & positive \\
Liman [14] & 1987 & supervised/individualized & yes & positive \\
O'Driscoll [15] & 1987 & supervised/individualized & yes & positive \\
Bulstrode [16] & 1987 & supervised/individualized & yes & no effect \\
Allington [17] & 1987 & group & no & positive \\
Mucha [18] & 1987 & group & no & positive \\
Keck [19] & 1988 & group & no & no effect \\
Rasmussen [20] & 1989 & group & yes & positive \\
Kraag [21] & 1990 & unsupervised/individualized & &
\end{tabular}

$\mathrm{RCT}=$ randomized controlled trial

* = effects of therapy on physical parameters

order to determine the effects as well as the costs of group therapy in AS. The study was supported by the Health Insurance Executive Board of the Netherlands (grant Nr. OG90018 ). Chapters 3 to 6 of this thesis describe this study of group physical therapy.

These chapters are preceded by a description of the present state of group physical therapy in AS in the Netherlands in chapter 2. Chapter 3 then reports on the influence of the duration of disease on the short term effects of supervised individualized physical therapy, based on a 'before-after' study. The purpose of this study was to test for differences in efficacy of therapy between patients with a longer duration of disease and more recently diagnosed patients. We present the results of physical outcome measures (mobility, fitness, functioning, and global health) after a 6-week period of supervised individualized therapy in 144 patients. This was a study with a weak study design: before-after comparisons were made and controls were not included.

Chapter 4 presents the results of a randomized controlled trial of group physical therapy compared with exercises at home. Physical outcome measures are reported after 9 months of exercises at home in $50 \%$ and the same plus supervised group physical therapy in the other $50 \%$ of the patients.

Chapter 5 presents the results of a randomized controlled trial of the persistence of the beneficial effects of group physical therapy. The participants were those patients who had been given group therapy in the preceding chapter. During a second 9 -month period $50 \%$ of these 
patients only exercised at home, while the other $50 \%$ did the same but also continued supervised group physical therapy. The same physical outcomes were assessed.

Cost-effectiveness can be used to help set priorities for funding health care programs. In chapter 6 the costs of the interventions are related to the beneficial effects of supervised group physical therapy. The results of this analysis are presented in terms of costs per unit of effect.

Factors related to patient's assessment of change in global health after the first 9-month period of group physical therapy are studied in chapter 7 .

The contribution of non-physical factors to health status in AS is the subject of chapter 8 . Results of the group trial indicated that supervised group physical therapy was superior to exercises at home in improving thoraco-lumbar mobility and fitness, but this superiority did not show up in health status self-reports such as the Health Assessment Questionnaire for the Spondyloarthropathies or the Sickness Impact Profile. One reason may be that it is not only physical factors such as mobility and fitness which contribute to the level of health status but personal and social factors as well. This chapter assesses the relative contributions of disabilityrelated factors, as well as personality traits and social network variables to health status in AS.

Chapter 9 presents a study of the discordance between self-reported and observed functional disability, related to specific rheumatological diagnoses, such as AS, Fibromyalgia and
Rheumatoid Arthritis. All participants completed selected items of the Functional Index or the Arthritis Impact Measurement Scales. Subsequently, they actually performed the selected activities. This was recorded on video, the tapes being assessed in random order by 6 occupational therapists and 6 clinicians.

Chapter 10 consists of a general discussion of the findings of this thesis.

\section{REFERENCES}

1. Khan MA, van der Linden S: Ankylosing Spondylitis and other Spondyloarthropathies. Rheum Dis Clin North America 1990; 16: 551-578

2. van der Linden S, Valkenburg HA, Cats A: Evaluation of diagnostic criteria for Ankylosing Spondylitis: A proposal for modification of the New York criteria. Arthritis Rheum 1984; 27: 361-368

3. van der Linden $S$, Valkenburg HA, de Jongh BM, Cats A: The risk of developing Ankylosing Spondylitis in HLA-B27 positive individuals. A comparison of relatives of Spondylitis patients with the general population. Arthritis and Rheum 1984; 27 : 241-249

4. Calin A, Marder A, Becks E, Burns T: Genetic differences between B27 positive patients with Ankylosing Spondylitis and B27 positive healthy controls. Arthritis Rheum 1983; 26: 1460-1464

5. van der Linden S, Khan MA, Rentsch HU: Chest pain without radiographic sacroiilitis 
in relatives of patients with Ankylosing Spondylitis. J Rheumatol 1988; 15 : 836839

6. Khan MA, Kushner I, Braun WE: Comparison of clinical features in HLAB27 positive and negative patients with Ankylosing Spondylitis. Arthritis Rheum 1977; 20: 909-912

7. Khan MA: Ankylosing Spondylitis. In: Calin A (ed): Spondyloarthropathies. New York: Grune \& Stratton, 1984; 69-117

8. Spring H: Funktionsorientierte Gymnastik und Sport bei der Spondylitis Ankylosans. In: Spondylitis Ankylosans. Bern: Verlag Hans Huber, 1989; 117-132

9. Fellmann N: Die rheumatischen Spondylitiden und ihre Bewegungstherapie. Krankengymnastik 1984; 1: 16-31

10. Sackett DL, Haynes RB, Guyatt GH, Tugwell P: Clinical epidemiology. A basic science for clinical medicine. Second edition. Boston / Toronto / London: Little, Brown and Company, 1991

11. Wynn-Parry CB: Management of Ankylosing Spondylitis. Proceed Roy Soc Med 1966; 59: 619-623

12. Dixon ASJ: Ankylosing Spondylitis and spinal osteotomy. Proceed Roy Soc Med $1977 ; 70: 53-54$

13. Tomlinson M, Barefoot J, Dixon AS: Intensive in-patient physiotherapy courses improve movement and posture in Ankylosing Spondylitis. Physiotherapy 1986; 72: $238-240$

14. Liman W, Weimann G: Kardiorespirato- rische Belastbarkeit Kranker mit ankylosierender Spondylitis und ihre Beeinflussbarkeit durch ergometrisches Training. Zeitschr Phys Med $1987 ; 5 ; 218-223$

15. O'Driscoll SL, Jayson MIV, Baddeley $\mathrm{H}$ : Neck movements in Ankylosing Spondylitis and their responses to Physiotherapy. Ann Rheum Dis 1987; 37: 64-66

16. Bulstrode SJ, Barefoot J, Harrison A, Clarke AK: The role of passive stretching in the treatment of Ankylosing Spondylitis. Br J Rheum 1987; 26: 40-42

17. Allington L, Cunnington SJ, Mathews M, Speedely J, Trussell EC, Ward E, McKenzie JMM, Swannell AJ: The effect of regular physiotherapy on mobility and shape of the spine in patients with Ankylosing Spondylitis over a two-year period. Br J Rheum 1987; 26 (Suppl 1): 70

18. Mucha C: Effizienz und Gestaltung ambulanter physikalisch-medizinischer Gruppentherapie bei Patienten mit ankylosierender Spondylitis. Zeitschr Phys Med Baln Klim 1987; 16: 65-78

19. Keck E, Cronenberg A: Spondylitis Ankylosans. Effizienz und Möglichkeiten der kranken-gymnastische Behandlung in einer Selbsthilfegruppe. Krankengymnastik 1988; 40: $821-826$

20. Rasmussen JO, Hansen TM: Physical training for patients with Ankylosing Spondylitis. Arthritis Care Res 1989; 2: 25-27

21. Kraag G, Stokes B, Groh J, Helewa A, Goldsmith C: The effects of comprehensive home physiotherapy and supervision on 
patients with Ankylosing Spondylitis. A randomized controlled trial. J Rheumatol $1990 ; 17: 228-233$
22. Schlumpf U: Ziele und Chancen der Physiotherapie bei Spondylitis Ankylosans. Schweiz Rundschau Med 1991; 21: 36-40 


\section{CHAPTER 2}

\section{GROUP PHYSICAL THERAPY IN ANKYLOSING SPONDYLITIS IN THE NETHERLANDS}

Alita Hidding and Sjef van der Linden

Department of Internal Medicine, Division of Rheumatology, University of Limburg and University Hospital Maastricht, The Netherlands 


\section{ABSTRACT}

Objective: To study the targets and organization of group physical therapy in patients with Ankylosing Spondylitis (AS) in the Netherlands.

Methods: A questionnaire was sent to the therapists of 31 groups engaged in physical therapy for AS. The questionnaire included 4 issues: overall targets, therapists (number, training and specialization), exercise group (accomodation and group size), and therapy (components and duration).

Results: A total of $25(81 \%)$ questionnaires were completed and returned. All therapists indicated as the most important targets: maintaining or improving mobility, strength, and fitness. In all, 63 therapists ( 58 physiotherapists, 5 P.E. teachers) supervised the 25 groups (median 2, range $1-11)$. Only $5(8 \%)$ of them had received a course in group therapy. The average group size was 22 (SD 11). All 25 therapy groups received at least physical training, while 21 groups engaged in sports and 18 groups received additional hydrotherapy. The total average therapy time was 95 (SD 30) minutes per week.

Conclusions: The results show a high level of agreement among therapists in the Netherlands regarding the targets of group physical therapy in AS. However, the organization, in terms of group size, components and duration of therapy, shows more diversity.

\section{INTRODUCTION}

Regular exercises and physical therapy for Ankylosing Spondylitis (AS) patients are thought to maintain or improve general functioning and quality of life [1 - 2]. In the Netherlands, patients diagnosed as having AS usually first receive a 6 -week course of supervised individualized physical therapy treatments. Afterwards, the patients are expected to exercise daily. Some patients then start supervised group physical therapy (supervised gym classes and pool sessions) with the intention to enhance the effects of the individual exercises [ 3 - 5]. Frequently, the patients initiate group physical therapy themselves. At this moment there are many physical therapy groups for AS patients in the Netherlands. The present study investigated the targets and organization of these physical therapy groups. The main topics of this study were the degree of consensus about the specific aims of the groups and ways of accomplishing these aims.

\section{METHODS}

\section{Participants}

The Dutch League against Rheumatism ('Nationaal Rheumafonds') provided information about the existing physical therapy groups for AS in the Netherlands. At that moment, in 1991, 31 groups were active. These groups were asked to participate in the study. 


\section{Questionnaire}

A questionnaire was developed including questions about the targets and organization of the group therapy in AS. This questionnaire was sent to the therapists of the 31 therapy groups.

The questionnaire included the following issues:

- overall targets;

- therapists, comprising questions about the number, professional training and specialization of the therapists;

- exercise group, comprising questions about accomodation and group size;

- therapy, asking about the constituent components such as physical exercises, sports and hydrotherapy, and about the duration of each of these elements of therapy. The physical exercise section comprised questions about the purposes and intensity of therapy, and the muscles and joints on which the therapy was focussed. The sports section comprised questions about the purposes of the sports, the types of sports and the nature of the sporting activities. The hydrotherapy section inquired about the purposes and nature of this kind of therapy as well.

\section{RESULTS}

Of the 31 questionnaires, $25(81 \%)$ were completed and returned. All therapists reported as the most important overall targets of group physical therapy: maintaining or improving mobility, strength, and fitness.
Specific targets of the physical exercises were improving shape and intensifying respiration. The physical training included exercises to improve mobility of the spine and peripheral joints, such as shoulders, knees and hips. In addition, exercises were done to strengthen the muscles of the trunk, the back muscles and the abdominal muscles, as well as the muscles of the legs and the respiratory muscles. The intensity of the physical exercises was reported using one of the two following descriptions: 'just reaching the pain limit' or 'exceeding the pain limit'. A total of $23(92 \%)$ groups chose 'just reaching the pain limit'.

The specific target of the sporting activities was stretching the back, for instance through volleyball, basketball or badminton. Social contacts and spontaneous exercising were important additional aims of the sporting activities. This was reflected by the answers about the nature of the sporting activities. Only 1 (5\%) group described the activities as competitive, while $9(47.5 \%)$ groups reported a recreative nature, and $9(47.5 \%)$ groups emphasized the easy and unconstrained nature of the sporting activities.

Hydrotherapy was given in heated water in order to relax the body, to reduce pain, and to improve mobility of the spine and peripheral joints. The intensity of hydrotherapy was reported using one of the two following descriptions: 'just reaching the pain limit' or 'exceeding the pain limit'. The intensity of therapy was de 
Table. Some characteristics of 25 groups of physical therapy for AS in the Netherlands (1991).

\begin{tabular}{|c|c|c|c|}
\hline \\
\hline therapists & total & mean & SD \\
\hline number of physiotherapists & 57 & 2.3 & 1.8 \\
\hline number of Mensendieck therapistg & 1 & 0.04 & 0.2 \\
\hline number of P.E. teachers & 5 & 0.2 & 0.8 \\
\hline total number of therapists & 63 & 2.5 & 2.2 \\
\hline \multicolumn{4}{|l|}{ exercise group } \\
\hline & mean & SD & range \\
\hline \multirow{2}{*}{$\begin{array}{l}\text { group size } \\
\text { (number of patients/group) }\end{array}$} & 21.9 & 11.1 & $4-45$ \\
\hline & total & percentage & \\
\hline \multirow{2}{*}{$\begin{array}{l}\text { number of groups with } \\
\text { hydrotherapy accomodation }\end{array}$} & 18 & $72 \%$ & \\
\hline & mean & $\mathrm{SD}$ & range \\
\hline water temperature $\left({ }^{\circ} \mathrm{C}\right)$ & 31.4 & 2.4 & $28-37$ \\
\hline therapy & total numbe & & \\
\hline components & of groups & percentage & \\
\hline physical exercise & 25 & $100 \%$ & \\
\hline sports & 21 & $84 \%$ & \\
\hline hydrotherapy & 18 & $72 \%$ & \\
\hline duration ( $\mathrm{min} /$ weekly therapy session) & mean & SD & range \\
\hline physical exercise & 39 & 14 & $15-60$ \\
\hline sports & 36 & 14 & $15-75$ \\
\hline hydrotherapy & 37 & 10 & $20-60$ \\
\hline total duration of therapy & 95 & 30 & $30-155$ \\
\hline
\end{tabular}

scribed as 'just reaching the pain limit' in nearly all cases $(94 \%)$. The patients received intensive supervision in $2(12.5 \%)$ groups, while less intensive supervision was reported in $2(12.5 \%)$ groups, and $12(75 \%)$ groups mentioned a very low level of interference by the therapists during the hydrotherapy.

Some characteristics of the 25 physical therapy groups for AS are given in the Table. In all, 63 physical therapists supervised the 25 groups (median 2, range 1 - 11). Of these, 57 $(90 \%)$ were physiotherapists, $\mathbb{1}(2 \%)$ was a Mensendieck therapist, and $5(8 \%)$ were P.E. teachers. Only $5(8 \%)$ of them had ever received a course in group therapy, such as a course on hydrotherapy or group gymnastics.

The average size of the groups was 22 (SD 11 , range $4-45)$ patients. A total of $14(56 \%)$ 
groups were supervised by 1 therapist, while 8 ( $32 \%$ ) groups were supervised by 2 therapists together. The remaining 3 groups did not answer this question.

All 25 therapy groups received at least physical training, while 21 (84\%) groups engaged in sports and $18(72 \%)$ groups received additional hydrotherapy, depending on the presence of a swimming pool. The average temperature of the water during the hydrotherapy sessions was $31.4{ }^{\circ} \mathrm{C}(\mathrm{SD} 2.4$, range $28-37$ ). The total average therapy time was 95 (SD 30, range 30 - 155) minutes per week. Time for physical training was, on average, 39 (SD 14, range 15 60) minutes, for sports 36 (SD 14, range 15 75 ) minutes, and for hydrotherapy 37 (SD 10, range $20-60$ ) minutes.

\section{DISCUSSION}

The results of the questionnaire show a high degree of consensus among therapists in the Netherlands regarding the specific aims or targets of group physical therapy in AS. There was, however, greater diversity in the opinions about the way in which these aims should be accomplished. The organization, i.e. group size, constituent components and duration of therapy varied considerably between therapists. This means that a standardization of group physical therapy in AS would require particular emphasis on the organization and management of therapy.
The prevalence of AS in the Netherlands is about $0.1 \%$ [6]. This means that there are at least 15000 persons in the Netherlands who have this disease. In 1991 there were 31 Dutch groups of AS patients receiving group physical therapy, with an average size of 22 persons. This means that $5 \%$ of the AS patients were receiving group physical therapy. It is worth stressing that group physical therapy in AS has largely arisen and expanded spontaneously. This probably explains the diversity in the organization. The rising popularity of group therapy is striking, because the effects of group therapy have only recently been studied in a randomized controlled trial [8 - 13]. Furthermore, the health insurers only refund part of the costs of group therapy.

The results of the questionnaire indicate that only $8 \%$ of the group physical therapists had ever received a course in group therapy, such as a course on hydrotherapy or group gymnastics. In the Netherlands there are as yet no specific courses for group physical therapy in AS. Setting up such a course will be necessary in order to train new therapists, to exchange experience and to provide in-service training for those therapists already working in this field. Such a course might allow attention to be paid to the targets as well as the organization, which might reduce the diversity regarding the organization of group therapy. If group physical therapy for AS patients is to be organized at a professional level, standardization of the organization will be inevitable. 


\section{REFERENCES}

1. Spring H: Funktionsorientierte Gymnastik und Sport bei der Spondylitis Ankylosans. In. Spondylitis Ankylosans. Bern: Verlag Hans Huber 1989; 117-132

2. Fellmann N: Die rheumatischen Spondylitiden und ihre Bewegungstherapie. Krankengymnastik 1984; 1: 16-31

3. Oosterveld FGJ, Ruesink A, Rasker JJ: Fysiotherapie in groepen bij patiënten met Spondylitis Ankylopoëtica. Een pilotstudy. Ned Tijdschr Fysiother 1987; 97 : 116-122

4. Abspoel M, Obbens HJM: Fysiotherapeutische interventies bij Spondylitis Ankylopoëtica. Ned Tijdschr Fysiother 1987; 97: 234-239

5. Obbens HJM, Abspoel M: Onderzoek naar het effect van fysiotherapeutische interventies bij Spondylitis Ankylopoëtica. Ned Tijdschr Fysiother 1987; 97: 240-247

6. Khan MA, van der Linden S: Ankylosing Spondylitis and other Spondyloarthropathies. Rheum Dis Clin North America $1000 ; 1.6: 551: 578$

7. Schlumpf U: Ziele und Chancen der Physiotherapie bei Spondylitis Ankylosans. Schweiz Rundschau Med 1991; 21: 36-40

8. Hidding A, de Witte L, Dijkmans B, van der Linden S: Groepsoefentherapie bij
Spondylitis Ankylopoëtica. Abstract. Ned Tijdschr Geneesk 1992; 42: 2104

9. Hidding $A$, Gielen $X$, van der Linden $S$ : Group physical therapy added to individual therapy in Ankylosing Spondylitis. Abstract. Clinical Rheumatology 1992; 11: 295

10. Hidding A, de Witte $\mathrm{L}$, van der Linden $S$ : Group physical therapy added to individual therapy in Ankylosing Spondylitis. Abstract. Arthritis Rheum 1991; 34: S173

11. Hidding $A$, van der Linden $S$, Boers $M$, Gielen X, Kester A, de Witte L, Dijkmans $\mathrm{B}$, Moolenburgh $\mathrm{D}$ : Is group physical therapy superior to individualized therapy in Ankylosing Spondylitis? A randomized controlled trial. Arthrits Care Res 1993, 6: 117-125

12. Hidding $A$, van der Linden $S$, Gielen $X$, de Witte L, Dijkmans B, Moolenburgh D: Continuation of group physical therapy is necessary in Ankylosing Spondylitis. Results of a randomized controlled trial. Arthritis Care Res 1994, in press

13. Bakker C, Hidding A, van der Linden S, van Doorslaer E: Cost-effectiveness of group physical therapy added to individualized therapy in Ankylosing Spondylitis. A randomized controlled trial. J Rheumatol 1994 , in press 


\section{CHAPTER 3}

\section{THERAPEUTIC EFFECTS OF INDIVIDUALIZED PHYSICAL THERAPY IN}

ANKYLOSING SPONDYLITIS RELATED TO DURATION OF DISEASE

Alita Hidding, Sjef van der Linden, and Luc de Witte ${ }^{1)}$

Department of Internal Medicine, Division of Rheumatology, University of Limburg and University Hospital Maastricht, 1) Institute for Rehabilitation Research, Hoensbroek, The Netherlands

Clinical Rheumatology 1993, 12: 334-340 


\section{ABSTRACT}

Objective: Physical therapy in Ankylosing Spondylitis (AS) is considered important in maintaining or improving mobility, fitness, functioning, and global health. We studied the influence of disease duration on the short term effects of supervised individualized therapy.

Methods: 144 AS outpatients (modified New York Criteria, mean age: 43 years, median duration of disease: 4 years, range: 0 - 33) received 12 supervised individualized treatment sessions, each lasting 30 minutes, in a 6-week course. Endpoints were: spinal mobility (thoracic and lumbar flexion and extension, chest expansion, cervical rotation), fitness (maximum work capacity by ergometry), functioning (Sickness Impact Profile (SIP) and Functional Index (FI)), and patient's global assessment of change on a visual analogue scale.

Results: After 6 weeks patients had improved in all endpoints, but only sigificantly so in rotation ( 8 degrees, $10 \%$ ), fitness ( 6 watt, $4 \%$ ), and SIP $(0.6,14 \%$; t-test, $\mathrm{p}<0.05)$. Global patient assessment improved by $1.1(22 \%)$. Plots of change scores and disease duration showed no evident relation. We also divided the population into two groups, with the median disease duration as cut-off. No relevant difference in improvement was found between the 'short duration' and 'long duration' groups (t-test of change scores, $\mathrm{p}>0.05$ ). In addition, no relevant correlation was found between change scores and disease duration $(p>0.01)$.

Conclusion: Irrespective of disease duration, short term supervised individualized therapy is effective in AS in slightly improving mobility, fitness, functioning and global health.

\section{INTRODUCTION}

Ankylosing Spondylitis (AS) is a chronic progressive inflammatory disorder mainly affecting the axial skeleton. The treatment of AS consists of the use of NSAIDs to reduce pain and inflammation, as well as regular exercises and physical therapy, in order to improve mobility, strength and fitness [1]. Three kinds of physical therapy for AS can be distinguished: supervised individualized therapy, unsupervised self-administered individualized therapy, and supervised group therapy. In the Netherlands, patients diagnosed as AS usually receive a course of supervised individualized therapy treatment.

A MEDLINE literature search of randomized controlled trials of physical therapy in AS covering the period 1983-1992 (keywords: Ankylosing Spondylitis, physical therapy, physiotherapy, and outcome) revealed only 1 review about physical therapy in AS [2]. This review reported on 5 controlled studies of individualized or group physical therapy in AS [37]. Four studies reported improvement in mobility, fitness, functioning and general pain after individualized therapy $[3-5,7]$, while 1 study reported stabilization of mobility after group therapy [6]. It was at yet unknown, however, whether the therapeutic effects were related to disease duration. We hypothesized a linear negative relation between disease duration 
and the effects of therapy on mobility, fitness, functioning, and global health. AS is a chronic inflammatory disorder with progressive ankylosing mainly of the spine. In a later stage of the disease it is very difficult to improve mobility. Physical therapy might be less effective in longstanding AS. Therefore, we decided to study the relation between disease duration and the effects of physical therapy.

\section{METHODS}

\section{Selection of patients}

333 AS patients from 2 outpatient rheumatology clinics were asked to participate in the study. All patients were younger than 70 years. A total of 163 (49\%) subjects agreed to participate in the study and gave written informed consent.

All participants were examined by one rheumatologist to check for the inclusion criteria (AS satisfying modified New York criteria [8]; presence of symptoms of pain, stiffness, or functional limitations within the last 3 months) and exclusion criteria (inability to engage in physical therapy, total hip replacement, pregnancy, hypertension [diastolic blood pressure $>100 \mathrm{~mm} \mathrm{Hg}$ at rest], cardiovascular disease [history of ischemic event, angina pectoris, heart failure], severe lung disease, diabetes mellitus, renal failure, chronic liver disease, malignancy, recent major surgery, mental retardation, serious emotional disorder). A total of 10 patients were excluded: 2 patients did not satisfy the modified New York criteria, 1 had had a to- tal hip replacement, 4 had cardiac problems, and 3 had emotional disorders, while 9 patients stated they were unable to exercise daily. Therefore, 144 patients received supervised individualized therapy. Characteristics of the population are given in Table 1.

\section{Study design}

All patients received supervised individualized therapy during 6 weeks. All patients were assessed by one observer at baseline and after 6 weeks.

Cointervention with additional use of medication was checked [9]. All patients continued to receive rheumatological care and medication during the study. The research team did not influence this care in any way.

\section{Intervention}

The supervised individualized therapy consisted of a series of 12 supervised treatment sessions, each lasting 30 minutes, two times a week, from a physiotherapist who had been selected by the patient. All therapists had received detailed oral and written instructions about the contents of the therapy from the investigator. The patients received an individualized exercise program directed at the entire spine, hip joints and peripheral joints $[10,11]$. The therapists encouraged the patients to continue the exercises at home for 30 minutes daily, over the whole study period. The patients were asked to note in diaries whether they had indeed performed un. supervised individualized therapy during the study. 
Table 1. Characteristics of population at baseline $(n=144)$.

\begin{tabular}{|c|c|c|}
\hline \multicolumn{3}{|l|}{ Age (years) } \\
\hline $\operatorname{Mean}(\mathrm{SD})$ & & $42.6(10.4)$ \\
\hline \multicolumn{3}{|c|}{ Duration of disease (years) } \\
\hline Median (ra & ige) & $4(0-33)$ \\
\hline \multicolumn{3}{|c|}{ Socio-demographic characteristics (\%) } \\
\hline male & & 78 \\
\hline married & & 67 \\
\hline employed & & 72 \\
\hline \multirow[t]{3}{*}{ income. 1) } & high & 20 \\
\hline & middle & 54 \\
\hline & low & 26 \\
\hline \multirow{3}{*}{$\begin{array}{l}\text { education } \\
\text { level:2) }\end{array}$} & high & 21 \\
\hline & middle & 44 \\
\hline & low & 35 \\
\hline \multicolumn{3}{|c|}{ Physical therapy (\% taking) } \\
\hline supervised & individualized & 83 \\
\hline \multicolumn{3}{|c|}{ Medications (\% taking) } \\
\hline NSAIDs & & 69 \\
\hline Analgetics & & 4 \\
\hline DMARDs & & 4 \\
\hline \multicolumn{3}{|c|}{ Sporting activities (hours/week) } \\
\hline Median (ra & ige) & $1(0-16.9)$ \\
\hline \multicolumn{3}{|c|}{ Erythrocyte Sedimentation } \\
\hline \multicolumn{3}{|c|}{ Rate (mm/hour) } \\
\hline Median (ra & ige) & $15(2-64)$ \\
\hline
\end{tabular}

NSAMs = nonsteroidal antintlammatory drugs.

DMARDs - disease modifying antirheumatic drugs.

1) US dollars net per month. high: $>2000$; middle: $1000-2000$ \$ low: $<1000 \$$

2) years of education (including primary school), high; $>15$ years; middle: $10=15$ years; low: $<10$ years

\section{Assessments}

Spinal mobility, physical fitness, functioning, and patient's assessment of change in global health had been defined as primary endpoints before the start of the study. In addition, general pain and stiffness, as well as a count of painful joints and entheses were assessed. These measures were considered as secondary endpoints.

\section{Spinal mobility was assessed as follows:}

- Thoraco-lumbar flexion and extension. The $10 \mathrm{~cm}$ segment method (flex/ext), as described by Miller, was used [12].

- Chest expansion. The difference in circumference between maximal inspiration and expiration was measured by a tape-measure placed circumferentially around the chest wall at the level of the xiphoid processus, while the patient was standing with hands on head $[13,14]$. Two readings were made and the second was recorded.

- Cervical rotation. A goniometer was placed horizontally on the crown of the head. The rotation was measured with the subject sitting in neutral position. The pivot of the goniometer was centred on the occiput with a line through the nose. Scores on cervical rotation were the sum of left and right rotations.

All spinal mobility assessments were standardized and executed by one trained observer at the same time of the day for each patient.

Physical fitness or aerobic power was measured using an electronically braked bicycle ergometer (Jaeger ER800, Breda, The Netherlands). The saddle height was adjusted to the patient's height. The internal power delivered by the bicycle remained constant over a pedalling range of 45 to $75 \mathrm{rpm}$. During the test, 
heart rate was measured continuously using a sports tester (Support PE3000, Almere, The Netherlands). An incremental exercise test was used. The protocol started at 50 watts for 5 minutes and then increased by 10 watts every minute. All subjects performed up to their subjective maximum workload. The exercise was interrupted if the patient developed chest pain or the heart rate exceeded 200 beats $/ \mathrm{min}$. At the end of the exercise patients scored on the Borg Scale, a scale analogous to the heart rate, indicating the degree of perceived fatigue (Borg score should be equal to heart rate / 10; range 6 - 20; 6 = extremely easy; $20=$ extremely heavy). The analysis of exercise used maximum work load (watt), heart rate at maximum load (hrmax), and perceived exertion at maximum load (Borg) [15 - 17].

Functioning or health status was assessed by Sickness Impact Profile (SIP) [18 - 20], and the Functional Index for AS $[21,22]$.

- The SIP is a generic measure of health status. Answers to the 136-item questionnaire, divided into 12 categories, are computed using a weighted score, yielding a total score of dysfunction. We have applied a simplified version, which avoids the weighting procedure and uses only 52 selected items, without losing much information. This shortened version has been validated, but not yet published (personal communication AF de Bruin). The following factors are included in the 52-item SIP: mobility range, social participation, mobility control, psychic autonomy, somatic autonomy and affective stability. Answers to the 52-item questionnaire are added, giving a total score of dysfunction (range 0 - 52). Higher scores indicate more dysfunction.

- The Functional Index for AS is a valid measure and consists of 20 questions corresponding to activities of daily living. These activities may be limited by the disease. A score of ' $O$ ' is given if the task can be accomplished without difficulty, ' 1 ' if it is possible but difficult, and ' 2 ' if it is impossible to do. The answers are added, giving a total score of dysfunction.

Patient's global assessment of change was assessed by asking the patient to describe his or her perceived change in general functioning after treatment on a $10 \mathrm{~cm}$ horizontal visual analogue scale $(-5=$ maximum worsening, $0=$ no change, $+5=$ maximum improvement).

Pain was indicated by the patient on a horizontal $10 \mathrm{~cm}$ visual analoque scale $(0=$ no pain or stiffness, $10=$ worst pain or stiffness imaginable), and stiffness in minutes.

The joints and entheses examinations were assessed by the blinded observer, who applied articular and enthesopathy indices [21, 23].

The test-retest reliability of the variables mobility, fitness, pain, stiffness, articular and enthesopathy index was assessed in 19 ran= domly chosen patients (Table 2). These measures were again applied by the same blinded observer after 48 hours. Intraclass correlation scores for test-retest reliability were very high for mobility measurements $(0.91,0,91$ and $0.96)$ and pain (0.91), reasonable for fitness (0.72), stiffness (0.43) and articular index 
$(0.59)$, and poor for enthesopathy index $(0.31$; Table 2). After exclusion of 1 patient, who had extraordinary muscular pain on the first occasion, intraclass correlation of the enthesopathy index increased from 0.31 to 0.52 , and that of morning stiffness from 0.43 to 0.77 . Tests showing coefficients below 0.66 should probably be called rather unreliable, thus weakening a statistically significant improvement.

Table 2. Test-retest reliability after 48 hours $(n=19)$.

\section{PRIMARY OUTCOMES}

Spinal mobility

flex/ext $(\mathrm{cm})$ expansion $(\mathrm{cm})$ rotation (deg)

Physical fitness max load (watt)

$\frac{\text { test }}{\text { mean SD }} \frac{\text { re-test }}{\text { mean SD ICC }}$

$\begin{array}{rrrrr}5.6 & 2.9 & 5.7 & 2.9 & .96 \\ 4.3 & 2.2 & 4.3 & 2.1 & .91 \\ 95 & 47 & 93 & 40 & .91 \\ 182 & 35 & 187 & 30 & .72\end{array}$

\section{SECONDARY OUTCOMES}

pain $(\mathrm{cm})$ stiffness (min) articullar index enthesopathy index

$\begin{array}{rrrrr}3.0 & 2.6 & 2.5 & 2.4 & .91 \\ 25.5 & 36.6 & 16.8 & 23.2 & .43 \\ 2.4 & 2.8 & 2.1 & 2.1 & .59 \\ 1.1 & 2.6 & 0.5 & 1.0 & .31\end{array}$

ICC $=$ intraclass correlation coefficient.

\section{Data management and statistical analysis}

Data were summarized by mean, standard deviation (SD) or standard error of the mean (SEM), and - if appropriate - by median and range. Scores at baseline and after the 6-week physical therapy were compared using the t-test. Disease duration and change scores were plotted in order to check the relation between these two variables. Afterwards, we divided the population into two groups, with the median of disease duration as a cut-off: a 'long duration' group, with a disease duration of 5 years or longer $(\mathrm{n}=71)$, and a 'short duration' group, with a disease duration less than 5 years $(n=73)$. Differences between the "short and long duration' groups were checked using the t-test of change scores. Lastly, the Spearman correlation between disease duration and change scores was calculated.

\section{RESULTS}

Impact of disease duration on short term effects of therapy

After 6 weeks the total population had improved on all primary and secondary outcomes, except stiffness (Table 3). Although there was a statistically significant change in the enthesopathy index, this was not a real clinical significance because of the poor test-retest reliability for this measure (intraclass correlation 0.31 ). No relation between duration of disease and change scores could be demonstrated in plots of these two variables (Fig. 1). No relevant differences in improvement were found between the "long and short duration' groups for any of the primary or secondary outcomes (Table 4). Finally, no significant correlation was found between disease duration and change scores (Table 5) 
Table 3. Scores at baseline and change after 6 weeks $(n=144)$.

\section{PRIMARY}

$$
\text { baseline change }
$$

\section{OUTCOMES}

Spinal mobility

\begin{tabular}{|c|c|c|c|c|c|}
\hline flex/ext $(\mathrm{cm})$ & 5.3 & 0.2 & 0.0 & 0.1 & .92 \\
\hline expansion $(\mathrm{cm})$ & 3.7 & 1.2 & 0.2 & 0.1 & .06 \\
\hline rotation (deg) & 86 & 3 & 8 & 1 & $<.01$ \\
\hline \multicolumn{6}{|l|}{ hysical fitness } \\
\hline \multicolumn{6}{|l|}{ unctioning } \\
\hline SIP & 4.2 & 0.4 & 0.6 & 0.3 & .02 \\
\hline Functional Index & 8.2 & 0.4 & 0.1 & 0.3 & .67 \\
\hline \multicolumn{6}{|c|}{ atient's global assessment } \\
\hline change $(\mathrm{cm})$ & $\ldots$ & -- & 1.1 & 0.1 & -.. \\
\hline
\end{tabular}

\section{SECONDARY OUTCOMES}

\begin{tabular}{lrrrrc} 
pain (cm) & 3.8 & 0.2 & 0.5 & 2.0 & .79 \\
stiffness (min) & 30.4 & 3.9 & -0.4 & 2.7 & .89 \\
articular index & 3.8 & 0.4 & 0.3 & 0.3 & .25 \\
enthesopathy index & 2.9 & 0.7 & 1.0 & 0.3 & $<.01$ \\
\hline
\end{tabular}

Positive change implies improvement.

*) Paired samples t-test.

Fig. 1. Plots of disease duration and change scores of primary outcomes.

\section{Physical fitness}

At no point during the study the exercise test on the bicycle ergometer had to be stopped because of chest pain. At baseline, patients reported a relatively low mean peak heart rate $(141$, range $78-200)$ related to a high perceived exertion (mean Borg score 15.9, range 13-20). After 6 weeks the exercise test was adequately performed: mean peak heart rate was 153 (range 85 - 199), and mean Borg score was 15.2 (range $11-19$ ).

\section{Compliance and cointervention}

During the 6-week period of supervised individualized therapy the patients reported in their diaries that they had spent an average time of 3.0 hours per week on their exercises at home (SD 1.8, range $0-10.2$ ) and 1.9 hours per week on sports (SD 2.5, range $0-17.5$ ).

Cointervention with additional use of medication was checked in experimental and control patients. No relevant changes in use of medication were found during the 6-week period (data not shown).

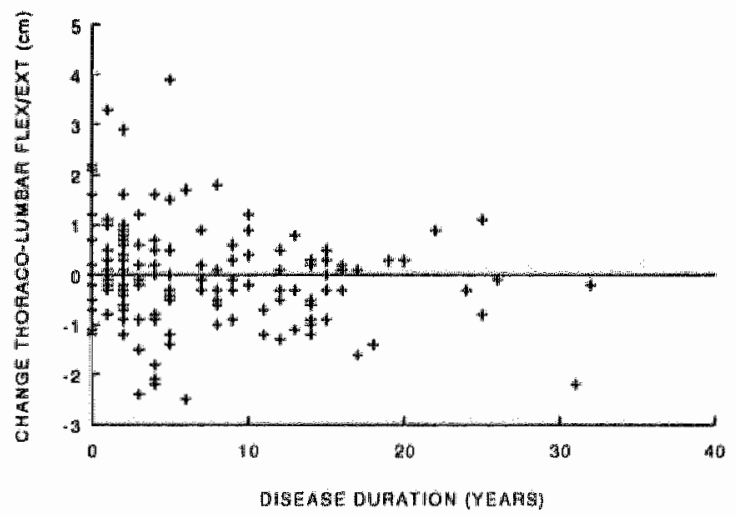



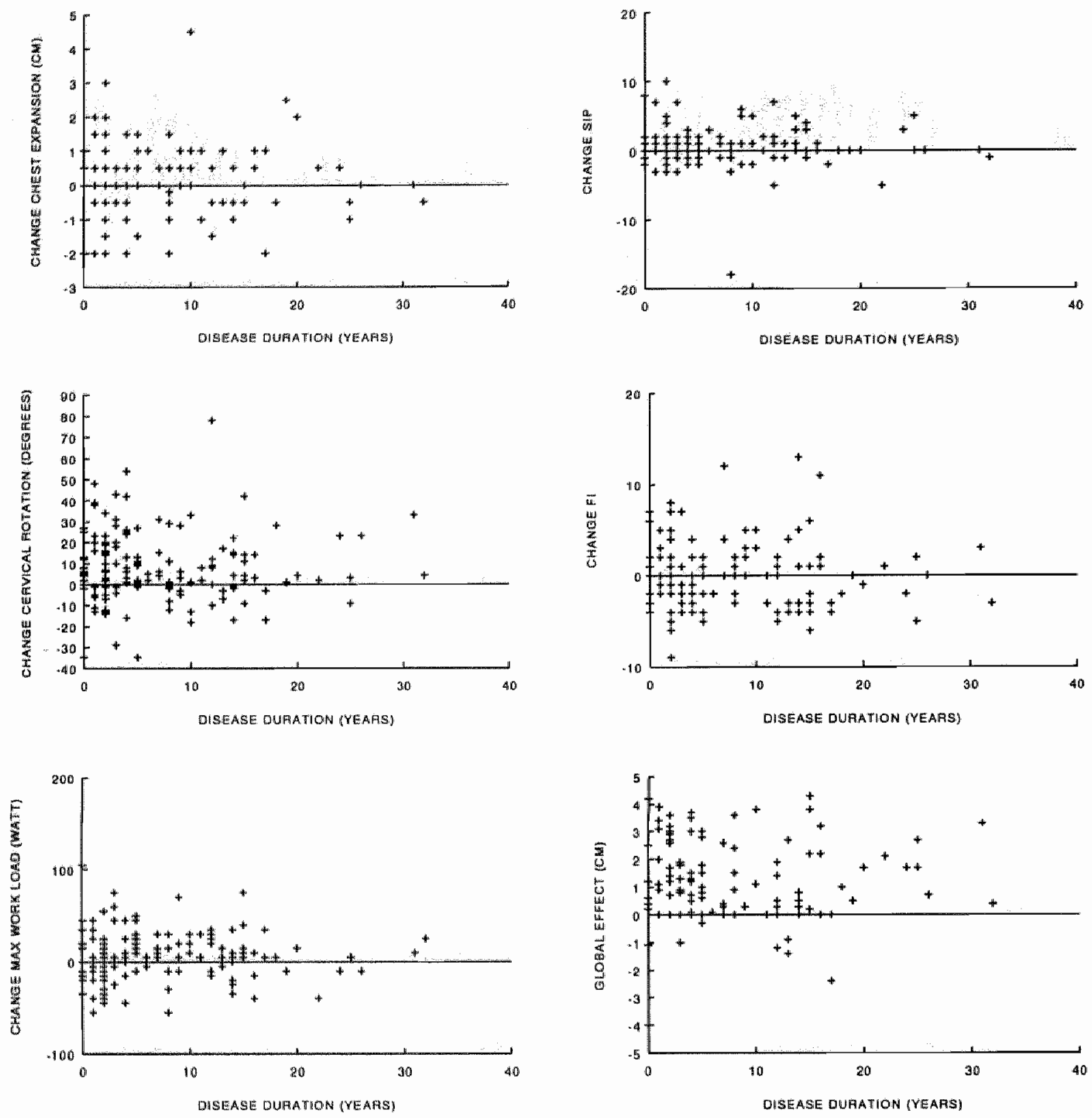
Table 4. Comparison between "long and short duration' groups.

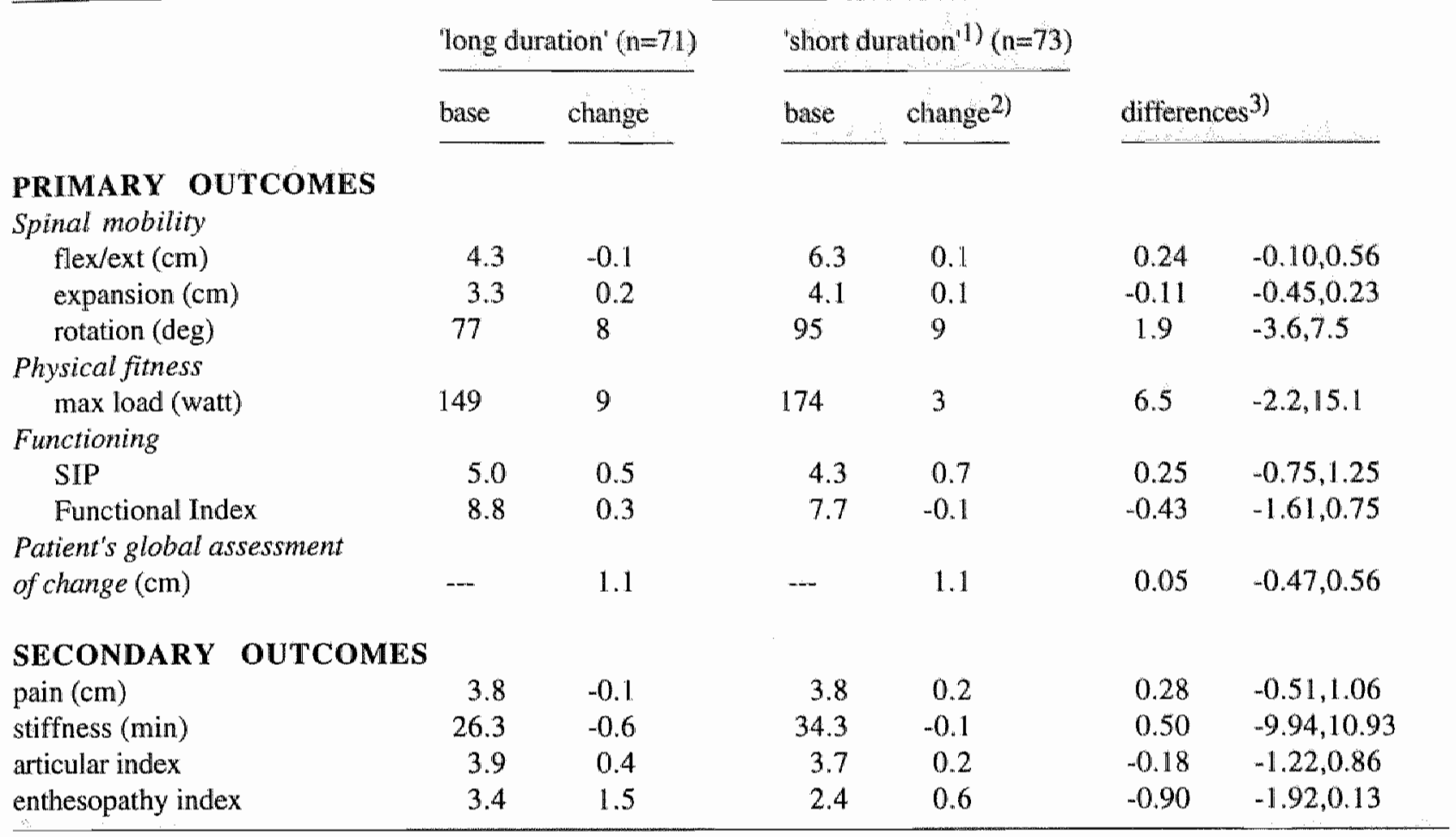

1) 'long duration' group: disease duration $\geq 5$ years; 'short duration' group: disease duration $<5$ years.

2) Values are mean at baseline, change scores at 6 weeks. Positive change implies improvement.

3) Differences between 'Jong and short duration' groups with $95 \%$ confidence interval.

\section{DISCUSSION}

\section{Study design}

In a group of patients of whom $83 \%$ had already received supervised individualized therapy in the past, this trial still found clinically rather small, but statistically significant positive effects of supervised individualized therapy on cervical mobility, fitness and functioning. In addition, a major improvement of $1.1 .(22 \%)$ in global health was reported by the patients. It should be noted that this study was not a blinded randomized controlled trial. This would. have required a control group of at least $50 \mathrm{pa}$ tients, applying the same measurements at baseline and after 6 weeks, without the treatment intervention of twelve 30 -minute sessions. This 
Table 5. Spearman correlation between disease duration and change scores of primary and secondary outcomes.

\begin{tabular}{|c|c|c|}
\hline \multicolumn{3}{|c|}{ PRIMARY OUTCOMES } \\
\hline \multicolumn{3}{|c|}{ Spinal mobility } \\
\hline flex/ext $(\mathrm{cm})$ & 0.21 & NS \\
\hline expansion $(\mathrm{cm})$ & 0.01 & NS \\
\hline rotation (deg) & 0.04 & NS \\
\hline \multicolumn{3}{|l|}{ Physical fitness } \\
\hline $\max \operatorname{load}(w a t)$ & -0.07 & NS \\
\hline \multicolumn{3}{|l|}{ Functioning } \\
\hline SIP & -0.01 & NS \\
\hline Functional Index & -0.04 & NS \\
\hline $\begin{array}{l}\text { Patient's global asse } \\
\text { of change (cm) }\end{array}$ & 0.01 & NS \\
\hline \multicolumn{3}{|c|}{ SECONDARY OUTCOMES } \\
\hline pain $(\mathrm{cm})$ & -0.13 & NS \\
\hline stiffness (min) & -0.05 & NS \\
\hline articular index & -0.03 & NS \\
\hline enthesopathy index & 0.11 & NS \\
\hline
\end{tabular}

$\mathrm{NS}=$ not significant, $p>0.01$

would have provided a definite background to compare the patients' response to therapy. Since no such control group was used, the positive short term effects of supervised individualized therapy might be attributable to other factors than therapy. For example, one cannot exclude psychological factors unconsciously infiuencing the patient's wish to please the therapist. To decrease this effect, assessments were not made by the physiotherapist, but by an independent assessor. Another problem of this trial is that the mobility and fitness assessments should ideally have been collected by an observer who was 'blinded'. This blinding is necessary to avoid bias due to the expectations of the observer [9]. Blinding is less critical in self-assessments such as SIP. In our opinion the reported improvement of $22 \%$ in self-assessed overall health after treatment is important, because it reflects the patient's values and priorities irrespective of possible assessor bias. Besides, the design of the study did not influence the question of the influence of disease duration.

\section{Participation rate}

The fact that the participation rate was low (144 [43\%] of 333 AS patients completed the study) leaves open whether there was a selection bias in favour of motivated and willing patients. A preliminary comparison between participants and non-participants revealed that they differed with regard to disease duration (an average of 9 years and 12 years respectively), but they did not differ significantly with regard to several socio-demographic characteristics such as marriage, employment and education level. Therefore, it would be wise not to generalize our results to all AS patients, but only to apply them to selected motivated individuals.

\section{Influence of disease duration}

The hypothesis of a negative linear relation between duration of disease and effects of therapy had to be rejected. All statistics used - plots, t-tests of change scores, and correlations - support these findings. Our findings show that it is possible to improve mobility, fit- 
ness, functioning, and global health even in longstanding AS.

AS is a chronic progressive inflammatory disorder. Obviously, the 'short duration' group performed better on all outcomes than the 'long duration' group, except for morning stiffness (Table 4). For all primary and secondary outcomes improvement after treatment was practically the same in the two groups. The 'short duration' group probably performed very well even at baseline and would need more demanding therapy for further improvement in performance.

In summary, this 'before-after' study indicates that short term supervised individualized physical therapy during 6 weeks has slight but positive effects on mobility, fitness, functioning, and global health. The magnitude of improvement is about the same in relatively recently diagnosed as well as longstanding AS.

\section{REFERENCES}

1. Spring H: Funktionsorientierte Gymnastik und Sport bei der Spondylitis Ankylosans. In: Spondylitis Ankylosans. Bern: Verlag Hans Huber, 1989; 117-132

2. Schlumpf U: Zielle und Chancen der Physiotherapie bei Spondylitis Ankylosans. Schweiz Rundschau Med 1991; 60: 36-40

3. Liman W, Weimann G: Kardiorespiratorische Belastbarkeit Kranker mit Ankylosierende Spondylitis und ihre Beeinflussbarkeit durch ergometrisches Training. Zeitschr Phys Med 1987; 5: 218-223
4. O'Driscoll SL, Jayson MIV, Baddeley H: Neck movements in Ankylosing Spondylitis and their responses to physiotherapy. Ann Rheum Dis 1987; 37: 64-66

5. Bulstrode SJ, Barefoot J, Harrison A, Clarke AK: The role of passive stretching in the treatment of Ankylosing Spondylitis. Br J Rheum 1987; 26: 40-42

6. Allington L, Cunnington SJ, Mathews M, et al.: The effect of regular physiotherapy on mobility and shape of the spine in patients with Ankylosing Spondylitis over a two-year period. Br J Rheum 1987; 26 (Suppl A1): 70

7. Kraag G, Stokes B, Groh J, Helewa A, Goldsmith $\mathrm{C}$ : The effects of comprehensive home physiotherapy and supervision on patients with Ankylosing Spondylitis. A randomized controlled trial. J Rheumatol 1990; 17: 228-233

8. van der Linden S, Valkenburg HA, Cats A: Evaluation of diagnostic criteria for Ankylosing Spondylitis: A proposal for modification of the New York criteria. Arthritis Rheum 1984; 27: 361-368

9. Sackett DL, Haynes RB, Guyatt GH, Tugwell P: Clinical epidemiology. A basic science for clinical medicine. Second edition. Boston / Toronto /London: Little, Brown and Company, 1991

10. Abspoel M, Obbens HJM: Fysiotherapeutische interventies bij Spondylitis Ankylopoëtica. Ned Tijdschr Fysiother 1987; 97: 234-239

11. Fellmann N: Die rheumatischen Spondyliti- 
den und ihre Bewegungstherapie. Krankengymnastik 1984; 1: 16-31

12. Miller MH, Lee P, Smythe HA, Goldsmith $\mathrm{H}$ : Measurement of spinal mobility in sagittal plane: New skin contraction technique compared with established methods. J Rheumatol 1984; 11: 507-511

13. Moll JMH, Wright V: An objective clinical study of chest expansion. Ann Rheum Dis $1972 ; 31: 1-8$

14. Roberts W, Larson M, Liang M, Harrison R, Barefoot J, Clarke A: Sensitivity of anthrometric techniques for clinical trials in Ankylosing Spondylitis. Br J Rheum 1988; 28: 40-45

15. Astrand PO, Rodahl K: Textbook of work physiology. Physiological bases of exercise. McGraw-Hill Book Company, 1977

16. Jones NL, Makrides L, Hitchcock C, Chypchar T, McCartney N: Normal standards for an incremental progressive cycle ergometer test. Am Rev Respir Dis 1985; 131: 700-708

17. Borg G: Subjective effort in relation to physical performance and working capacity. Psychology: from research to practice. Plenum Publishing Corporation, 1978

18. Bergner M, Bobbit RA, Kressel S, Pollard WE, Gilson BS, Morris JR: The Sickness
Impact Profile: Conceptual formulation and methodology for the development of a health status measure. Int J Hlth Serv 1976; 6: $393-415$

19. McDowell I, Newell C: Measuring health: A guide to rating scales and questionnaires. New York / Oxford: Oxford University Press, 1987

20. de Bruin AF, de Witte LP, Stevens FCJ, Diederiks JPM: De bruikbaarheid van de Sickness Impact Profile als generieke maat voor functionele toestand. Tijdschr Soc Gezondheidsz 1992; 70: 160-170

21. Dougados M, Gueguen A, Nakache JP, Nguyen M, Mery C, Amor B: Evaluation of a Functional and an Articular Index in Ankylosing Spondylitis. J Rheumatol 1988; 15: 302-307

22. Dougados $M$, Gueguen A, Nakache JP, Nguyen M, Mery C, Amor B: Evaluation of a Functional Index for patients with Ankylosing Spondylitis. J Rheumatol 1990; 17: 1254-1255

23. Mander M, Simpson JM, McLellan A, Walker D, Goodacre JA, Dick WC: Studies with an enthesis index as a method of clinical assessment in Ankylosing Spondylitis. Ann Rheum Dis 1987; 46: 197-202 


\section{CHAPTER 4}

\section{IS GROUP PHYSICAL THERAPY SUPERIOR TO INDIVIDUALIZED THERAPY IN ANKYLOSING SPONDYLITIS? A RANDOMIZED CONTROLLED TRIAL}

Alita Hidding, Sjef van der Linden, Maarten Boers, Xandra Gielen, Luc de Witte ${ }^{1}$, Arnold Kester $^{2)}$, Ben Dijkmans ${ }^{3)}$, and Danièl Moolenburgh4)

Department of Internal Medicine, Division of Rheumatology, University of Limburg and University Hospital Maastricht, 1) Institute for Rehabilitation Research, Hoensbroek, 2) Department of Medical Informatics and Statistics, University of Limburg, Maastricht, 3) Department of Rheumatology, University Hospital Leiden, 4) Department of Rheumatology, Medical Centre Alkmaar, The Netherlands

Arthritis Care and Research 1993; 6: 117-125 


\section{ABSTRACT}

Objective: To study the effects of adding supervised group physical therapy to unsupervised individualized therapy in Ankylosing Spondylitis (AS).

Methods: 144 patients were randomized to exercises at home, or the same plus weekly group physical therapy for 9 months. Endpoints were spinal mobility, fitness (maximum work capacity by ergometry), functioning (Sickness Impact Profile, HAQ for the Spondyloarthropathies, and Functional Index), and patient's global assessment of change on a $10 \mathrm{~cm}$ visual analogue scale.

Results: Thoraco-Jumbar flexion and extension had increased by an average of $0.5 \mathrm{~cm}(9 \%)$ after home exercises, and by $0.9 \mathrm{~cm}(16 \%)$ after group therapy. Maximum load in ergometry had decreased by 2 watts (1\%) after home exercises, but had increased by 7 watts (4\%) after group therapy. Global assessment had improved by $0.3(6 \%)$ after home exercises, and by 1.7 (34\%) after group therapy. These 3 differences were statistically significant $(\mathrm{p}<0.05)$. There were no significant differences in chest expansion, cervical rotation, or the self-assessments of functioning.

Conclusions: Group physical therapy proved superior to individualized therapy in improving thoraco-lumbar mobility and fitness, and had an important effect on global health reported by the patients.

\section{INTRODUCTION}

Ankylosing Spondylitis (AS) is a chronic systemic inflammatory disorder of unknown etiology, affecting mainly the axial skeleton. Sacroiliac joint involvement (sacroiliitis) is its hallmark.

Currently, there is no cure for AS, but most patients can be adequately managed [1]. The aim of treatment of AS is to maintain or improve general functioning and quality of life. Nonsteroidal anti-inflammatory drugs can reduce pain and inflammation, while regular exercises and physical therapy of AS patients are thought to improve mobility, strength and fitness [2]. Three kinds of physical therapy for AS can be distinguished: supervised individualized therapy, unsupervised self-administered individualized therapy, and supervised group therapy.

In the Netherlands, patients diagnosed as having AS usually first receive a 6-week course of individualized supervised physical therapy treatment. Afterwards, the patients are expected to exercise daily. Some patients then start doing supervised group physical therapy (supervised gym classes and pool sessions) with the intention to enhance the effects of the individual exercises. Frequently, the patients initiate group physical therapy themselves. However, the therapeutic effects of (group) physical therapy on mobility, fitness and function are as yet unknown. Therefore, we studied the additional beneficial effects, if any, of group physical 
therapy compared to those of the self-administered individualized therapy in a randomized controlled trial.

\section{METHODS}

\section{Selection of patients}

Patients with AS were recruited from 2 outpatient rheumatology clinics in Leiden and Alkmaar. These 2 cities were chosen because group physical therapy did not yet exist in these places. In Leiden 259 AS patients were located via the diagnostic register of the hospital, whereas in Alkmaar the patient records of the outpatient rheumatology clinic were checked for a diagnosis of AS, yielding 98 patients. Eligible patients had to be younger than 70 years, had to live within $25 \mathrm{~km}$ of a location of group physical therapy and should not have had prior exposure to group physical therapy within the last year. Patients fulfilling these criteria $(n=333)$ were asked to participate in the study. A total of $163(49 \%)$ subjects agreed to participate in the study and gave written informed consent. Questionnaires were sent to all 170 non-participants in order to detect differences between participants and non-participants and to explore reasons for nonparticipation. To compare health-related orientation between participants and non-participants, we used an adapted Dutch version of the Multidimensional Health Locus of Control Scale [3, 4]. This scale distinguishes 3 different controlling agencies: the person himself, doctors, and chance, while doctor orientation and chance orientation can be seen as 2 specifications of external orientation.

All participants were examined by one rheumatologist to check for the inclusion criteria. Patients were included if they fulfilled the modified New York criteria [5] and showed one or more of the following features: symptoms of pain, stiffness, or functional limitations within the last 3 months. Patients unable to engage in physical therapy, those with total hip replacement, pregnant patients and those with severe hypertension [diastolic blood pressure $>100$ $\mathrm{mm} \mathrm{Hg}$ at rest], cardiovascular disease [history of ischemic event, angina pectoris, heart failure], severe lung disease, diabetes mellitus, renal failure, chronic liver disease, malignancy, recent major surgery, mental retardation or serious emotional disorders were excluded. This resulted in 10 patients being excluded from the study ( 2 patients did not satisfy the modified New York criteria, 1 had had a total hip replacement, 4 had cardiac problems, and 3 had emotional disorders), while an additional 9 patients stated that they were unable to exercise daily and were therefore excluded from the study. Thus, 144 patients were available for the study and they were randomized into 2 groups.

\section{Study design}

Before randomization all patients received supervised individualized therapy for 6 weeks, in order to standardize their pretreatment condition and to better reflect clinical practice [6]. Afterwards, patients were randomized into 2 groups: self-administered, unsupervised daily 
individualized therapy or the same plus weekly group physical therapy. Randomization was stratified by center (Alkmaar and Leiden). All patients were assessed by one 'blinded' observer at baseline and subsequently every 3 months, up to 9 months.

Any additional therapeutic interventions, such as massage, sauna or the use of NSAIDs, were recorded. There was no change in the patients' rheumatological treatment.

\section{Study treatments}

Before the trial all patients received a series of 12 supervised individualized physical therapy treatment sessions from a physiotherapist who had been selected by the patient [6]. This treatment was given two times a week for 30 minutes over a period of 6 weeks. All physiotherapists had received detailed oral and written instructions about the aims, goals and methods of the physical therapy from the investigator [7]. The patients received an individual exercise program which was directed at the entire spine, hip joints and peripheral joints. The therapists encouraged the patients to continue the exercises at home for 30 minutes daily over the entire study period. The patients were asked to keep a diary of whether they had indleed performed unsupervised individualized therapy during the study.

After individualized therapy and randomization 50 percent of the patients received additional group physical therapy once a week over a period of 9 months. To improve compliance, the other 50 percent were promised group therapy after the trial period of 9 months.
Altogether, 7 therapists trained 7 groups, with an average size of 10 patients (range 9 13). Before the study, these 7 therapists had received instruction and training in group therapy from an expert who provided supervision during the study $[2,8,9]$. This expert had been trained in group physical therapy in the 'Rheuma and Rehabilitations Clinic' at Leukerbad (Switzerland). Group therapy sessions consisted of 1 hour of physical training, followed by 1 hour of sporting activities and 1 hour of hydrotherapy. The physical training included exercises to improve the mobility of the spine and peripheral joints and to strengthen the muscles of the trunk and legs. During the sporting activities the therapists emphasized stretching of the back, for instance through volleyball or badminton. Hydrotherapy was given in heated water (mean: 31, range: 29 $32{ }^{\circ} \mathrm{C}$ ) to reduce pain and improve mobility of the spine and peripheral joints. Compliance with group physical therapy was checked by the therapists who monitored the attendance to the group sessions.

\section{Assessments}

Spinal mobility, physical fitness, functioning, and global assessment were defined as primary endpoints before the start of the study. In addition, general pain and stiffness were assessed, as well as the number of painful joints and entheses. These measures were taken as secondary endpoints.

Spinal mobility was assessed as follows:

- Thoraco-lumbar flexion and extension, us- 
ing the $10 \mathrm{~cm}$ segment method (flex/ext) described by Miller [10].

- Chest expansion: the difference in circumference between maximum inspiration and expiration was measured by means of a tapemeasure placed circumferentially around the chest wall at the level of the xiphoid processus, while the patient was standing with hands on head $[11,12]$. Two readings were made, the second of which was recorded.

- Cervical rotation: a goniometer was placed horizontally on the crown of the head. The rotation was measured with the subject sitting in neutral position. The pivot of the goniometer was centred on the occiput, with a line through the nose. Scores on cervical rotation were the sum of left and right rotations.

All spinal mobility assessments were standardized and executed by one trained observer at the same time of the day for each patient.

Physical fitness or aerobic power was measured using an electronically braked bicycle ergometer (Jaeger ER800, Breda, The Netherlands). The saddle height was adjusted to the patient's height. The internal power delivered by this bicycle remains constant over a pedalling range of 45 to $75 \mathrm{rpm}$. During the test, heart rate was measured continuously, using a sports tester (Support PE3000, Almere, The Netherlands). An incremental exercise test was used. The protocol started at 50 watts for 5 minutes and then increased by 10 watts every minute. All subjects performed up to their subjective maximum work load. The exercise was interrupted if the patient developed chest pain or the heart rate exceeded 200 beats $/ \mathrm{min}$. At the end of the exercise patients scored on the Borg Scale, indicating the degree of perceived fatigue (range $6-20 ; 6=$ extremely easy; $20=$ extremely heavy; Borg score should be equal to heart rate / 10). The analysis of exercise used maximum work load (watt), heart rate at maximum load (hrmax), and perceived exertion at maximum load (Borg) [13 - 15].

Functioning or health status was assessed by Sickness Impact Profile (SIP) [16 - 18], Health Assessment Questionnaire for the Spondyloarthropathies (HAQ-S) [19], and the Functional Index for AS [20,21].

- The SIP is a generic measure of health status. Answers to the 136-item questionnaire, divided into 12 categories, are computed using a weighted score and yielding a total score of dysfunction. We applied a simplified version, which avoids the weighting procedure and uses only 52 selected items, without losing much information. This shortened version has been validated, but not yet published (personal communication, $\mathrm{AF}$ de Bruin). The following factors are included in the 52-item SIP: mobility range, social participation, mobility control, psychic autonomy, somatic autonomy and affective stability. Answers to the 52-item questionnaire are added, giving a total score of dysfunction (range 0 - 52). Higher scores indicate more dysfunction.

- The HAQ-S, a valid measure, consists of 3 subscales: the original HAQ scale (dressing, rising, eating, walking, hygiene, reach, grip, and activities) and two spondylitis subscalles: 
carrying, sitting, and working at a desk; and looking in the rearview mirror of a car and driving in reverse. A score of ' $O$ ' is given if the patient is able to perform the activity without any difficulty, ' 1 ' if with some difficulty, ' 2 ' if with much difficulty, and ' 3 ' if the patient is unable to perform the activity. Answers are added and divided by the number of items, yielding a mean $\mathrm{HAQ}-\mathrm{S}$ score ranging from ' 0 ' (no difficulties whatsoever) to ' 3 ' (unable to do anything).

- The Functional Index is a valid measure and consists of 20 questions corresponding to activities of daily living. These activities may be limited by AS. A score of ' $O$ ' is given if the task can be accomplished without difficulty, " 1 ' if it is possible but difficult, and ' 2 ' if it is impossible to do. The answers are added, giving a total score of dysfunction.

Patient's global assessment of change was assessed by asking the patient to describe his or her perceived change in general functioning after treatment on a $10 \mathrm{~cm}$ horizontal visual analogue scale $(-5=$ maximum worsening, $0=$ no change, $+5=$ maximum improvement).

Pain and stiffness were indicated by the patient on a horizontal $10 \mathrm{~cm}$ visual analogue scale $(0=$ no pain or stiffness, $10=$ worst pain or stiffness I can imagine).

The joints and entheses were assessed by the 'blinded' observer, who applied articular and enthesopathy indices [22].

The test-retest reliability was assessed in 19 randomly chosen patients by the intraclass correlation coefficient of the following variables: mobility, fitness, pain, stiffness, articular index and enthesopathy index [6]. These measures were applied by the same 'blinded' observer after 48 hours. The intraclass correlation scores for test-retest reliability were extremely high for mobility and pain $(0.91-0.96)$, reasonably high for physical fitness, stiffness and articular index $(0.43-0.72)$, and moderately high for enthesopathy index $(0.31)$.

\section{Data management and statistical analysis}

An intention-to-treat analysis was done [23]. This means that all patients were analysed within the group to which they were originally assigned by randomization. Data were summarized by mean, standard deviation (SD), and - if appropriate - by median and range. Differences between treatment groups at baseline were calculated to check for imbalance after randomization. At 9 months the treatment groups were compared for mean improvement using the t-test of change scores. Differences between participants and non-participants were checked by means of the Chi-Square test for dichotomic variables, the Mann-Whitney test for ordered categorical data, and the t-test for continuous variables.

\section{RESULTS}

Effects of intervention in experimental and control groups

There were no relevant differences between the study groups at baseline (Table 1). Both groups improved on almost all primary out- 
Table 1. Scores on descriptive variables of study groups at baseline.

$\begin{array}{ll}\text { individualized } & \text { individualized + group } \\ \text { physical therapy }(n=76) & \text { physical therapy }(n=68)\end{array}$

Age (years)

Mean (SD)

Duration of disease (years)

Median (range)

Socio-demographic characteristics $(\%)$

male

married

employed

income: 1 )

$\begin{array}{ll} & \text { middle } \\ & \text { low } \\ \left.\text { education level: }{ }^{2}\right) & \text { high } \\ & \text { middle } \\ & \text { low }\end{array}$

Physical therapy (\% taking)

supervised individualized

Medications (\% taking)

NSAIDs

Analgetics

DMARDs

Sporting activities (hours/week)

Median (range)

Erythrocyte Sedimentation Rate (mm/hour)

Median (range)

\section{$41.5(10.3)$}

$4(0-32)$

$43.7(10.4)$

$5(0-25)$

83

67

76

19

59

22

21

41

38

72

68

66

23

48

29

22

46

32

$85-81$

$\begin{array}{ll}74 & 78\end{array}$

$70 \quad 72$

4

3

3

$\mathbb{1} .4(0-16.4)$

$1(0-16.9)$

$15(2-78)$

$14(4-48)$

NSAIDs = nonsteroidal antiinflammatory drugs.

DMARDs = disease modifying antirheumatic drugs.

1) US dollars net per month; high: $>2000 \$$; middle: $1000-2000$; low: $<1000 \$$.

2) Years of education (including primary school); high: > 15 years; middle: $10-15$ years; low: < 10 years.

comes (Table 2, Fig. 1). Improvement on all primary outcomes was greater after group therapy than after individualized therapy; this difference was statistically significant for thoracolumbar mobility, fitness, and overall (global) ef- fect on health as assessed by the patients $(\mathrm{p}<0.05)$. Improvement in functioning and all secondary outcomes was similar in the two groups (Table 2). In addition, we analysed SIP and HAQ-S, excluding patients with scores of 
Table 2. Baseline and change scores after 9 months therapy.

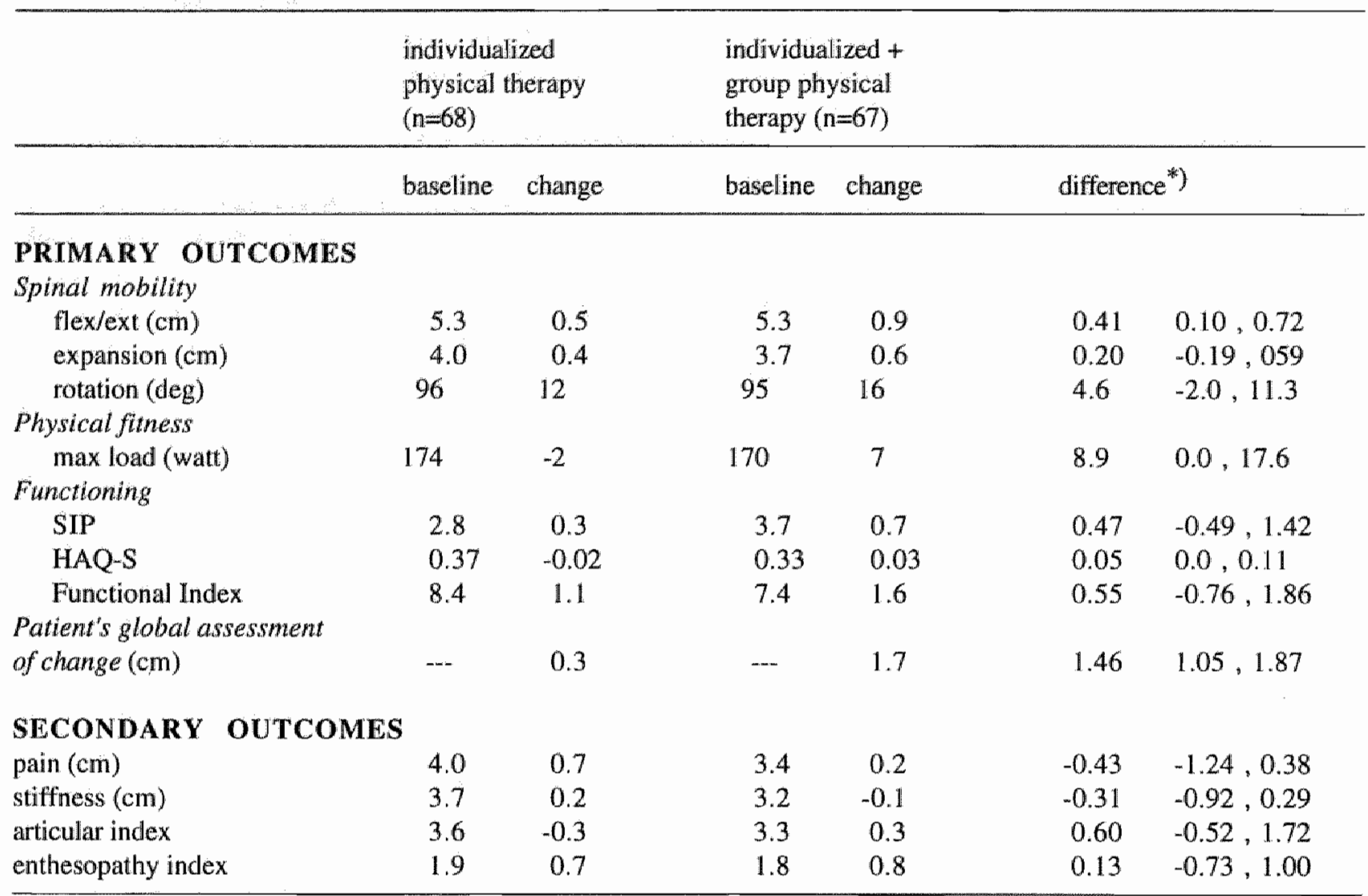

Values are means. Positive change implies improvement. $\left.{ }^{*}\right)$ Group differences with $95 \%$ confidence interval.

Two-sample t-test.

zero at baseline. This still did not yield any significant additional effect of group therapy for functioning (data not shown).

\section{Physical fitness}

The exercise test was adequately performed: mean peak heart rate was 153 beats per min, and mean perceived exertion (Borg score) was 15.2 at baseline (range $9-18$ ). After individualized therapy, scores were 154 (range 106 - 198) and 15.4 (range $12-19)$, and after group therapy 155 (range $95-186$ ) and 15.7 (range 13 - 19). 

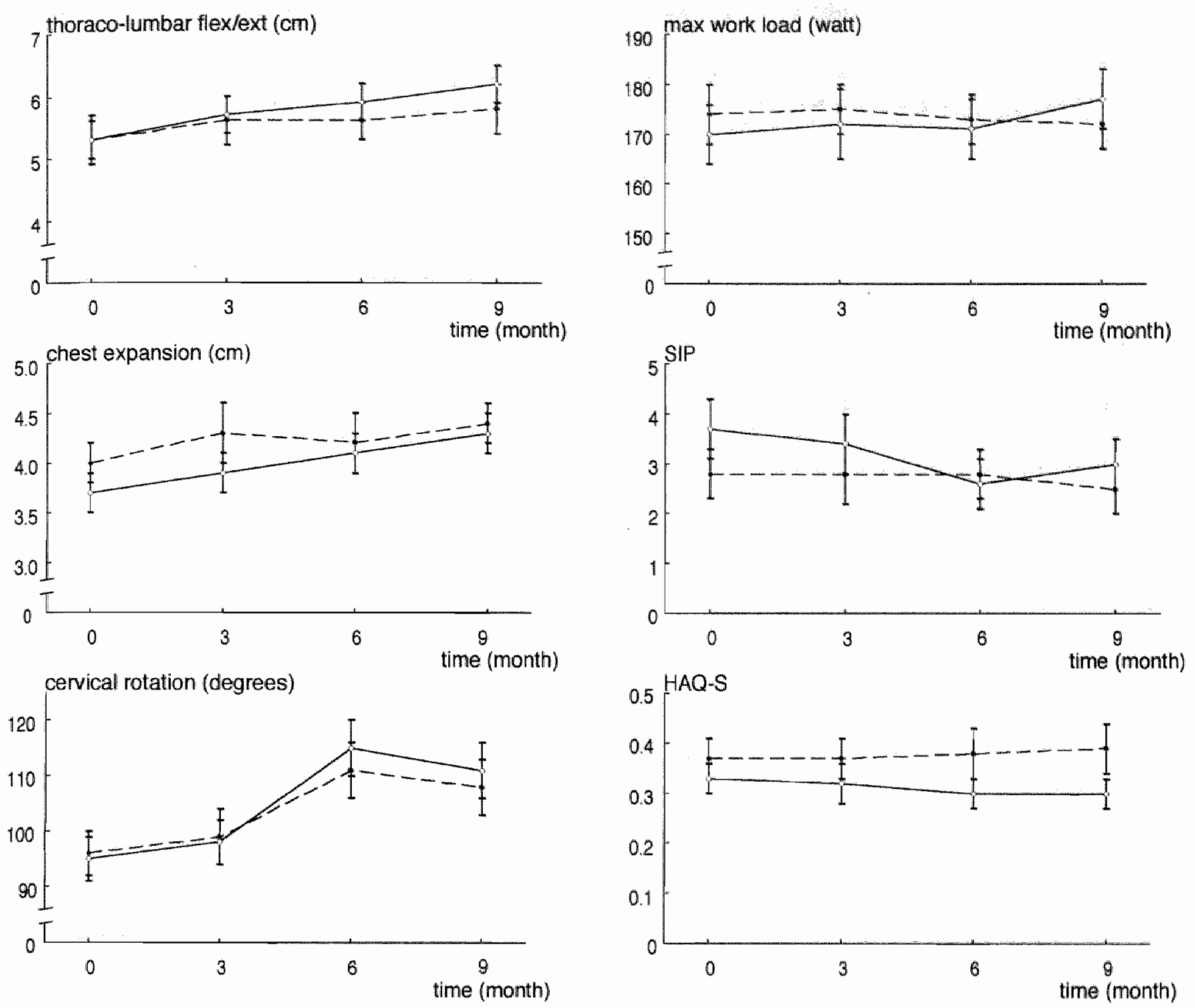

Fig. 1. Scores on primary outcomes after self-administered individualized physical therapy (- - - ) and after self-administered individualized plus supervised group physical therapy $(-\bullet-)$ at baseline, and after 3,6, and 9 months of follow-up. Values are mean and SEM. 


\section{Compliance and co-intervention}

During the 6-week period of supervised individualized therapy before randomization, patients reported in their diaries that they had spent an average time of 3.0 hours per week on their exercises at home (SD 1.8, median 2.6, range $0-10.2$ ), and 1.9 hours per week on sports (SD 2.5, median 1.0, range $0-17.5$ ). During the subsequent 9-month period these averages were 2.2 (SD 1.8 , median 1.9 , range $0-8.9$ ) and 2.0 (SD 2.3, median 1.4, range $0-12.0$ ) respectively, excluding time for group physical therapy. No significant differences between the experimental and control groups were found in exercise behavior or time spent on sporting activities. The average attendance in group therapy as checked by the therapists was $73.5 \%$ (SD 24.3, range 3-100). A total of 8 patients $(12 \%)$ had an attendance of $<50 \%$ in group therapy.

Co-intervention with additional treatment and use of medication were checked in experimental and control patients. There were no significant differences in this type of treatment between experimental and control patients. In addition, no relevant changes in the use of medication were found during the 9-month period (data not shown).

\section{Drop-outs}

During the 9-month experimental period 9 patients ( 1 in the individualized and 8 in the group therapy) dropped out, for the following reasons: moved $(n=1)$, pregnant $(n=1)$, spinal surgery $(n=1)$, cardiac or lung disease $(n=2)$, inability to exercise individually $(n=4)$. Therefore, the intention-to-treat analysis was applied to 135 subjects.

\section{Comparison of participants and non-participants}

A total of $114(67.1 \%)$ of the 170 questionnaires sent out to the non-participants were returned. The inclusion and exclusion criteria for the non-participants were checked by questionnaire in order to obtain comparable groups. A total of 26 non-participants were excluded from the analysis for various reasons. Hence, a comparison was made between a population of 144 participants and 88 non-participants (Table 3). The participants and the non-participants showed statistically significant differences in disease duration.

The reasons given for not participating in the group physical therapy included: personal circumstances $(47 \%)$, opposed to therapy in groups $(21 \%)$, therapy too demanding $(21 \%)$, and not enough $(16 \%)$ or too many (10\%) complaints of AS. Analysis of the locus of control data showed a lower internal and doctor orientation, and a significantly higher chance orientation in non-participants than in participants $(p<0.05)$. Non-participants, who had longer average disease durations ( 13 years, compared with 7 years), might consider their disease to be less controllable by their own behavior and by doctors and, therefore, may be less willing to participate in group physical therapy. 
Table 3. Comparison of baseline characteristics of participants and eligible non-participants.

\begin{tabular}{|c|c|c|c|}
\hline & \multirow{2}{*}{$\begin{array}{l}\text { participants } \\
(n=144)\end{array}$} & \multicolumn{2}{|c|}{ non-participants } \\
\hline & & $(n=88)$ & p \\
\hline \multicolumn{4}{|l|}{ Age (years) } \\
\hline Mean (SD) & $42.6(10.4)$ & $44.4(11.8)$ & $\left.\mathrm{NS}^{5}\right)$ \\
\hline Median (range) & $44(17-64)$ & $43(22-69)$ & \\
\hline \multicolumn{4}{|c|}{ Duration of disease (years) } \\
\hline Mean (SD) & $8.8(8.3)$ & $12.1(9.5)$ & $<.01^{4)}$ \\
\hline Median (range) & $5(0-33)$ & $10(1-38)$ & \\
\hline \multicolumn{4}{|l|}{$\begin{array}{l}\text { Socio-demographic } \\
\text { characteristics (\%) }\end{array}$} \\
\hline male & 78 & 80 & $\mathrm{NS}^{3)}$ \\
\hline married & 67 & 79 & $\mathrm{NS}^{3)}$ \\
\hline employed & 72 & 61 & $\mathrm{NS}^{3)}$ \\
\hline \multirow{3}{*}{$\begin{aligned} \text { income: } & { }^{1} \text { high } \\
& \text { midd } \\
& \text { low }\end{aligned}$} & 20 & 34 & $\mathrm{NS}^{4)}$ \\
\hline & 54 & 45 & \\
\hline & 26 & 21 & \\
\hline \multirow{3}{*}{$\begin{array}{ll}\text { education high } \\
\text { level: } 2) \text { middlle } \\
& \text { low }\end{array}$} & 21 & 24 & $\mathrm{NS}^{4)}$ \\
\hline & 44 & 33 & \\
\hline & 35 & 43 & \\
\hline \multirow{4}{*}{$\begin{array}{l}\text { Medications (\% taking) } \\
\text { NSAIDs } \\
\text { Analgetics } \\
\text { DMARDs }\end{array}$} & 76 & 76 & $\mathrm{NS}^{3)}$ \\
\hline & 71 & 72 & $\mathrm{NS}^{3)}$ \\
\hline & 4. & 5 & $\mathrm{NS}^{3)}$ \\
\hline & 4 & 5 & $\mathrm{NS}^{3)}$ \\
\hline
\end{tabular}

NSAIDs = nonsteroidal antiinflammatory drugs,

DMARDs = disease modifying antirheumatic drugs.

$\mathrm{NS}=$ not significant $(\mathrm{p}>0.05)$.

1) US dollars net per month; high: $>2000 \$$; middle: $1000-2000$ \$; low: < $1000 \$$.

2) Years of education (including primary school); high $>15$ years; middle: $10-15$ years; low: $<10$ years.

3) Chi-square test.

4) Mann-Whitney test.

5) Two-sample t-test.

\section{DISCUSSION}

This randomized controlled trial found statistically significant positive effects of group physical therapy on thoraco-lumbar mobility, fitness and global (or overall) effect on the health of AS patients. How do our findings compare with other studies? We found no randomized controlled trials of group physical therapy in AS in a MEDLINE literature search covering the period 1983-1991 (keywords: Ankylosing Spondylitis, physical therapy, physiotherapy, randomized controlled trial, and outcome). Only one recent study of weekly outpatient group physical therapy over a 5 year period could be retrieved by MEDLINE search [24]. In this trial mobility was maintained at a stable level. However, this study was not a randomized controlled trial.

Some aspects of our study will now be discussed in more detail: assessments in AS, study design, and impact of group physical therapy.

\section{Assessments in AS}

Spinal mobility. The thoraco-lumbar junction is a potential early site of decreased mobility [10]. The usefulness of the $10 \mathrm{~cm}$ segment method, a measure of thoraco-lumbar nobility, therefore, lies in the increased sensitivity conferred by the inclusion of the upper segment as opposed to both the classical and modified Schober methods $[25,26]$. The present trial showed the greatest improvement after therapy in the middle segment (data not shown).

Physical fitness. Fisher [27] suggests that 
during physical therapy efforts should be directed not only towards improving spinal mobility, but also towards increasing cardio-respiratory fitness in patients with AS. Our study shows that it is possible to improve fitness by group therapy, in spite of an already high level of fitness at baseline. Apparently, group therapy as described allows further, although moderate, improvement in physical fitness.

Functioning. Responsiveness to change is of paramount importance because the principal goal of the evaluative process is to detect clinically important changes in health status [28]. Some questionnaires may be relatively insensitive, others sufficiently responsive. Our study shows baseline scores on SIP and HAQ-S of zero in one fourth of our patient population; any further improvement of function is impossible in such patients. Therefore, SIP and HAQ-S were also analysed excluding patients with scores of zero at baseline. Still, no significant additional effect of group therapy relative to individualized therapy was found ( $t$-test of change scores, $\mathrm{p}>0.05$ ). SIP and HAQ-S may not be sensitive enough to detect change in patients with AS. These results, therefore, raise questions about the utility of SIP and HAQ-S as a gold standard for clinically relevant improvement. Sample size may also be a problem in detecting clinically important changes in health status. The present trial shows a heterogeneous population with respect to duration of disease and physical disabillity. Therefore, it would be wise to increase (if possible) the sample size in order to detect more precisely any differences in functioning after individualized and group therapy. With our sample size of 68 (n/group) it is possible to detect a true difference of 1.6 in the SIP and 0.1 points in the HAQ-S, with a power of $90 \%$ ( $\alpha=0.05, B=0.1, \mathrm{SD}_{\text {SIP }}$ change $=2.8$, SDHAQ-S change $=0.18)$.

\section{Study design}

Prior to the study the patients received supervised individualized therapy in order to standardize their pretreatment condition and to better reflect clinical practice. The disadvantage is that the supervised individualized therapy may already have taken away some room for improvement. Another solution for dealing with heterogeneity is to stratify individuals with major differences in disease duration and activity and to identify particular subgroups in order to answer specific questions. Using small subgroups, however, would decrease the generalizability of the results and reduce statistical power. In this trial we deliberately chose to include patients who had a variable duration of disease, making them representative of the target population, and who had received supervised individualized treatment, making them reflect clinical practice more accurately.

\section{Impact of group physical therapy}

This trial showed a mean improvement of $0.5 \mathrm{~cm}(9 \%)$ on thoraco-lumbar flexion and extension and a mean additional improvement of $0.4 \mathrm{~cm}(7 \%)$ after group therapy. The notion of responsiveness to change expresses the idea that any measure used in a trial should be sensitive 
to 'clinically important changes' in response to therapy [28]. A conceptual difficulty arises in specifying what is a clinically important change: an improvement of 16 percent in flexion/extension index, or an improvement of 34 percent in overall health? And after how much time: 9 months, 9 years, or a lifetime? Clearly, the ideal study on the effect of group therapy should have many years of follow-up. In that case other significant outcomes could have emerged. This study focused on the impact of group therapy on physical factors. The contribution of non-physical factors to overall wellbeing and perceived effect of treatment has not been studied in any detail. We feel that the difference observed in global health is important, because it reflects the patient's values and priorities. It is worth noting that in spite of the relatively small effects measured on physical parameters, our patients were very enthusiastic about the group physical therapy, and $75 \%$ of them wanted to continue it. Baumberger [9] mentions the following advantages of group physical therapy: opportunity to draw comparisons with other patients, mutual encouragement, reciprocal motivation, shared pleasures in gymnastics, exchange of experience, companionable contact with peers in similar circumstances, and saving of expenses. Further studies should address these added advantages of group physical therapy.

In summary: after 9 months supervised group physical therapy was found to be superior to individualized therapy in improving thoraco-lumbar mobility and fitness, and had an important effect on overall health from the point of view of the AS patients.

\section{REFERENCES}

1. Khan MA, van der Linden S: Ankylosing Spondylitis and other Spondyloarthropaties. Rheum Dis Clin North America 1990; 16: $551-578$

2. Spring H: Funktionsorientierte Gymnastik und Sport bei der Spondylitis Ankylosans. In: Spondylitis Ankylosans. Bern: Verlag Hans Huber, 1989; 117-132

3. Wallston KA, Wallston BS, DeVellis R: Development of the multidimensional health locus of control (MHLC) scales. Health Education Monographs 1978; 6: 160-169

4. Halfens R: Locus of control: de beheersingsorientatie in relatie tot ziekte-en gezondheidsgedrag. Thesis. Maastricht: University of Limburg, 1985

5. van der Linden S, Valkenburg HA, Cats A: Evaluation of diagnostic criteria for Ankylosing Spondylitis: A proposal for modification of the New York criteria. Arthritis Rheum 1984; 27: 361-368

6. Hidding $A$, van der Linden $S$, de Witte $L$ : Therapeutic effects of individualized physical therapy in Ankylosing Spondylitis related to duration of disease. Clin Rheumatol 1993, 12: 334-340

7. Abspoel M, Obbens HJM: Fysiotherapeutische interventies bij Spondylitis AnkyJopoëtica. Ned Tijdschr Fysiother 1987; 97: 234-239 
8. Fellmann N: Die rheumatischen Spondylitiden und ihre Bewegungstherapie. Krankengymnastik 1984; 1: 16-31

9. Baumberger $\mathrm{H}$ : Schweizerische Vereinigung Morbus Bechterew: eine PatientenSelbsthilfeorganisation. Schweiz Rundschau Med 1991; 80: 644-649

10. Miller MH, Lee P, Smythe HA, Goldsmith $\mathrm{H}$ : Measurement of spinal mobility in sagittal plane: New skin contraction technique compared with established methods. J Rheumatol 1984; 11: 507-511

11. Moll JMH, Wright V: An objective clinical study of chest expansion. Ann Rheum Dis 1972;31:1-8

12. Roberts W, Larson M, Liang M, Harrison $R$, Barefoot J, Clarke A: Sensitivity of anthrometric techniques for clinical trials in Ankylosing Spondylitis. Br J Rheum 1988; 28: $40-45$

13. Astrand PO, Rodahl K: Textbook of work physiology. Physiological bases of exercise. McGraw-Hill Book Company, 1977

14. Jones NL, Makrides L, Hitchcock C, Chypchar $\mathrm{T}$, McCartney $\mathrm{N}$ : Normal standards for an incremental progressive cycle ergometer test. Am Rev Respir Dis $1985 ; 131: 700-708$

15. Borg G: Subjective effort in relation to physical performance and working capacity. Psychology: from research to practice. Plenum publishing Corporation, 1978

16. Bergner M, Bobbit RA, Kressel S, Pollard WE, Gilson BS, Morris JR: The Sickness Impact Profile: Conceptual formulation and methodology for the development of a health status measure. Int J Hlth Serv 1976; 6: 393-415

17. McDowell I, Newell C: Measuring health: A guide to rating scales and questionnaires. New York / Oxford: Oxford University Press, 1987

18. de Bruin AF, de Witte LP, Stevens FCJ, Diederiks JPM: De bruikbaarheid van de Sickness Impact Profile als generieke maat voor functionele toestand. Tijdschr Soc Gezondheidsz 1992; 70: 160-170

19. Daltroy HL, Larson MG, Roberts WN, Liang MH: A modification of the Health Assessment Questionnaire for the Spondyloarthropathies. J Rheumatol 1990; 17: 946-950

20. Dougados $M$, Gueguen A, Nakache JP, Nguyen M, Mery C, Amor B: Evaluation of a Functional and an Articular Index in Ankylosing Spondylitis. J Rheumatol. 1988; 15: 302-307

21. Dougados M, Gueguen A, Nakache JP, Nguyen M, Mery C, Amor B: Evaluation of a Functional Index for patients with Ankylosing Spondylitis. J Rheumatol 1990; 17: 1254-1255

22. Mander M, Simpson JM, McLellan A, Walker D, Goodacre JA, Dick WC: Studies with an enthesis index as a method of clinical assessment in Ankylosing Spondylitis. Ann Rheum Dis 1987; 46: 197-202

23. Sackett DL, Haynes RB, Guyatt GH, Tugwell P: Clinical epidemiology. A basic science for clinical medicine. Second 
edition. Boston / Toronto / London: Little, Brown and Company, 1991

24. Rasmussen JO, Hansen TM: Physical training for patients with Ankylosing Spondylitis. Arthritis Care Res 1989; 2: 25-27

25. Schober P: The lumbar vertebral column and backache. Munchener Medizinische Wochenschrift 1937; 84: 336-338

26. MacRae IF, Wright V: Measurement of back movement. Ann Rheum Dis 1969; 28:
584-589

27. Fisher LR, Cawley MID, Holgate ST: Relation between chest expansion, pulmonary function, and exercise tolerance in patients with Ankylosing Spondylitis. Ann Rheum Dis 1990; 49: 921-925

28. Laurent MR, Buchanan WW, Bellamy N: Methods of assessment used in Ankylosing Spondylitis clinical trials: A review. Br J Rheum 1991; 30: 326-329 


\section{CHAPTER 5}

CONTINUATION OF GROUP PHYSICAL THERAPY IS NECESSARY IN ANKYLOSING SPONDYLITIS. RESULTS OF A RANDOMIZED CONTROLLED TRIAL

Alita Hidding, Sjef van der Linden, Xandra Gielen, Luc de Witte ${ }^{1)}$, Ben Dijkmans ${ }^{2)}$, and Daniël Moolenburgh ${ }^{3}$ )

Department of Internal Medicine, Division of Rheumatology, University of Limburg and University Hospital Maastricht, 1) Institute for Rehabilitation Research, Hoensbroek, 2) Department of Rheumatology, University Hospital Leiden, 3) Department of Rheumatology, Medical Centre Alkmaar, The Netherlands

Arthritis Care and Research 1994, in press 


\section{ABSTRACT}

Objective: We studied whether beneficial effects of group physical therapy in patients with Ankylosing Spondylitis (AS) persisted alter cessation of the intervention.

Methods: After a 9-month period of supervised group physical therapy, 68 AS outpatients (mean age: 44 years, median duration of disease: 4 years) were randomized for another 9 months to unsupervised daily exercises at home (discontinuation group), or continuation of weekly sessions of supervised group physical therapy (continuation group). Endpoints were spinal mobility (thoraco-lumbar flexion and extension, chest expansion, cervical rotation), fitness (maximum work capacity), functioning (Sickness Impact Profile (SIP), Health Assessment Questionnaire for the Spondyloarthropathies (HAQ-S), the Functional Index (FI)), and patient's global health assessment on a visual analogue scale.

Results: Time spent on exercises at home was significantly higher in the continuation than in the discontinuation group (mean duration 1.9 versus 1.2 hours per week, $\mathrm{p}<0.05$ ). The continuation group improved in global health (mean improvement 1.6) and in SIP score (dysfunctioning decreasing from 1.6 to 1.2). Scores for thoraco-lumbar mobility and HAQ-S did not change very much, whereas chest expansion decreased by $0.6 \mathrm{~cm}$, cervical rotation by 13 degrees and fitness by 5 watts, while FI slightly deteriorated, from 4.8 to 5.3. The average attendance for group therapy sessions was
$62 \%$. The discontinuation group improved only marginally $(0.2,4 \%)$ in global health, whereas all other endpoints decreased: thoraco-lumbar mobility by $0.4 \mathrm{~cm}$, chest expansion by $0.7 \mathrm{~cm}$, cervical rotation by 13 degrees and fitness by 6 watts, while SIP deteriorated from 3.4 to 3.7 , HAQ-S from 0.28 to 0.36 , and FI from 5.6 to 7.0. Only for global health and HAQ-S were the differences statistically significant in favour of the continuation group.

Conclusions: Global health and functioning are sustained or even further improved if group physical therapy is continued. Spinal mobility decreased slightly in both groups.

\section{INTRODUCTION}

The treatment of patients with Ankylosing Spondylitis (AS) comprises medication to reduce pain and inflammation, as well as regular exercises and physical therapy in order to improve or maintain mobility, fitness, functioning and overall health. Recently, we have reported a randomized controlled trial on the effects of supervised group physical therapy added to unsupervised individualized self-administered physical therapy, i.e. exercises at home [1]. At 9 months, group physical therapy significantly improved lumbar mobility, fitness and overall health compared to unsupervised therapy at home. On average, thoraco-lumbar flexion and extension improved by an additional $0.4 \mathrm{~cm}$ in patients who received weekly group therapy compared to patients who exercised at home. The mean difference between the two groups 
was 9 watts for fitness and $28 \%$ for global health, both in favour of group therapy. To investigate whether these beneficiall effects persisted after the cessation of group therapy, we designed the present study.

\section{METHODS}

\section{Selection of patients and study design}

Altogether, 333 patients with AS from 2 outpatient rheumatology clinics were asked to participate in the study. A total of 163 gave written informed consent. All participants were examined by one rheumatologist to check for the inclusion and exclusion criteria. Only patients fulfilling the modified New York criteria were included [2]. Patients unable to engage in physical therapy, those with total hip replacement, pregnant patients, and those with severe hypertension [diastolic blood pressure > $100 \mathrm{~mm} \mathrm{Hg}$ ], cardiovascular disease [history of ischemic event, angina pectoris, heart failure], severe lung disease, diabetes mellitus, renal failure, chronic liver disease, malignancy, recent major surgery, mental retardation or serious emotional disorders were excluded. A total of 10 patients were excluded: 2 patients did not satisfy the modified New York criteria, 1 had a total hip replacement, 4 had cardiac problems, and 3 had emotional disorders, while an additional 9 patients stated they were unable to exercise daily. Thus, 144 patients were available and were randomized in to 2 groups: 1) unsupervised daily individualized exercises at home during 9 months; and 2) the same plus weekly group physical therapy, also during 9 months. A total of 9 patients dropped out ( 8 in individualized and 1 in group therapy) for the following reasons: moved $(n=1)$, pregnant $(n=1)$, spinal surgery $(n=1)$, cardiac or lung disease $(n=2)$, inability to exercise individually $(\mathrm{n}=4)$. Thus, 135 patients completed the first 9 month experimental period, of whom 68 had only exercised at home and 67 had also had group therapy. This last group of 67 patients plus the 1 patient who was pregnant in this period were available for the present study and they were randomized again into 2 new groups: a discontinuation group, who now had to do daily exercises at home $(n=34)$ and a continuation group, who again received weekly supervised group physical therapy for another 9 months $(n=34)$. All patients had to continue their daily exercises at home.

All patients were assessed by one and the same 'blinded' observer at baseline and subsequently every 3 months, up to 9 months. Prescriptions of medication, such as NSAIDs, were recorded. The decision to prescribe or to adjust such medication was not influenced by the research team.

\section{Interventions}

Before the trial all patients received a series of 12 supervised individualized physical therapy sessions from a physiotherapist [3]. This comprised an individualized exercise program which was directed at the entire spine, hips, shoulders and peripheral joints. The therapists encouraged the patients to continue the exercises at home for 
30 minutes daily over the entire study period. The patients were asked to keep a diary and to note during the entire study whether they had indeed performed their daily exercises.

Group therapy consisted of sessions of 3 hours per week: 1 hour of physical training, 1 hour of sporting activities and 1 hour of hydrotherapy. All sessions were supervised by a physical therapist [1]. The physical training included exercises to improve the mobility of the spine and the peripheral joints and to strengthen the muscles of the trunk and legs. During the sporting activities the therapists emphasized stretching of the back, for instance through volleyball or badminton. Hydrotherapy was given in heated water (mean temperature: $31^{\circ} \mathrm{C}$; range: $29-32{ }^{\circ} \mathrm{C}$ ) to reduce pain and improve mobility of the spine and peripheral joints. For standardization purposes the therapists received instructions and training in group therapy from an expert before the study. This expert also provided supervision during the study as described elsewhere $[1,4-7]$. Compliance with group therapy was checked by the therapists who registered the attendance to the group sessions.

\section{Assessments}

Spinal mobility, physical fitness, functioning, and global health were defined as primary endpoints before the start of the study. In addition, general pain and stiffness were assessed, as well as the number of painful joints and entheses. These measures were taken as secondary endpoints.
Spinal mobility was assessed as follows: - Thoraco-lumbar flexion and extension, using the $10 \mathrm{~cm}$ segment method (flex/ext) [8].

- Chest expansion, measured at the level of the xiphoid processus $[9,10]$. Two readings were made, the second of which was recorded.

- Cervical rotation, measured with a goniometer placed horizontally on the crown of the head [1]. Scores on cervical rotation were the sum of left and right rotations.

All spinal mobility assessments were standardized and executed by one trained observer at the same time of the day for each patient.

Physical fitness or aerobic power was measured using an electronically braked bicycle ergometer (Jaeger ER800, Breda, The Netherlands). During the test, heart rate was measured continuously using a sports tester (Support PE3000, Almere, The Netherlands). An incremental exercise test was used. The protocol started at 50 watts for 5 minutes and then increased by 10 watts every minute. All subjects performed up to their subjective maximum workload. At the end of the exercise patients scored on the Borg Scale, indicating the degree of perceived exertion (range $6-20 ; 6=$ extremely easy; 20 = extremely heavy; Borg score should be equal to heart rate / 10). The analysis of ergometry used maximum work load (watt), heart rate at maximum load, and perceived exertion at maximum load [1 - 13].

Functioning or health status was assessed by Sickness Impact Profile (SIP) [14 - 16], Health Assessment Questionnaire for the Spondyloarthropathies (HAQ-S) [17], and the 
Functional Index for AS [18, 19].

- A shortened 52-item SIP, a general measure of health status, was used [personal communication, AF de Bruin]. Answers to the questionnaire were added, yielding a total score of dysfunction (range 0 - 52). Higher scores indicated more dysfunction.

- The HAQ-S is a disease specific 13-item measure for AS. Answers were added and divided by the number of items, yielding a mean HAQ-S score ranging from ' 0 ' (no difficulties whatsoever) to ' 3 ' (unable to do anything).

- The Functional Index is a 20 -item questionnaire specifically designed for AS. The answers were added, yielding a total score of dysfunction (range 0 - 40). Higher scores indicated more dysfunction.

Patient's global assessment of change was measured by asking the patient to describe his or her perceived change in general functioning after the 9-month treatment period on a $10 \mathrm{~cm}$ horizontal visual analogue scale $(-5=$ maximum worsening, $0=$ no change, $+5=$ maximum improvement).

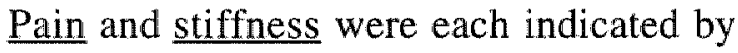
the patient on a $10 \mathrm{~cm}$ horizontal visual analogue scale $(0=$ no pain or stiffness, $10=$ worst pain or stiffness I can imagine).

The joints and entheses examinations were assessed by the 'blinded' observer, who applied articular and enthesopathy indices $[18,20]$.

The 48-hours test-retest reliability had been assessed beforehand in 19 randomly chosen patients, as recently described in this journal [1].
The intraclass correlation coefficients were high for mobility and pain $(0.91-0.96)$, reasonable for fitness, stiffness and articular index (0.43 0.72 ), and moderate for the enthesopathy index (0.31) [1].

\section{Data management and statistical analysis}

Data were summarized by mean, standard deviation (SD) or standard error of the mean (SEM), or - where appropriate - by median and range. Baseline differences between the continuation and discontinuation groups were assessed by the Chi-Square test for dichotomic variables, by the Mann-Whitney test for ordered categorical data, and by the t-test for continuous variables. At the end of the study the continuation and the discontinuation group were compared for mean improvement by means of the $t$ test of change scores. This analysis was applied according to the intention-to-treat principle [21]. Thus, all patients remained in the group to which they were assigned by randomization. This included drop-outs, insofar as they participated in the effect measurements, and patients with low compliance (attendance) in group therapy. To study the influence of compliance, an efficacy analysis was also applied. Patients with low compliance (attendance in group therapy below $50 \%$ ) were excluded from the efficacy analysis. In order to study the relation between change scores on primary outcomes and attendance in group therapy, plots were made and correlations were calculated. 


\section{RESULTS}

\section{Drop-outs}

No patient in the discontinuation group and 4 patients in the continuation group dropped out, for the following reasons: knee surgery $(n=1)$, and inability to continue exercises in group therapy $(n=3)$. Effect measurements were not available for these 4 patients. Therefore, the intention-to-treat analysis was done for 64 subjects. Because 8 patients had an attendance in group therapy below $50 \%$, the efficacy analysis was done for 56 subjects.

\section{Effects of intervention in experimental and con- trol groups}

At baseline, there were no relevant differences between the continuation and the discontinuation group (Table 1). Scores on primary and secondary outcomes after 9 months of follow-up are given in Table 2. Global health assessment had improved in both groups, whereas SIP scores had improved in the continuation group only. For other primary endpoints, deterioration in the discontinuation group was more pronounced than in the continuation group. In this intention-to-treat analysis the differences were only statistically significant for the primary outcomes of patient's global health assessment and HAQ-S, and for the secondary outcome of articular index ( $t$-test of change scores, $\mathrm{p}<0.05$ ). No striking differences were found between the intention-to-treat and efficacy analyses (results not shown).
Table 1. Characteristics of study groups at baseline.

discontinuation continuation group $(n=34) \quad$ group $(n=30)$

Age (years)

Mean (SD)

$44.3(11.1) \quad 42.3(9.5)$

Duration of disease (years)

Mean (range)

$6.8(5.8) \quad 7.9(7.9)$

Socio-demographiic

characteristics (\%)

male

married

employed

income: 1) high

middle

low

education high

level: ${ }^{2)}$ middle low

Medications (\% taking)

NSAIDs.

Analgetics

DMARDs

Sporting activities (hours/week)

Median (range)

Erythrocyte Sedimentation

Rate (mm/hour)

Median (range)

$12(4-99)$

$18(3-68)$

NSAIDs $=$ nonsteroidal antiinflammatory drugs.

DMARDs = disease modifying antirheumatic drugs.

1) US dollars net per month; high: $>2000 \$$; middle: $1000-2000$ \$; low: < $1000 \$$.

2) Years of education (including primary school); high: $>15$ years; middle: $10-15$ years; low: < 10 years. 
Table 2. Mean scores at baseline and mean change scores after 9 months (intention-to-treat analysis).

\begin{tabular}{|c|c|c|c|c|c|}
\hline \multirow[b]{2}{*}{ month } & \multicolumn{2}{|c|}{$\begin{array}{l}\text { discontinuation group } \\
(n=34)\end{array}$} & \multicolumn{2}{|c|}{$\begin{array}{l}\text { continuation group } \\
(n=30)\end{array}$} & \multirow[b]{2}{*}{ difference $^{2)}$} \\
\hline & $\begin{array}{l}0 \\
\text { mean }\end{array}$ & $\begin{array}{l}9 \\
\text { change }\end{array}$ & $\begin{array}{l}0 \\
\operatorname{mexh}\end{array}$ & $\begin{array}{l}9 \\
\text { change l) }\end{array}$ & \\
\hline \multicolumn{6}{|l|}{ PRIMARY OUTCOMES } \\
\hline \multicolumn{6}{|l|}{ Spinal mobility } \\
\hline flex/ext $(\mathrm{cm})$ & 6.5 & -0.4 & 6.3 & 0 & 0.4 \\
\hline expansion $(\mathrm{cm})$ & 4.4 & -0.7 & 4.2 & -0.6 & 0.1 \\
\hline rotation (deg) & 113 & -13 & 115 & -13 & 0 \\
\hline \multicolumn{6}{|l|}{ Physical fitness } \\
\hline max load (watt) & 168 & -6 & 186 & -5 & 1 \\
\hline \multicolumn{6}{|l|}{ Functioning } \\
\hline SIP & 3.4 & -0.3 & 1.6 & 0.4 & 0.7 \\
\hline HAQ-S & 0.28 & -0.08 & 0.24 & 0.01 & $\left.0.09^{*}\right)$ \\
\hline Functional Index & 5.6 & -1.4 & 4.8 & -0.5 & 0.9 \\
\hline \multicolumn{6}{|l|}{ Patient's global assessment } \\
\hline of change $(\mathrm{cm})$ & --- & 0.2 & $-\infty$ & 1.6 & $\left.1.4^{\$ 3}\right)$ \\
\hline \multicolumn{6}{|l|}{ SECONDARY OUTCOMES } \\
\hline pain $(\mathrm{cm})$ & 2.7 & -0.4 & 3.2 & -0.1 & 0.3 \\
\hline stiffness $(\mathrm{cm})$ & 3.3 & -0.2 & 3.1 & -0.6 & -0.4 \\
\hline articular index & 2.2 & -1.6 & 2.8 & 0.1 & $\left.1.7^{s \mid k}\right)$ \\
\hline enthesopathy index & 1.1 & -0.9 & 0.7 & 0.3 & 1.2 \\
\hline
\end{tabular}

1) Positive change implies improvement.

2) Indicates difference in favor of continuation grousp.

*) Statistically significant difference. Two-sample t-test.

Pearson correlation coefficients between change scores on primary outcomes and attendance in group therapy were not significant ( $>0.10)$ : plots of the change scores and the attendance in group therapy showed no evident relations (Fig. 1).

\section{Physical fitness}

The exercise test was adequately performed: mean peak heart rate and mean Borg score at 9 months were, respectively, 151 (range 96 . 178 ) and 16.1 (range $13-19$ ) for those who exercised at home, and 156 (range $115-186$ ) 

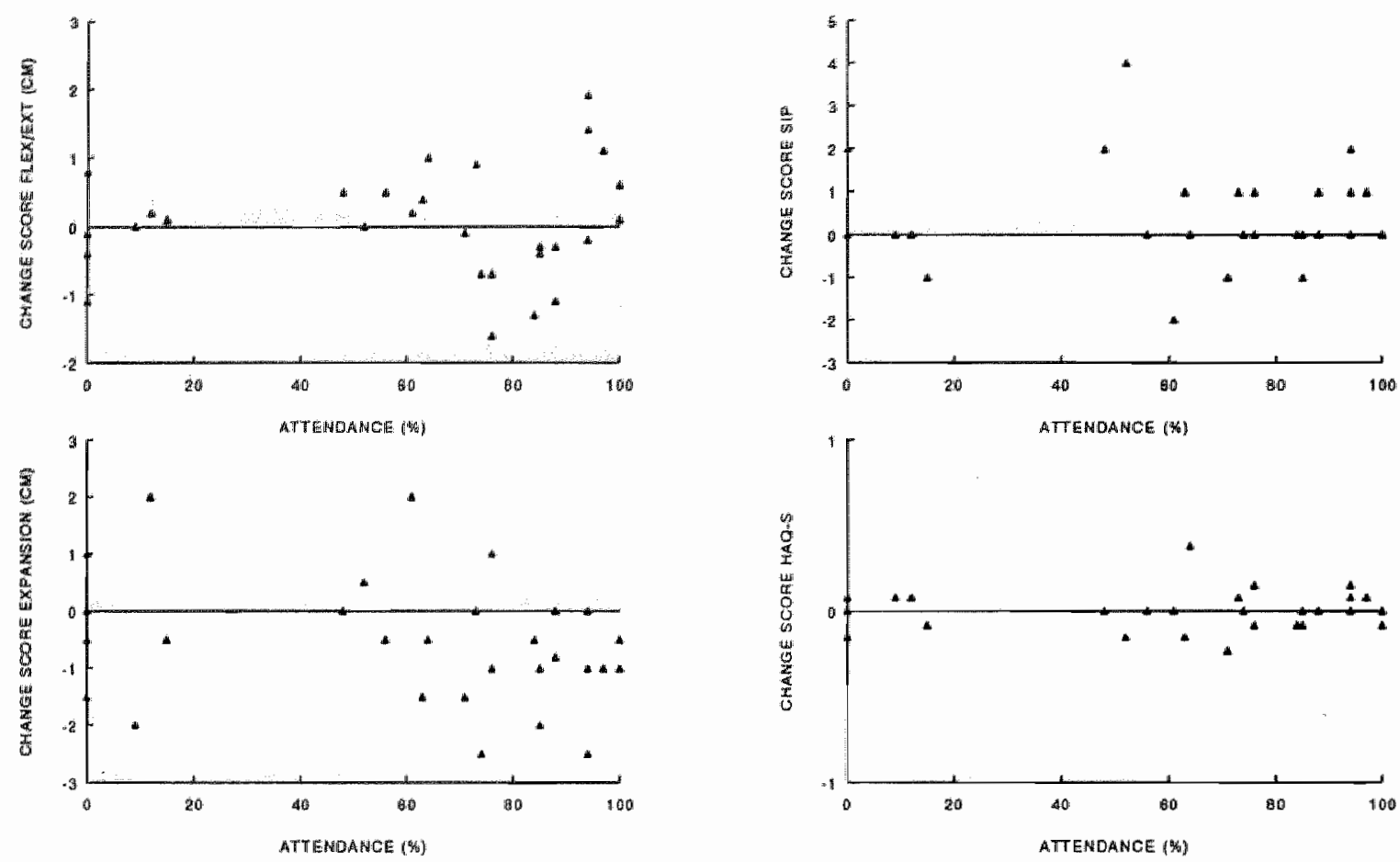

and 15.8 (range $13-19$ ) for those who participated in group therapy.

\section{Compliance and co-intervention}

Patients reported by diary that they had spent an average of 1.8 hours per week doing exercises at home (SD, 1.7, range $0-9.3$ ). Time spent on exercises at home was significantly longer in the continuation group than in the discontinuation group (mean duration 1.9 versus 1.2 hours per week, $\mathrm{p}<0.05$ ). The mean attendance for group therapy was $62 \%$ (SD $35 \%$, range $0 \%-100 \%$ ), whereas 8 patients $(27 \%)$ had an attendance below $50 \%$.

No relevant changes in the reported use of medication were found between the two groups, as reported elsewhere [22]. 

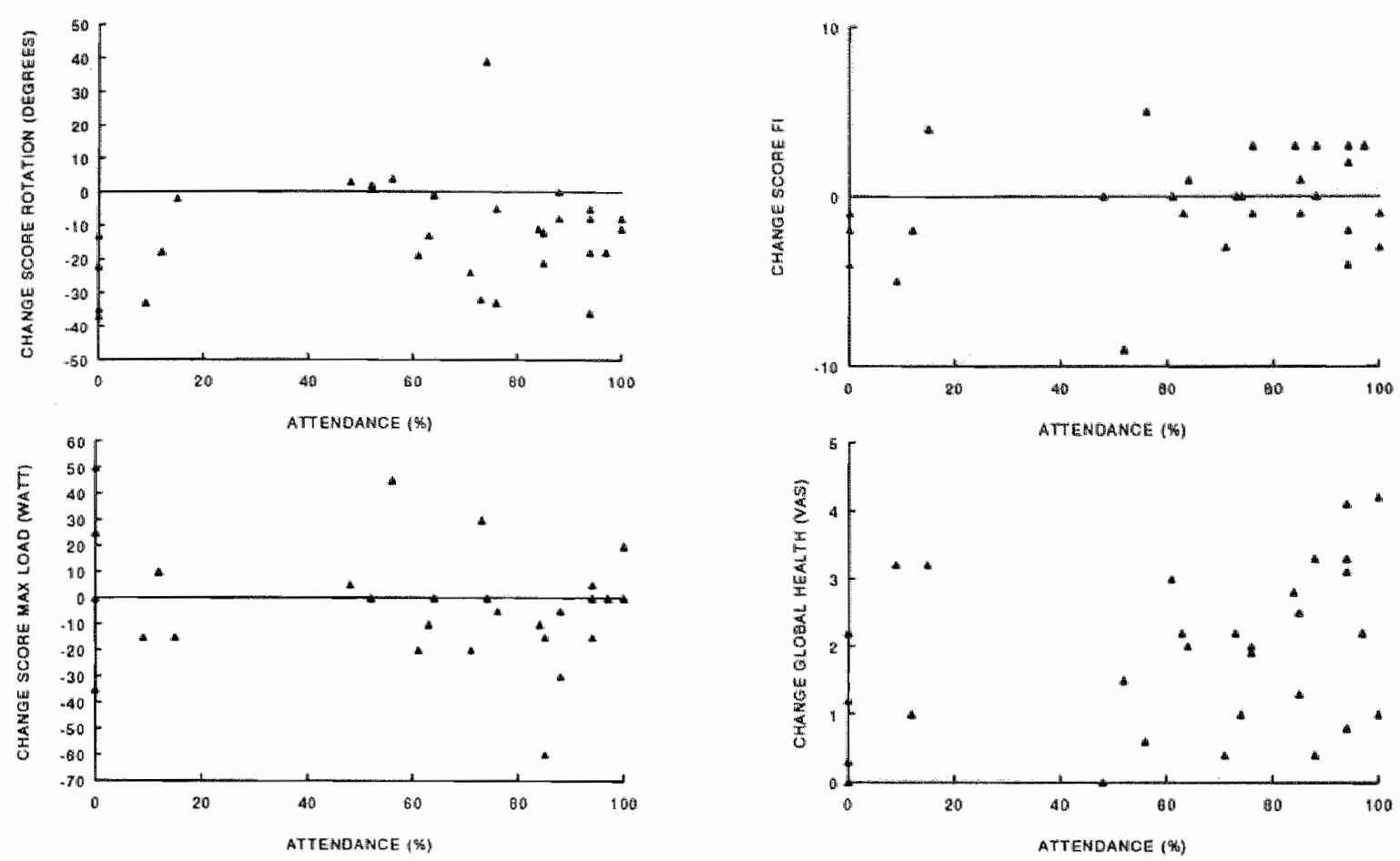

Fig. 1. Change scores for primary outcomes related to degree of attendance in the group who continued physical therapy. (Positive scores indicate improvement).

\section{DISCUSSION}

Continuation of group physical therapy proved to be necessary to sustain global health and functioning. It should be noted that the trial presented here is in fact a 9-month extension of a study recently published in this journal [1]. As many patients had already improved considerably before this extension period, room for further improvement during the second 9-month study period was only small [1]. Indeed, the total mean improvement in functioning for the combined studies was rather impressive, e.g. a decrease in dysfunctioning from 2.6 to 1.2 in SIP score (Fig. 2). Also, the total mean improvement in global health was striking: $70 \%$ on a visual analogue scale. These improvements in functioning and global health after the entire 

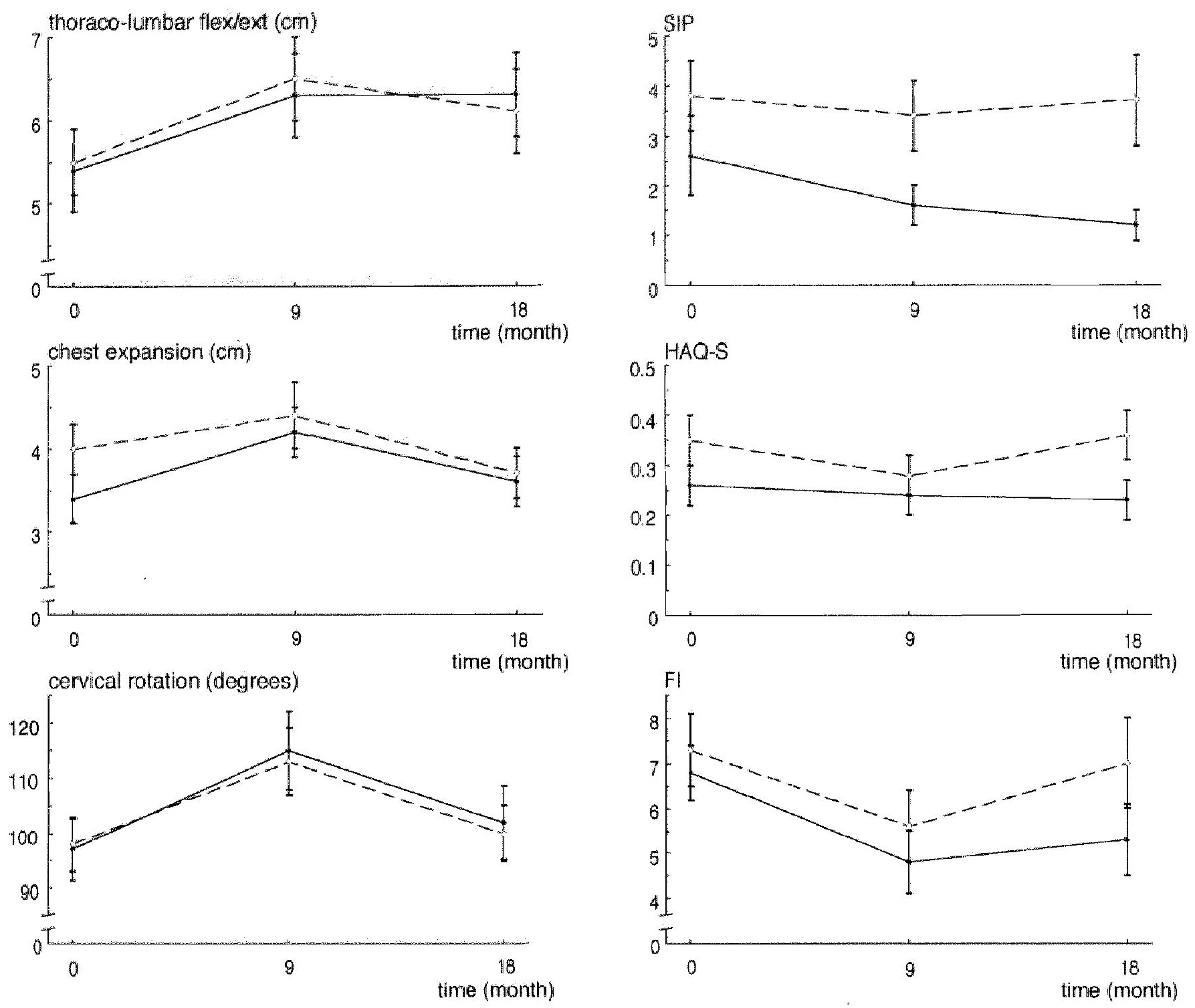

Fig. 2. Scores of the continuation group (- - -) and the discontinuation group (- - - ) on primary outcomes at baseline, after 9 months and after 18 months of group therapy. Values are mean and SEM. Both groups had group physical therapy during the first 9 months. 


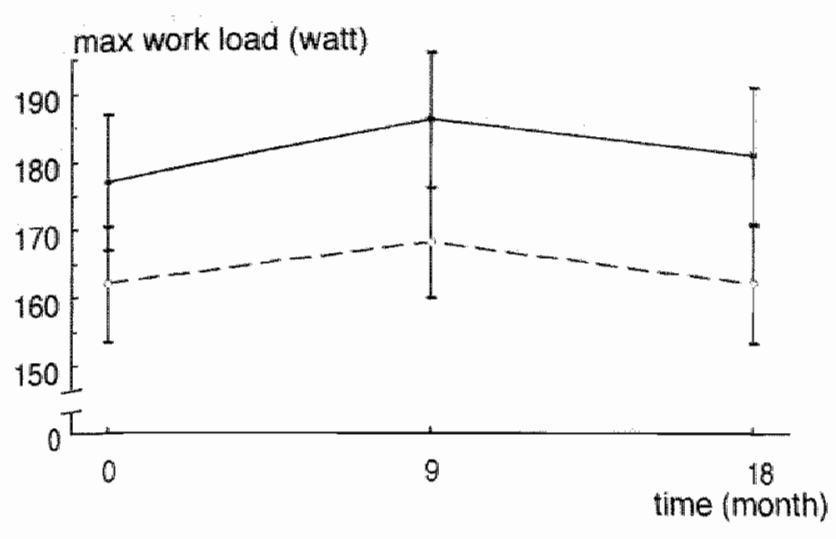

study are irrefutable, clinically important changes. However, the levels of spinal mobility only improved in the first 9-month period and decreased in the 9-month extension period. Therefore, much of the benefits of group therapy may have resulted from the conditioning effects of sustained exercise.

Compliance with group therapy in this study declined with time. The average attendance in group therapy decreased from $74 \%$ in the first 9-month period to $62 \%$ in the second 9month period. Attendance was below $50 \%$ in $12 \%$ of the patients in the first study [1], increasing to $27 \%$ in the present study. Surprisingly, we found no relation between the effects of group therapy and attendance. This suggests that the effectiveness of group therapy is relatively independent of the degree of attendance. This raises the question which factors might be responsible for the beneficial effects of group therapy. During the entire study compliance with unsupervised exercises at home decreased as well, from an average of 2.2 hours per week during the first study to 1.8 hours per week in the present study [1]. However, the amount of time spent exercising at home was significantly higher in the continuation group $(1.9$, mean value) than in the discontinuation group $(1.2, \mathrm{p}<0.05)$. Peer pressure, as would be applied by the group, as well as the added stimulus of the supervisor, could encourage compliance, and by inference, benefits. However, Fig. 1 does not suggest that the extent of compliance correlates with the outcome, so the reasons are open to speculation. The benefits do not seem directly related to compliance with weekly group therapy sessions, but are possibly related to the amount of time spent doing exercises at home. Indeed the relatively higher compliance to exercises at home for patients who had group therapy could have reinforced the beneficial effects of group therapy.

In summary: continuation of group physical therapy in AS seems to be important. It may have a positive influence on exercises performed at home. Continuation of group therapy can sustain positive effects on global health and functioning.

\section{REFERENCES}

1. Hidding $A$, van der Linden $S$, Gielen $A$, Kester A, de Witte L, Dijkmans B, Moolenburgh $\mathrm{J}$ : Is group physical therapy superior to individualized therapy in Ankylosing Spondylitis? A randomized controlled trial. Arthritis Care Res 1993; 6: $117-125$ 
2. van der Linden $\mathbf{S}$, Valkenburg HA, Cats $\mathbf{A}$ : Evaluation of diagnostic criteria for Ankylosing Spondylitis: A proposal for modification of the New York criteria. Arthritis Rheum 1984; 27: 361-368

3. Hidding $A$, van der Linden $S$, de Witte $L$ : Therapeutic effects of individualized physical therapy in Ankylosing Spondylitis related to duration of disease. Clin Rheumatol $1993,12: 334-340$

4. Abspoel M, Obbens HJM: Fysiotherapeutische interventies bij Spondylitis Ankylopoëtica. Ned Tijdschr Fysiother 1987; 97: 234-239

5. Spring H: Funktionsorientierte Gymnastik und Sport bei der Spondylitis Ankylosans. In: Spondylitis Ankylosans. Bern: Verlag Hans Huber, 1989; 117-132

6. Fellmann N: Die rheumatischen Spondylitiden und ihre Bewegungstherapie. Krankengymnastik 1984; 1: 16-31

7. Baumberger H: Schweizerische Vereinigung Morbus Bechterew: eine PatientenSelbsthilfeorganisation. Schweiz Rundschau Med 1991; 80: 644-649

8. Miller MH, Lee P, Smythe HA, Goldsmith $\mathrm{H}$ : Measurement of spinal mobility in sagittal plane: New skin contraction technique compared with established methods. J Rheumatol 1984; 1 1: 507-511

9. Moll JMH, Wright V: An objective clinical study of chest expansion. Ann Rheum Dis 1972; $31: 1-8$

10. Roberts W, Larson M, Liang M, Harrison $\mathbb{R}$, Barefoot J, Clarke A: Sensitivity of an- thrometric techniques for clinical trials in Ankylosing Spondylitis. Br J Rheum 1988; 28: $40-45$

11. Astrand PO, Rodahl K: Textbook of work physiology. Physiological bases of exercise. McGraw-Hill Book Company, 1977

12. Jones NL, Makrides L, Hitchcock C, Chypchar T, McCartney N: Normal standards for an incremental progressive cycle ergometer test. Am Rev Respir Dis 1985; 131: 700-708

13. Borg G: Subjective effort in relation to physical performance and working capacity. Psychology: from research to practice. Plenum publishing Corporation, 1978

14. Bergner M, Bobbit RA, Kressel S, Pollard WE, Gilson BS, Morris JR: The Sickness Impact Profile: Conceptual formulation and methodology for the development of a health status measure. Int J Hlth Serv 1976; 6: $393-415$

15. McDowell I, Newell C: Measuring health: A guide to rating scales and questionnaires. New York / Oxford: Oxford University Press, 1987

16. de Bruin AF, de Witte LP, Stevens FCJ, Diederiks JPM: De bruikbaarheid van de Sickness Impact Profile als generieke maat voor functionele toestand. Tijdschr Soc Gezondheidsz 1992; 70: 160-170

17. Daltroy HL, Larson MG, Roberts WN, Liang MH: A modification of the Health Assessment Questionnaire for the Spondyloarthropathies. J Rheumatol 1990; 17 : 946-950 
18. Dougados $M$, Gueguen A, Nakache JP, Nguyen M, Mery C, Amor B: Evaluation of a Functional and an Articular Index in Ankylosing Spondylitis. J Rheumatol 1988; 15:302-307

19. Dougados M, Gueguen A, Nakache JP, Nguyen M, Mery C, Amor B: Evaluation of a Functional Index for patients with Ankylosing Spondylitis. J Rheumatol 1990; 17: 1254-1255

20. Mander M, Simpson JM, McLellan A, Walker D, Goodacre JA, Dick WC: Studies with an enthesis index as a method of clini- cal assessment in Ankylosing Spondylitis. Ann Rheum Dis 1987; 46: 197-202

21. Sackett DL, Haynes RB, Guyatt GH, Tugwell P: Clinical epidemiology. A basic science for clinical medicine. Second edition. Boston / Toronto / London: Little, Brown and Company, 1991

22. Bakker $\mathrm{C}$, Hidding $\mathrm{A}$, van der Linden $\mathrm{S}$, van Doorslaer E: Cost-effectiveness of group physical therapy added to individualized therapy in Ankylosing Spondylitis. A randomized controlled trial. J Rheumatol 1994, in press 


\section{CHAPTER 6}

\section{COST-EFFECTIVENESS OF GROUP PHYSICAL THERAPY ADDED TO INDIVIDUALIZED THERAPY FOR ANKYLOSING SPONDYLITIS. A RANDOMIZED CONTROLLED TRIAL}

Carla Bakker, Alita Hidding, Sjef van der Linden, and Eddy van Doorslaer ${ }^{1)}$

Department of Internal Medicine, Division of Rheumatology, University of Limburg and University Hospital Maastricht, 1) Institute for Medical Technology Assessment, Erasmus University, Rotterdam, The Netherlands

Journal of Rheumatology 1994, in press 


\section{ABSTRACT}

Objective: Cost-effectiveness analysis is helpful in setting priorities for the funding of health care programs. We studied the cost-effectiveness of supervised group physical therapy added to un supervised exercises at home in Ankylosing Spondylitis (AS) patients.

Methods: A total of 144 AS patients (modified New York criteria; mean age: 43 years) were randomized to unsupervised daily individualized exercises at home for 9 months or the same plus supervised group physical therapy ( 3 hours weekly). At baseline and after 9 months we measured spinal mobility (thoraco-lumbar flexion and extension), fitness (maximum work capacity by ergometry), and patient's global assessment of change as measured on a visual analogue scale. We used a questionnaire at baseline and a diary during the trial to measure AS related direct medical costs, such as doctor visits, paramedical treatment, medication and hospitalization.

Results: The mean effects of group therapy and home exercises were, respectively, $+0.9 \mathrm{~cm}$ $(16 \%)$ and $+0.5 \mathrm{~cm}(9 \%)$ for mobility, +7 watt $(4 \%)$ and -2 watt $(-1 \%)$ for fitness, and +1.7 $(34 \%)$ and $+0.3(6 \%)$ for global health. These 3 differences were significant ( $p<0.01$ for mobility, $p=0.05$ for fitness and $p<0.01$ for global health). In the course of the trial total medical costs decreased by an average of US $\$ 379$ (44\%) for group therapy, and by $\$ 257(35 \%)$ per patient per year for the 'home' group. Additional costs of group therapy were esti- mated at $\$ 531$ per patient per year $(\$ 177$ for accommodation, $\$ 256$ for therapist and $\$ 98$ for materials). After the study $75 \%$ of the patients wanted to continue group physical therapy and were willing to pay for it.

Conclusion: Compared to therapy at home, additional benefits of group therapy cost $\$ 531$ per year, but reduced direct medical costs by $\$ 122$ per year. Hence, the beneficial effects of group therapy cost $\$ 409$ per AS patient per year.

\section{INTRODUCTION}

Health care costs are a growing concern to patients, physicians, and policy makers [1 - 4]. In making therapeutic choices medical as well as economic consequences have to be taken into account. This also applies to chronic diseases such as Ankylosing Spondylitis (AS), whose impact lies in impairing the quality rather than reducing the length of life [5]. AS is a chronic systemic inflammatory disorder of unknown etiology, affecting mainly the axial skeleton [6].

There is currently no cure for AS, but most patients can be adequately managed. The aim of treatment of AS is to maintain or improve general functioning and quality of life. Nonsteroidal anti-inflammatory drugs can reduce pain and inflammation, while regular exercises and physical therapy can improve mobility, strength and fitness [7, 8]. A recent randomized controlled trial in AS showed supervised group physical therapy to be superior to unsupervised individualized exercises at home in improving thoracolumbar mobility, fitness, and patient's global 
assessment of change as measured on a visual analogue scale [9]. During this 9-month trial, costs were recorded in order to assess the financial implications of these therapeutic interventions. We report the cost-effectiveness of group physical therapy to patients with AS compared with individualized physical therapy at home.

\section{METHODS}

A total of 333 AS patients from 2 outpatient rheumatology clinics were asked to participate in the study. Of these, $163(49 \%)$ gave written informed consent. All participants were examined by one rheumatologist to check for the inclusion criteria. We included patients fulfilling the modified New York criteria [10] and showing one or more of the following features: continuous symptoms of pain, stiffness, or functional limitations within the last 3 months, age below 70 and living within $25 \mathrm{~km}$ of a location of group physical therapy. Patients unable to engage in physical therapy, those with total hip replacement, pregnant patients, and those with severe hypertension [diastolic blood pressure > $100 \mathrm{~mm} \mathrm{Hg}$ at rest], cardiovascular disease [history of ischemic event, angina pectoris, heart failure], severe lung disease, diabetes mellitus, renal failure, chronic liver disease, malignancy, recent major surgery, mental retardation or serious emotional disorders were excluded. Altogether, 10 patients were excluded: 2 patients did not satisfy the modified New York criteria, 1 had a total hip replacement, 4 had cardiac problems, and 3 had emotional disorders, while an additional 9 patients stated that they were unable to exercise daily. Thus, 144 patients were available for the study.

\section{Design and treatments}

During a period of 6 weeks before the study all patients received 12 sessions of supervised individualized physical therapy [11]. Afterwards, patients were randomized into 2 groups: 1) unsupervised daily individualized exercises at home; or 2) the same plus weekly group physical therapy [9]. The therapists encouraged the patients to continue the exercises at home for 30 minutes daily over the entire study period of 9 months.

Each weekly group therapy session consisted of 1 hour of physical training, followed by 1 hour of sporting activities and 1 hour of hydrotherapy. The physical training included exercises to improve the mobility of the spine, hips, shoulders and peripheral joints and to strengthen the muscles of the trunk and legs [8, 9]. During the sporting activities the therapists emphasized stretching of the back, for instance through volleyball or badminton. Hydrotherapy was given in heated water (mean: 31 , range: 29 $-32^{\circ} \mathrm{C}$ ) to reduce pain and to improve mobility of the spine, hip, shoulders and peripheral joints.

All patients continued to receive their usual reumatological care and medication during the study. The research team did not attempt to keep the doses of any analgesics or anti-inflammatory drugs used by the patient at a constant level. 
However, the use of these drugs was monitored in order to detect beneficial effects.

\section{Assessments of physical therapy}

Primary predefined endpoints of therapy were spinal mobility, physical fitness, functioning and patient's global health.

Spinal mobility was assessed using the 10 $\mathrm{cm}$ segment method to measure thoraco-lumbar flexion and extension (flex/ext) [12].

- Physical fitness or aerobic power was measured using an electronically braked bicycle ergometer (Jaeger ER800, Breda, The Netherlands). During the test, heart rate was measured continuously using a sports tester (Support PE3000, Almere, The Netherlands). An incremental exercise test was used. The protocol started at 50 watts for 5 minutes and then increased by 10 watts every minute. All subjects performed up to their subjective maximum workload [13].

- Patient's global health was assessed by asking the patient to describe his or her perceived change in overall daily functioning after the 9-month treatment period, applying a $10 \mathrm{~cm}$ horizontal visual analogue scale $(-5=$ maximum worsening, $0=$ no change, $+5=$ maximum improvement) [9].

The spinal mobility and fitness tests were assessed by one trained and 'blinded' observer. These tests took place at the same time of the day for each patient. The 48 hours test-retest reliability of the mobility and fitness tests was assessed beforehand in 19 randomly chosen patients. The intraclass correlation coefficients for test-retest reliability were high for mobility $(0.96)$, and reasonable for fitness $(0.72)$ [11].

\section{Assessments of costs}

A questionnaire at baseline and a diary during the trial were used to measure AS related direct medical costs. The questionnaire at baseline asked for costs incurred during the 1-year pre-trial period. A diary was used to assess these costs during the 9-month experimental period. These costs were converted to annual figures. Both instruments aimed to measure 4 AS related direct medical costs (expressed in US dollars):

- Outpatient AS related visits to family physician, rheumatologist, ophthalmologist, orthopedist and other visits (such as surgeon or dermatologist). Costs for family physicians were set at $\$ 15.90$ per visit [14]. Fees for specialists used in this study represent a weighted average of the fees of the state health insurance system and the private insurance fees. All charges are all-out fees of continuation consults. This calculation was based on a telephone survey (SIG Health Information Utrecht, The Netherlands). Costs for rheumatologists were estimated at $\$ 15.05$, those for ophthalmologists at $\$ 12.61$, and for orthopedists at $\$ 14.05$.

- Other care, comprising physical therapy, mental health care, and alternative care, including acupuncture, sauna and massage. Costs of physical therapy, using the same weighted average as for the costs for specialists, were assessed at $\$ 13.94$. Costs of mental health care were put at $\$ 68.90$, the normal fee of a psychia- 
trist per visit. Costs of alternative care were calculated from an average charge for the 3 different modes of treatment as determined by a telephone survey (\$19.88).

- Purchases of medication, comprising nonsteroidal anti-inflammatory drugs (NSAIDs), disease modifying antirheumatic drugs (DMARDs, salazopyrine), analgesics, stomach medication, and eye medication. In the analysis, use of medication was converted into standard daily doses for each of these 5 groups. The costs of medicine consumption are based on current average retail prices [15]. The average costs for one day doses for each of the 5 groups of medication are $\$ 0.80$ for NSAIDs, $\$ 0.77$ for DMARDs, $\$ 0.18$ for analgesics, $\$ 1.53$ for stomach medication and $\$ 3.13$ for eye medication. The costs were added, yielding a total amount for medicine consumption.

- Hospitalization: disease related days of admission for AS. Costs were calculated using the average of the all-out charges of the 3 participating rheumatology hospital departments $(\$ 324.40)$.

After the study all patients who had received group physical therapy were asked if they wanted to continue this treatment and if so, whether they were willing to pay for it.

\section{Statistical analysis}

Data were summarized by mean, standard deviation (SD) or standard error of the mean (SEM). Baseline differences between groups regarding scores on the pre-trial questionnaire were studied using the Mann-Whitney test. At 9 months the groups were compared for mean improvement by t-test of change scores. Scores on the pre-trial questionnaire and the diary were compared by Mann-Whitney test. The cost-effectiveness was calculated using the formula given in Fig. 1.

Before the study, we predefined spinal mobility, fitness, functioning and global assessment as primary outcomes. We defined an effect size of $20 \%$ for spinal flexion and exten-

Fig. 1. Cost-effectiveness formula.

$\frac{\Delta \mathrm{C}}{\Delta \mathrm{E}}=\frac{\mathrm{C}_{\mathrm{Int}}-\mathrm{C}_{\mathrm{Con}}}{\mathrm{E}_{\mathrm{Int}}-\mathrm{E}_{\mathrm{Con}}}$

$\Delta \mathrm{C}=$ Costs of group therapy + $\left(\left(\mathrm{C}_{\mathrm{Gr}}\right.\right.$ trial $-\mathrm{C}_{\mathrm{Gr}}$ pre-trial $)$ -

(CIndtrial - $\mathrm{C}_{\text {Indpre-trial }) \text { ) }}$

$=\$ 531+(-\$ 379-(-\$ 257))=\$ 409$

$\Delta \mathrm{E}=$ (flex/ext $\mathrm{Gr}_{\mathrm{r}} 9$ months - flex/ext $\mathrm{Gr}$ baseline) (flex/ext Ind 9 months - flex/ext Ind baseline) $=(6.2-5.3)-(5.8-5.3)=0.4 \mathrm{~cm}$ and

(fitness ${ }_{\mathrm{Gr}} 9$ months - fitness $\mathrm{Gr}$ baseline) (fitness Ind 9 months - fitness Ind baseline) $=(177-170)-(172-174)=9$ watt and

change global health 9 months change global health 1 d 9 months)

$=1.7-0.3=1.4$

$\mathrm{C}=\operatorname{costs} ; \mathrm{E}=$ effects; Int $=$ intervention; $\mathrm{Con}=$ control; $\mathrm{Gr}=$ group physical therapy; Ind = individualized exercises at home. 
sion or fitness as clinically important effects. We calculated that a sample size of 80 for each group would be required to provide a power of $90 \%$ to detect such an effect with a probability of $5 \%$.

\section{RESULTS}

\section{Description of study population}

At baseline, $131(91 \%)$ patients completed the pre-trial questionnaire. During the 9-month experimental period 9 patients ( 8 in individual and 1 in group therapy) dropped out for the following reasons: moved $(n=1)$, pregnant $(n=1)$, spinal surgery $(n=1)$, cardiac or lung disease $(n=2)$, inability to exercise individually $(n=4)$. After the 9-month experimental period 111 patients (77\%) returned a completed diary. The cost-effectiveness analysis is therefore based on 111 subjects (Table 1).

Baseline differences on costs between the treatment groups were not significant (Table 2).

\section{Costs of supervised group physical therapy}

In calculating the costs of supervised group physical therapy the preferred size of the group was defined as 12 patients, and the number of sessions at 40 a year. Costs for accomodation included: weekly rent of a gymnasium (1 hour physical training and 1 hour sports, total costs US \$1060) and rent for 1 hour weekly of a swimming pool with water at $32^{\circ}$ degrees Celsius ( $\$ 1060)$. Annual depreciation costs for materials included $\$ 636$ for exercise mats, $\$ 382$ for exercise balls and $\$ 159$ for volleyballs.
Table 1. Characteristics of 111 participants at baseline.

\begin{tabular}{|c|c|c|}
\hline \multicolumn{3}{|l|}{ Age (years) } \\
\hline Mean (SD & & $42.7(10.3)$ \\
\hline \multicolumn{3}{|c|}{ Duration of disease (years) } \\
\hline Mean (SD & & $7.1(7.2)$ \\
\hline \multicolumn{3}{|c|}{ Patient's global assessment ${ }^{1}$ ) } \\
\hline Mean (SD) & & $7.2(1.7)$ \\
\hline \multicolumn{3}{|c|}{ Physician's global assessment2) } \\
\hline Mean (SD) & & $3.4(0.8)$ \\
\hline \multicolumn{3}{|c|}{ Socio-demographic characteristics (\%) } \\
\hline male & & 77 \\
\hline married & & 72 \\
\hline employed & & 73 \\
\hline \multirow[t]{3}{*}{ income ${ }^{3)}$ : } & high & 22 \\
\hline & middle & 56 \\
\hline & low & 22 \\
\hline education & high & 32 \\
\hline \multirow{2}{*}{ level ${ }^{4)}$ : } & middle & 46 \\
\hline & low & 22 \\
\hline
\end{tabular}

1) $10 \mathrm{~cm}$ visual analogue scale $(0=$ worst; $10=$ best $)$.

2) 5 point scale ( $1=$ worst; 5 = best $)$.

3) US dollars net per month; high: $>2000 \$$; middle: $1000-2000 \$$; low: $<1000 \$$.

4) Years of education (including primary school); high: $>15$ years; middle: $10-15$ years; low: $<10$ years.

Costs of the physical therapist comprised $\$ 3074$ for wages. Calculated costs per patient per year were $\$ 177$ for accommodation, $\$ 98$ for materials, and $\$ 256$ for therapist. Hence, total additional costs of supervised group physical therapy were estimated at $\$ 531$ per patient per year, or an average of $\$ 44$ per month.

\section{Effects of intervention}

After 9 months the mean effects of group 
Table 2. Annualized disease related medical expenses in $11 \mathrm{AS}$ patients.

\begin{tabular}{|c|c|c|c|c|c|c|c|c|c|}
\hline & \multicolumn{5}{|c|}{ Pre-trial } & \multicolumn{4}{|l|}{ Trial } \\
\hline & \multicolumn{2}{|l|}{ Ind } & \multicolumn{2}{|c|}{ Ind+gr } & \multirow[t]{2}{*}{$\mathrm{p}^{1)}$} & \multicolumn{2}{|l|}{ Ind } & \multicolumn{2}{|c|}{ Ind $+\mathrm{gr}$} \\
\hline \multicolumn{9}{|c|}{ DOCTOR VISITS 2 ) } & \\
\hline Family physician & 0.71 & 0.22 & 1.93 & 0.90 & 0.19 & 1.41 & 0.45 & 1.33 & 0.51 \\
\hline Rheumatologist & 2.12 & 0.31 & 2.23 & 0.23 & 0.32 & 1.11 & 0.21 & 1.63 & 0.32 \\
\hline Ophthalmologist & 0.14 & 0.12 & 0.30 & 0.30 & 0.46 & 0.56 & 0.11 & 0.72 & 0.14 \\
\hline Orthopedist & 0.02 & 0.02 & 0.00 & 0.00 & 0.27 & 0.28 & 0.05 & 0.00 & 0.00 \\
\hline Other spec & 0.10 & 0.06 & 0.32 & 0.13 & 0.28 & 0.83 & 0.60 & 0.78 & 0.16 \\
\hline \multicolumn{10}{|l|}{ OTHER CARE ${ }^{2)}$} \\
\hline Physiotherapy & 12.85 & 3.88 & 13.97 & 3.09 & 0.30 & 4.22 & 1.53 & 4.88 & 1.67 \\
\hline Mental Health & 0.00 & 0.00 & 0.03 & 0.02 & 0.20 & 0.83 & 0.30 & 0.00 & 0.00 \\
\hline Alternative & 1.28 & 0.83 & 1.62 & 1.40 & 0.33 & 4.66 & 1.69 & 2.63 & 0.90 \\
\hline \multicolumn{10}{|l|}{ MEDICATION 3 ) } \\
\hline NSAIDs & 0.49 & 0.07 & 0.60 & 0.07 & 0.27 & 0.57 & 0.09 & 0.59 & 0.07 \\
\hline DMARDs & 0.02 & 0.02 & 0.06 & 0.03 & 0.35 & 0.00 & 0.00 & 0.03 & 0.02 \\
\hline Analgesics & 0.02 & 0.02 & 0.00 & 0.00 & 0.27 & 0.02 & 0.02 & 0.00 & 0.00 \\
\hline Stomach & 0.05 & 0.03 & 0.03 & 0.02 & 0.85 & 0.03 & 0.03 & 0.01 & 0.01 \\
\hline Eye & 0.04 & 0.03 & 0.07 & 0.03 & 0.56 & 0.02 & 0.02 & 0.02 & 0.02 \\
\hline \multicolumn{10}{|c|}{ HOSPITALIZATION 4$)$} \\
\hline Admission & 0.84 & 0.84 & 0.84 & 0.59 & 0.71 & 0.03 & 0.03 & 0.27 & 0.17 \\
\hline
\end{tabular}

Vallues are mean and SEM per patient per year. 1) Mann-Whitney test for pre-triall difference between individuallized and group therapy. 2) Mean number of visits or sessions. ${ }^{3)}$ Mean number of daily doses. 4) Mean number of admission days. NSAIDs $=$ Nonsteroidal anti-inflammatory drugs. DMARDs $=$ Disease modifying antirheumatic drugs. Ind $=$ individualized exercises at home. $\mathrm{Gr}=$ group physical therapy.

physical therapy and individualized exercises at home were, respectively, $+0.9 \mathrm{~cm}(16 \%)$ and $+0.5 \mathrm{~cm}(9 \%)$ for mobility, +7 watts $(4 \%)$ and -2 watts $(-1 \%)$ for fitness, and $+1.7 \mathrm{~cm} \mathrm{(34 \% )}$ and $+0.3 \mathrm{~cm}(6 \%)$ for patient's global assessment of change in health [9]. These 3 differences were statistically significant $(\mathrm{p}<0.01$ for mobility, $\mathrm{p}=0.05$ for fitness, and $\mathrm{p}<0.01$ for global health). Outcome measures of functional status, the Sickness Impact Profile [16] and the
Health Assessment Questionnaire for the Spondyloarthropathies [17] did not show statistical significance [9] and were not used in the cost-effectiveness analysis. Results of the significant measures indicated that, compared to individualized therapy at home, group physical therapy produced $7 \%$ extra increase in mobility, $5 \%$ extra increase in fitness, and $28 \%$ extra increase in global health. 
Table 3. Annualized costs in 111 AS patients.

\begin{tabular}{|c|c|c|c|c|c|c|c|}
\hline & \multicolumn{2}{|c|}{ Pre-trial } & \multicolumn{2}{|c|}{ Trial } & \multicolumn{3}{|c|}{ Difference } \\
\hline & Ind & Ind + gr & Ind & Ind $+\mathrm{gr}$ & Ind & Ind $+\mathrm{gr}$ & $p^{1)}$ \\
\hline \multicolumn{8}{|c|}{ DOCTOR VISITS 2 ) } \\
\hline Familly physician & 11 & 31 & 22 & 21 & +11 & -10 & 0.57 \\
\hline Rheumatologist & 32 & 34 & 17 & 24 & -15 & -10 & 0.95 \\
\hline Ophthalmologist & 2 & 4 & 7 & 9 & +5 & +5 & 0.84 \\
\hline Orthopedist & 1 & 0 & 4 & 0 & +3 & 0 & $<0.01$ \\
\hline Other specialists & 2 & 5 & 13 & $\llbracket 2$ & +11 & +7 & 0.11 \\
\hline Total & 48 & 74 & 63 & 66 & +15 & -8 & 0.54 \\
\hline \multicolumn{8}{|l|}{ OTHER CARE2) } \\
\hline Physiotherapy & 179 & 195 & 59 & 68 & -120 & -127 & 0.49 \\
\hline Mental Health & 0 & 2 & 57 & 0 & +57 & -2 & $<0.01$ \\
\hline Alternative & 25 & 32 & 93 & 52 & +68 & +20 & 0.42 \\
\hline Total & 204 & 229 & 209 & 120 & +5 & -109 & 0.10 \\
\hline \multicolumn{8}{|l|}{ MEDICATION 3 ) } \\
\hline NSAIDs & 142 & 175 & 167 & 173 & +25 & -2 & 0.93 \\
\hline DMARDs & 6 & 15 & 0 & 10 & -6 & -5 & 0.85 \\
\hline Analgesics & 1 & 0 & 2 & 0 & +1 & 0 & 0.27 \\
\hline Stomach & 26 & 16 & 15 & 2 & -11 & -14 & 0.42 \\
\hline Eye & 46 & 75 & 23 & 19 & -23 & -56 & 0.41 \\
\hline Total & 221 & 281 & 207 & 204 & -14 & -77 & 0.28 \\
\hline \multicolumn{8}{|c|}{ HOSPITALIZATION 4 ) } \\
\hline Admission & 271 & 271 & 8 & 86 & -263 & -185 & 0.70 \\
\hline TOTAL COSTS & 744 & 855 & 487 & 476 & -257 & -379 & 0.05 \\
\hline
\end{tabular}

Values are mean U.S. dollars per patient per year (1991 prices). 1) Marnw Whitney test. ${ }^{2}$ ) Number of visits or sessions.

3) Number of daily doses. 4) Number of admission days. NSAIDs = Nonsteroidal anti-inflammatory drugs. DMARDs = Disease modifying antirheumatic drugs. Ind $=$ individualized exercises at home. $\mathrm{Gr}=$ group physical therapy.

\section{Cost differences as effect of intervention}

Total medical costs decreased by an average of $\$ 257(35 \%)$ per patient per year for individualized exercises at home and by $\$ 379(44 \%)$ for group therapy (Table 3). Most direct medical costs decreased more or increased less for those patients who had group therapy than for those who only exercised at home, with the exception of visits to rheumatologists and days of admission. The total decrease in medical costs was $\$ 122$ greater for those who had group therapy than for those who exercised at home. The dif- 
ferences in decrease between the two groups were significant with regard to orthopedists, mental health treatments and total medical costs.

\section{Cost-effectiveness of intervention}

Group physical therapy cost $\$ 531$ per patient per year. The therapy reduced medical costs by $\$ 122$. Therefore, $7 \%$ extra increase in mobility, $5 \%$ extra increase in fitness and $28 \%$ extra increase in global health cost $\$ 409$ extra per AS patient per year (Fig. 1). After the study $75 \%$ of the patients wanted to continue group physical therapy and were willing to pay for it.

\section{DISCUSSION}

This study compared the effects and costs of group physical therapy with individualized exercises at home. The decrease in the costs of physical therapy in this study was partly due to the exclusion by the study protocol of supervised individualized physical therapy. Costs for alternative treatment during the trial increased especially for patients who had no group therapy.

In the pre-trial period, hospitalization costs accounted for a reasonable part of total medical costs. Costs of doctor visits, paramedical treatment and medication in the pre-trial period, $\$ 473$ for exercises at home and $\$ 584$ for group therapy, were increased by $\$ 271$ hospitalization costs. In patients who exercised at home these hospitalization costs were caused by a total of 41 admission days for only 1 patient. In group therapy 2 patients together accounted for 51 days of admission. Days of admission were reduced during the trial to 1 day in individualized and to 16 days in group therapy. The mean costs and the mean difference in costs of hospitalization depended largely on a small number of expensive cases. This small number of patients accounted for the total decrease in medical costs in the patients exercising at home. The cost savings of group therapy, $\$ 8$ for doctor visits, $\$ 109$ for treatment and $\$ 77$ for medication, were greatly outweighed by the difference in hospitalization costs saved.

This study focused on the direct medical costs, not because other effects are conceptually less relevant, but because our indirect costs assessments (e.g. decreased earnings or (un)paid help) were not very accurate.

In our analysis we fixed the price of exercises at home at zero. It is worthwhile to stress that supervised therapy is necessary beforehand in order enable the patient to practice home exercises afterwards. Thus, treatment costs had already been made before the start of the trial.

In this analysis annualized medical costs before the trial were compared with the effects of a 9-month treatment period. A longer (1year) treatment period might be more beneficial, as the costs of therapy remain the same.

The pre-trial estimates of AS related direct medical costs were assessed and calculated retrospectively, while the expenses during the trial were collected prospectively. It is possible that the patient's recall of pre-trial expenses may be less accurate than for expenses during the trial. However, this would probably only marginally 
influence the cost-effectiveness analysis, because the analysis focused on the differences in reduction of medical costs (Fig. I). However, it could mean that the reduction in medical costs would decrease and the costs of the beneficial effects of group therapy would be higher.

After this study we have to answer the question: is group physical therapy really costeffective in AS? Doubilet et all. have pointed out that a treatment that is more expensive than the alternative can be considered cost-effective if it has an additional benefit worth the additional costs [18]. Indeed, cost-effectiveness of a treatment should be related to the cost-effectiveness of the alternative treatments. It might be argued that a $28 \%$ increase in global assessment is worth its price $(\$ 409)$ in view of its clinical relevance. This might be supported by the fact that $75 \%$ of the patients wanted to continue group physical therapy and were willing to pay for it.

In a more complete cost-effectiveness analysis of group physical therapy for a chronic disease like AS it is necessary to measure direct as well as indirect costs, e.g. decreased earnings [19]. Also, in a slowly progressive chronic disease a longer study period may be more appropriate to ascertain these longer term consequences. In addition, one might want to assess not only disability-related, but also more personality-related effects, e.g. feelings of inadequacy or effect on one's health locus of control [20].

This study was done in the Netherlands. The results are applicable to countries with comparable health care systems and comparable health care costs. In countries with other health systems, where the current health care delivery system is much more costly, the beneficial effects of group therapy may cost considerably more than $\$ 409$ per AS patient per year.

In summary, it can be said that compared to individualized therapy at home, group physical therapy produced an extra increase of $7 \%$ in spinal mobility, $5 \%$ in fitness and $28 \%$ in global health, at a cost of $\$ 531$ per year, and decreased medical costs by $\$ 122$ per year. The beneficial effects of group therapy in AS thus required extra outlays of $\$ 409$ per patient per year.

\section{REFERENCES}

1. Department of clinical epidemiology and biostatistics, McMaster University Health Science Centre: How to read clinical journals: VII. To understand an economic evaluation (part A). Can Med Assoc J 1984; 130: $1428-1433$

2. Department of clinical epidemiology and biostatistics, McMaster University Health Science Centre: How to read clinical journals: VII. To understand an economic evaluation (part B). Can Med Assoc J 1984; 130: $1542-1549$

3. Detsky AS, Naglie IG: A clinician's guide to cost- effectiveness analysis. Ann Intern Med 1990; 113: 147-154

4. Udvarhelyi S, Colditz GA, Rai A, Epstein AM: Cost- effectiveness and cost-benefit analyses in the medical literature. Are the methods being used correctly? Ann Intern 
Med 1992; 116: 238-244

5. Thompson MS, Read JL, Hutchings HC, Paterson M, Harris ED: The cost-effectiveness of Auranofin: Results of a randomized clinical trial. J Rheumatol 1988; 15: 35-42

6. Khan MA, van der Linden S: Ankylosing Spondylitis and other Spondyloarthropathies. Rheum Dis Clin North America 1990; 16: 551-578

7. Kraag G, Stokes B, Groh J, Helewa A, Goldsmith C: The effects of comprehensive home physiotherapy and supervision on patients with Ankylosing Spondylitis. A randomized controlled trial. J Rheumatol 1990; 17: 228-233

8. Spring H: Funktionsorientierte Gymnastik und Sport bei der Spondylitis Ankylosans. In: Spring H, Spondylitis Ankylosans. Bern: Verlag Hans Huber, 1989: 117-132.

9. Hidding $A$, van der Linden $S$, Boers $M$, Gielen X, Kester A, de Witte L, Dijkmans $\mathrm{B}$, Moolenburgh D: Is group physical therapy superior to individualized therapy in Ankylosing Spondylitis? A randomized controlled trial. Arthritis Care Res 1993; 6: 117-125

10. van der Linden $\mathrm{S}$, Valkenburg $\mathrm{HA}$, Cats $\mathrm{A}$ : Evaluation of diagnostic criteria for Ankylosing Spondylitis: A proposal for modification of the New York criteria. Arthritis Rheum 1984; 27:361-368

11. Hidding A, van der Linden S, de Witte L: Therapeutic effects of individualized physical therapy in Ankylosing Spondylitis related to duration of disease. Clin Rheumatol
$1993,12: 334-340$

12. Miller MH, Lee P, Smythe HA, Goldsmith $\mathrm{H}$ : Measurement of spinal mobility in sagittal plane: New skin contraction technique compared with established methods. J Rheumatol 1984; 11: 507-5॥ 1

13. Jones NL, Makrides L, Hitchcock C, Chypchar T, McCartney N: Normal standards for an incremental progressive cycle ergometer test. Am Rev Respir Dis 1985; 131: 700-708

14. Rutten FFH, van Ineveld BM, van Ommen R, van Hout BA, Huijsman R: Kostenberekening bij gezondheidszorgonderzoek; richtlijnen voor de praktijk. Steering Committee on Future Health Scenarios. Utrecht, van Arkel, 1993

15. van der Kuy A, et al: Farmacotherapeutisch Kompas 1991: medische farmaceutische voorlichting. Amstelveen: Centrale Medisch Pharmaceutische Commissie Ziekenfondsraad, 1982

16. Bergner M, Bobbit RA, Kressel S, Pollard WE, Gilson BS, Morris JR: The Sickness Impact Profile: Conceptual formulation and methodology for the development of a health status measure. Int J HIth Serv 1976; 6: $393-415$

17. Daltroy HL, Larson MG, Roberts WN, Liang MH: A modification of the Health Assessment Questionnaire for the Spondyloarthropathies. J Rheumatol 1990; 17 : 946-950

18. Doubilet $\mathrm{P}$, Weinstein MC, McNeil BJ: Use and misuse of the term 'cost effective' 
in medicine. N Engl J Med 1986; 314: 253256

19. Meenan RF, Yelin EH, Henke CJ, Curtis DL, Epstein WV: The costs of Rheumatoid Arthritis: A patient-oriented study of chronic disease costs. Arthritis Rheum
$1978 ; 21: 827-833$

20. Lawrence VA, Tugwell P, Gafni A, Kosuwon W, Spitzer WO: Acute low back pain and economics of therapy: The iterative loop approach. J Clin Epidemiol 1992; 45: 301-311 


\section{CHAPTER 7}

\section{FACTORS RELATED TO CHANGES IN GLOBAL HEALTH AFTER GROUP PHYSICAL THERAPY IN ANKYLOSING SPONDYLITIS}

Alita Hidding and Sjef van der Linden

Department of Internal Medicine, Division of Rheumatology, University of Limburg and University Hospital Maastricht, The Netherlands

Arthritis Care and Research, submitted 


\section{ABSTRACT}

Objective: To assess factors related to self-reported change in global health after group physical therapy in Ankylosing Spondylitis (AS).

Methods: After 9 months of weekly group physical therapy, we studied the following explanatory variables in 67 AS patients (modified New York criteria): disease duration, changes in spinal mobility (thoraco-lumbar flexion and extension, chest expansion and cervical rotation), fitness (maximum work capacity in ergometry), functioning (Sickness Impact Profile, Health Assessment Questionnaire for the Spondyloarthropathies and Functional Index), pain, stiffness, and articular and enthesis indices. Change scores were calculated as baseline values minus scores at 9-month follow-up. Other explanatory variables were personality traits (neuroticism, social inadequacy, self-esteem and health locus of control) and loneliness. Patient's assessment of change in global health was self-reported on a $10 \mathrm{~cm}$ visual analogue scale $(-5=$ maximum worsening, $0=$ no change, $+5=$ maximum improvement). Correlations were calculated between global health and all explanatory variables. Multiple and stepwise regression analyses were performed to study the relations between global health and all explanatory variables.

Results: Pearson correlation coefficients between change in global health and the explanatory variables were only significant for lower selfesteem $(0.27)$ and improvements in chest expansion (0.31), fitness (0.32), HAQ-S (0.29), and stiffness (0.33). A stepwise regression analysis revealed 2 significantly explanatory steps: change in fitness explained $16 \%$ of total variance of changes in global health, and change in stiffness contributed an additional $11 \%$.

Conclusion: In AS, self-reported change in global health after group physical therapy is partly related to improvements in fitness and relief from stiffness.

\section{INTRODUCTION}

The use of patient's and physician's global assessments is recommended in clinical trials in rheumatology [1 - 7]. Global assessments are often taken as the main indicator or 'gold standard' of response to therapy [8]. However, the relative contributions of health status factors to these global assessments remain unclear [9].

In a recent randomized controlled trial in Ankylosing Spondylitis (AS) supervised weekly group physical therapy resulted in better thoraco-lumbar mobility and fitness than daily exercises at home [10]. Group therapy also had an important effect on patient's global health. There was a mean improvement of $34 \%$ on a visual analogue scale [10]. The present study assessed the relative contributions of several health status factors to the patient's perception of global health.

\section{METHODS}

\section{Selection of patients}

Briefly, a total of 163 (49\%) out of 333 AS 
patients from 2 outpatient rheumatology clinics gave written informed consent [10]. After examination by one rheumatologist 10 patients were excluded because they did not meet the criteria [10]. In addition, 9 patients stated they were unable to exercise daily. Therefore, a total of 144 AS patients (modified New York criteria [11]) could be randomized. One group was asked to do unsupervised daily exercises at home during 9 months. The other group received additional weekly group physical therapy during 9 months. A total of 135 patients completed the study, of whom 68 had done exercises at home and 67 had also had weekly group therapy [10]. Our analysis is restricted to the 67 subjects who received group physical therapy.

\section{Assessments}

The following measurements were used:

- The duration of disease was taken from the patient's medical record.

- Patient"s assessment of change in global health was assessed by asking the patient to describe his or her perceived change in general functioning on a $10 \mathrm{~cm}$ horizontal visual analogue scale $(-5=$ maximum worsening, $0=$ no change, $+5=$ maximum improvement).

- Spinal mobility was assessed by thoracolumbar flexion and extension [12]), chest expansion (difference in circumference between maximum inspiration and expiration around the chest wall at the level of the xiphoid processus $[13,14])$ and cervical rotation (placing a goniometer horizontally on the crown of the head $[10])$.
- Physical fitness was measured using an electronically braked bicycle ergometer (Jaeger ER800, Breda, The Netherlands). An incremental exercise test was used. The protocol started at 50 watts for 5 minutes and then increased by 10 watts every minute. All subjects performed up to their subjective maximum workload $[15,16]$.

- Functioning was assessed by Sickness Impact Profile (SIP) [17 - 19], Health Assessment Questionnaire for the Spondyloarthropathies (HAQ-S) [20], and the Functional Index for AS [21, 22].

- Pain and stiffness were each assessed by asking the patient to describe his or her perceived pain or stiffness on a $10 \mathrm{~cm}$ horizontal visual analogue scale $(0=$ no pain or stiffness, $10=$ worst pain or stiffness imaginable).

- The numbers of joints and entheses involved were assessed by applying both the articular and the enthesopathy index [23].

For all outcomes, except the patient's global change in health, change scores were scores at baseline minus scores at 9-month follow-up.

In addition to disease related measures, some personality traits and a social network variable were assessed:

- Three of the 7 scales of the Dutch Personality Inventory were administered cross-sectionally: the neuroticism, social inadequacy, and self-esteem scales [24, 25].

The Multidimensional Health Locus of Control Scales was administered assessing 3 dimensions: internal orientation, physician orientation and chance orientation [26-29]. 
Table 1. Scores of 67 AS patients on descriptive variables at baseline.

$\begin{array}{ll}\begin{array}{l}\text { Age (years) } \\ \text { Mean (SD) }\end{array} & 44(10) \\ \text { Duration of disease (years) } & 5(0-25) \\ \text { Median (range) } & \\ \text { Socio-demographic characteristics (\%) } & 72 \\ \text { male } & 68 \\ \text { married } & 66 \\ \text { employed } & 23 \\ \text { income: } 1 \text { ) high } & 48 \\ \quad \text { middle } & 29 \\ \quad \text { low } & 22 \\ \text { education high } & 46 \\ \text { level:2) midlde } & 32 \\ \text { Medications: (\% taking) } & 78 \\ \text { NSAIDs } & 72 \\ \text { Analgetics } & 3 \\ \text { DMARDs } & 6 \\ \text { Erythrocyte Sedimentation } & \\ \text { Rate (mm/hour) } & \\ \text { Median (range) } & 15(2-78)\end{array}$

NSAIDs $=$ nonsteroidal antiinflammatory drugs.

DMARDs = disease modifying antirheumatic drugs.

1) US dollars net per month; high: $>2000$ \$; rniddle: $1000-2000 \$ ;$ low: < $1000 \$$.

2) Years of education (including primary school); high: $>15$ years; middle: $10-15$ years; low: $<10$ years.

- The social network variable was assessed by applying the Loneliness Scale [30 - 32].

Personality traits and loneliness were assessed at baseline. The Health Locus of Control was applied at 9 months. Higher scores represent stronger traits or more loneliness.
Table 2. Pearson correlations between changes in global health ${ }^{1}$ ) after 9 months of group therapy and explanatory variables in 67 AS patients.

\begin{tabular}{lcc}
\hline & $\begin{array}{c}\text { Pearson } \\
\text { correlation }\end{array}$ & $p$ \\
\hline duration of disease & 0.20 & 0.06 \\
MPROVEMENTS IN DISEASE RELATED OUTCOMES & \\
chest expansion & 0.31 & $<\mathbf{0 . 0 1}$ \\
cervical rotation & 0.05 & 0.36 \\
physical fitness & 0.32 & $<\mathbf{0 . 0 1}$ \\
Sickness Impact Profile & 0.14 & 0.14 \\
Health Assessment Questionnaire & 0.30 & $\mathbf{0 . 0 1}$ \\
Functional Index & 0.16 & 0.10 \\
stiffness & 0.33 & $<\mathbf{0 . 0 1}$ \\
articular index & 0.18 & $\mathbf{0 . 0 8}$ \\
enthesopathy index & 0.02 & 0.43
\end{tabular}

\begin{tabular}{lcl} 
PERSONALITY TRAITS AND LONELINESS & \\
neuroticism & 0.01 & 0.49 \\
social inadequacy & 0.09 & 0.23 \\
self-esteem & -0.27 & $\mathbf{0 . 0 2}$ \\
internal orientation & -0.06 & 0.32 \\
physician orientation & -0.15 & 0.13 \\
chance orientation & -0.01 & 0.48 \\
loneliness & 0.12 & 0.18 \\
\hline
\end{tabular}

1) Higher scores imply improvement.

2) For all disease related outcomes change scores were calculated as scores at baseline minus scores after 9 months of follow-up.

3) Higher scores represent stronger traits or more loneliness. 


\section{Statistical analysis}

Pearson correlation coefficients were calculated between changes in global health and duration of disease, changes in disease related outcomes, personality traits and loneliness. Subsequently, a multiple and a stepwise regression analysis were performed to study the relation between change in global health as dependent variable and the explanatory variables [33].

\section{RESULTS}

Patient characteristics are given in Table 1. Pearson correlations between change in global health and disease duration, changes in disease related outcomes, personality traits and loneliness are given in Table 2. The coefficients for chest expansion, fitness, HAQ-S, stiffness, and self-esteem were reasonably high and statistically significant $(\mathrm{p}<0.05)$, whereas all other coefficients were low. Improvement in self-reported global health after 9 months group therapy corresponded with increased chest expansion, better aerobic power, better function and less stiffness. Improvements in global health were especially seen in patients with lower self-esteem.

In a multiple regression analysis, with glo- bal health as dependent and all explanatory variables as independent variables, a total of $48 \%$ of the total variance in global health was explained. In this analysis only change in fitness contributed significantly $(p=0.03)$. A stepwise regression analysis revealed 2 significantly explanatory steps (Table 3 ): change in fitness and change in stiffness together explained $27 \%$ of variance in global health.

\section{DISCUSSION}

This study indicates that in AS self-reported change in global health after group therapy is related to improvement in fitness and relief from stiffness.

Durarion of disease correlated weakly with global health, but in the multiple as well as in the stepwise regression analyses no significant relation was found between change in global health and duration of disease. This is in agreement with findings from an earlier report [34]. Because beneficial effects of supervised individualized physical therapy were about the same in recently diagnosed patients and in longstanding AS, patients may profit from physical therapy irrespective of the duration of disease.

Table 3. Stepwise regression analysis of changes in global health among 67 AS patients.

\begin{tabular}{llllrl}
\hline Step & Variable & $\begin{array}{l}\text { Multiple } \\
\mathrm{R}^{2}\end{array}$ & $\begin{array}{l}\text { Change } \\
\text { in } \mathrm{R}^{2}\end{array}$ & F ratio & \multicolumn{1}{c}{$\mathrm{P}$} \\
\hline 1 & change in fitness & 0.16 & & 10.5 & 0.002 \\
2 & change in stiffness & 0.27 & 0.11 & 9.7 & $<0.001$ \\
\hline
\end{tabular}


Neither of the two regression analyses found significant contributions of changes in chest expansion or HAQ-S to global health. It should be noted, however, that changes in chest expansion correlated rather highly with changes in fitness $(0.29, p=0.01)$, as did changes in HAQ-S with changes in stiffness $(0.23$, $\mathrm{p}=0.04)$. This probably explains why no significant contributions of changes in chest expansion and changes in HAQ-S were found in the regression analyses.

Although self-esteem did not contribute significantly to changes in global health after group therapy, the correlation between self-esteem and changes in global health was reasonably high (Table 2). It is worth stressing that group physical therapy was most successful in patients with a lower self-esteem. It seems possible that in these patients in particular the following factors contribute to the beneficial effects of group therapy: the opportunity to compare oneself with other -sometimes more disabled - patients, mutual encouragement, reciprocal motivation and companoniable contact with peers in similar circumstances of illhealth [35].

In the group physical therapy trial, patient's assessment of change in global health was predefined as a primary outcome [10]. This patient reported measurement is important because it reflects his/her values and priorities. Improvements with regard to fitness and stiffness together explained a considerable proportion $(27 \%)$ of the variance of the self-reported improvement in global health. However, $73 \%$ of total variance in global health is due to otheras yet unknown - sources.

In conclusion, the beneficial effects of group therapy were found to be partly mediated by increased fitness and relief from stiffness. Ordering or advising weekly group physical therapy in patients with AS is worthwhile because it may be expected to improve global health status and to bring relief from characteristic symptoms of disease such as stiffness.

\section{REFERENCES}

1. Fries JF: Towards an understanding of patient outcome measurement. Arthritis Rheum 1983; 26: 697-704

2. Anderson JJ, Felson DT, Meenan RF, Williams HJ: Which traditional measures should be used in Rheumatoid Arthritis clinical trials? Arthritis Rheum 1989; 32 : 1093-1099

3. Felson DT: Choosing a core set of disease activity measures for use in Rheumatoid Arthritis clinical trials. J Rheumatol 1993; 20: 531-534

4. Goldsmith $\mathrm{CH}$, Boers M, Bombardier C, Tugwell $P$, for the OMERACT COMMITTEE: Criteria for clinically important changes in outcomes: Development, scoring and evaluation of Rheumatoid Arthritis patient and trial profiles. $J$ Rheumatol 1993; 20: 561-565

5. Tugwell $\mathrm{P}$, Boers $\mathrm{M}$ : OMERACT conference on outcome measures in Rheumatoid Arthritis clinical trials: Conclusions. J 
Rheumatol 1993; 20:590

6. Gotzsche PC: Sensitivity of effect variables in Rheumatoid Arthritis: A meta-analysis of 130 placebo controlled NSAID trials. J Clin Epidemiol 1990; 43: 1313-1318

7. Bombardier C, Raboud J, Auranofin Cooperating Group: A comparison of health-related quality-of-life measures for Rheumatoid Arthritis patients. Cont Clin Trials 1991; 12: 243S-256S

8. Scott DL: European preferences in assessing Rheumatoid Arthritis. I Rheumatol 1993; $20: 542$

9. van Zeben D, Hazes JMW, Breedveld FC, Zwinderman AH, Vandenbroucke JP: Which clinical variables contribute to the physician's assessment of medium term outcome in Rheumatoid Arthritis? J Rheumatol 1993; 20: 33-39

10. Hidding $A$, van der Linden $S$, Gielen $A$, Kester A, de Witte L, Dijkmans B, Moolenburgh $\mathrm{J}$ : Is group physical therapy superior to individualized therapy in Ankylosing Spondylitis? A randomized controlled trial. Arthritis Care Res 1993; 6:1.17-125

11. van der Linden S, Valkenburg HA, Cats A: Evaluation of diagnostic criteria for Ankylosing Spondylitis: A proposal for modification of the New York criteria. Arthritis Rheum 1984; 27: 361-368

12. Miller MH, Lee P, Smythe HA, Goldsmith $\mathrm{H}$ : Measurement of spinal mobility in sagittal plane: New skin contraction technique compared with established methods.
J Rheumatol 1984; 11: 507-511

13. Moll JMH, Wright V: An objective clinical study of chest expansion. Ann Rheum Dis 1972; $31: 1-8$

14. Roberts W, Larson M, Liang M, Harrison R, Barefoot J, Clarke A: Sensitivity of anthrometric techniques for clinical trials in Ankylosing Spondylitis. Br J Rheum 1988; 28: $40-45$

15. Astrand PO, Rodahl K: Textbook of work physiology. Physiological bases of exercise. McGraw-Hill Book Company, 1977

16. Jones NL, Makrides L, Hitchcock C, Chypchar T, McCartney N: Normal standards for an incremental progressive cycle ergometer test. Am Rev Respir Dis 1985; 131: 700-708

17. Bergner M, Bobbit RA, Kressel S, Pollard WE, Gilson BS, Morris JR: The Sickness Impact Profile: Conceptual formulation and methodology for the development of a health status measure. Int J HIth Serv 1976; 6: $393-415$

18. McDowell I, Newell C: Measuring health: A guide to rating scales and questionnaires. New York / Oxford: Oxford University Press, 1987

19. de Bruin AF, de Witte LP, Stevens FCJ, Diederiks JPM: De bruikbaarheid van de Sickness Impact Profile als generieke maat voor functionele toestand. Tijdschr Soc Gezondheidsz 1992; 70: 160-170

20. Daltroy HL, Larson MG, Roberts WN, Liang MH: A modification of the Health Assessment Questionnaire for the Spondy- 
loarthropathies. J Rheumatol 1990; 17 : 946-950

21. Dougados $M$, Gueguen A, Nakache JP, Nguyen M, Mery C, Amor B: Evaluation of a Functional and an Articular Index in Ankylosing Spondylitis. J Rheumatol 1988; 15:302-307

22. Dougados $M$, Gueguen A, Nakache JP, Nguyen M, Mery C, Amor B: Evaluation of a Functional Index for patients with Ankylosing Spondylitis. J Rheumatol 1990; 17: 1254-1255

23. Mander M, Simpson JM, McLellan A, Walker D, Goodacre JA, Dick WC: Studies with an enthesis index as a method of clinical assessment in Ankylosing Spondylitis. Ann Rheum Dis 1987; 46: 197-202

24. Luteyn F, Starren J, van Dijk J: Handleiding bij de Nederlandse Persoonlijkheids Vragenlijst. Amsterdam: Swets \& Zeitlinger, 1985

25. Luteyn F: De relaties tussen ABV, MMPI en NPV. Ned Tijdschr Psychol 1980; 35: 215-222

26. Wallston KA, Wallston BS, DeVellis R: Development of the Multidimensional Health Locus of Control (MHLC) Scales. Health Education Monographs 1978; 6: 161. 170

27. Levenson $\mathrm{H}$ : Differentiating among internality, powerful others, and chance. In $\mathrm{H}$.
Lefcourt (Ed.): Research with the locus of control construct (Vol. 1). New York: Academic Press, 1981

28. Sanders GS, Suls J: Social psychology of health and illness. London: Lawrence Erlbaum Associates Publishers, 1982

29. Halfens R: Locus of control: de beheersingsorientatie in relatie tot ziekte- en gezondheidsgedrag. Thesis. Maastricht: University of Limburg, 1985

30. de Jong-Gierveld J: Eenzaamheid: een meersporig onderzoek. Deventer: Van Loghum Slaterus, 1984

31. de Jong-Gierveld J, Kamphuis F: The development of a Rasch-type Loneliness Scale. Appl Psychol Measurement 1985; 9: 289-299

32. de Jong-Gierveld J: Developing and testing a model of loneliness. J Pers Soc Psychol 1987; 53: 119-128

33. Norusis MJ: SPSS statistical data analysis. Chicago: SPSS Inc, 1990

34. Hidding A, van der Linden S, de Witte L: Therapeutic effects of individualized physical therapy in Ankylosing Spondylitis related to duration of disease. Clin Rheumatol 1993, 12: 334-340

35. Baumberger H: Schweizerische Vereinigung Morbus Bechterew: eine PatientenSelbsthilfeorganisation. Schweiz Rundschau Med 1991; 80: 644-649 


\section{CHAPTER 8}

\section{DETERMINANTS OF SELF-REPORTED HEALTH STATUS IN ANKYLOSING SPONDYLITIS}

Alita Hidding, Luc de Witte ${ }^{1}$ ), and Sjef van der Linden

Department of Internal Medicine, Division of Rheumatology, University of Limburg and University

Hospital Maastricht, 1) Institute for Rehabilitation Research, Hoensbroek, The Netherlands

Journal of Rheumatology 1994, in press 


\section{ABSTRACT}

Objective: To assess the relative contributions of disability-related variables, personality traits and social network characteristics to self-reported general health status in Ankylosing Spondylitis (AS).

Methods: For 144 AS patients (modified New York criteria; 112 males) the following variables were assessed cross-sectionally: disability-related variables (age, duration of disease, spinal mobility, physician's global assessment), personality traits (neuroticism, social inadequacy, self-esteem, health locus of control) and loneliness. Health status was assessed by means of 3 self-administered instruments: Sickness Impact Profile, Health Assessment Questionnaire for the Spondyloarthropathies and Self-assessed Function:

Results: Factor analysis of the 3 health status instruments suggested one underlying health status score. This derived health status score correlated significantly with each of the disability-related variables, the personality traits and loneliness $(p<0.05)$, but not with social inadequacy and physician oriented health control. In multiple regression analysis 4 variables contributed significantly, together explaining $44 \%$ of the total variance in the derived health status score: neuroticism $25 \%$, physician's global assessment $8 \%$, internal oriented health control $6 \%$ and spinal mobility $5 \%(\mathrm{p}<0.001)$.

Conclusion: In AS, self-reported health status is more strongly related to personality traits than to the degree of disability. When assessing health status in AS by self-report, personality traits must be taken into account.

\section{INTRODUCTION}

In a recent randomized controlled trial in Ankylosing Spondylitis (AS) patients, supervised weekly group physical therapy resulted in better thoraco-lumbar mobility, fitness and patient's global assessment than regular exercises at home [1]. No significant treatment effects were found for self-report health status measures such as the generic Sickness Impact Profile (SIP) or the disease oriented Health Assessment Questionnaire for the Spondyloarthropathies (HAQ-S) [1]. To explain this discrepancy we assessed the relative contributions of disability-related variables, personality traits and social network characteristics to self-reported health status in these patients.

\section{METHODS}

\section{Selection of patients}

In all, 333 AS patients from 2 outpatient rheumatology clinics were asked to participate in the original study [1]. A total of $163(49 \%)$ patients gave written informed consent. All participants were examined by one rheumatologist to check for the inclusion and exclusion criteria. Only patients fulfilling the modified New York criteria were included [2]. Patients unable to engage in physical therapy, those with total hip replacement, pregnant patients and those with severe hypertension [diastolic blood pressure > 
$100 \mathrm{~mm} \mathrm{Hg}$ ], cardiovascular disease [history of ischemic event, angina pectoris, heart failure], severe lung disease, diabetes mellitus, renal failure, chronic liver disease, malignancy, recent major surgery, mental retardation or serious emotional disorders were excluded. Altogether, 10 patients were excluded: 2 patients did not satisfy the modified New York criteria, $\mathbb{1}$ had a total hip replacement, 4 had cardiac problems, and 3 had emotional disorders, while 9 patients stated they were unable to exercise daily. Hence, 144 patients were included in the study.

\section{Assessments}

The following socio-demographic characteristics of the patients were assessed: age, gender, marriage, employment, income, and education.

The following disability-related variables were obtained:

\section{- Duration of disease.}

- Spinal mobility measured by thoraco-lumbar flexion and extension [3]. With the subject standing erect, a mark was placed at the lumbosacral junction. The subject then bent forward as far as possible and 3 more marks were made at $10 \mathrm{~cm}$ intervals measured cranially from the first. The lenghts of the three $10 \mathrm{~cm}$ intervals were remeasured with the subject fully extending the spine. The sum of the changes in the measurements was designated as the spinal mobility score.

- Physician's global assessment. The physi- cian indicated the activity of the disease on a 5point scalle ( $1=$ low activity, $5=$ high activity).

To assess personality traits the following questionnaires were administered:

The Dutch Personality Inventory: 3 of the 7 available scales: neuroticism, social inadequacy, and self-esteem $[4,5]$. The neuroticism scale consists of 21 items and measures whether patients consider themselves inadequate and troubled by vague physical complaints, depressed moods, nonspecific anxieties and feelings of inadequacy. The social inadequacy scale consists of 15 items and measures avoidance and unhappiness in social contacts. The self-esteem scale consists of 19 items and measures self-recognition. Answers are given on a 3-point scale: agree, don't know, and disagree. High scores on these 3 scales indicate more neuroticism, inadequacy, and a higher self-esteem, respectively.

- The Multidimensional Health Locus of Control Scale comprises the following dimensions: internal orientation, physician orientation and chance orientation [6 - 9]. The questionnaire consists of three 6-item scalles, using a 6point response format (strongly agree, moderately agree, slightly agree, slightly disagree, etc.). The internal scale measures health internality, i.e., the extent to which individuals believe they can influence their health/illness. The physician orientation scale assesses beliefs that one's health is determined by powerful other people such as physicians. The chance orientation scale measures the extent to which one be 
lieves that health/illness is a matter of fate, luck or chance. Higher scores indicate a stronger orientation.

The social network characteristic was determined by means of the Loneliness Scale [1012]. This questionnaire consists of 11 items and measures the emotionall experience of loneliness such as feelings of deprivation and missing companionship. Answers are given on a 5-point scale (yes!, yes, neutral, no, no!). Higher scores indicate more loneliness, and presumably a less effective network.

Health status was assessed by the following self-reports:

- Sickness Impact Profile (SIP), a 136-item generic measure of health status [13 - 15]. There are 12 categoryscores and 2 dimensionscores of physical and psychosocial dysfunction (range 0 - 100). The psychosocial dimension contains 9 items in the category of emotional behaviour. Some of these items are also part of the neuroticism scale of the Dutch Personality Inventory. Higher scores on SIP indicate more dysfunction.

- The Health Assessment Questionnaire for the Spondyloarthropathies (HAQ-S) is a disease specific 13-item questionnaire about physical function in AS [16]. The HAQ-S comprises 3 subscales: the original HAQ scale and 2 spondylitis subscales, all corresponding to activities of daily living. A score of ' 0 ' is given if the patient is able to perform the activity without any difficulty, ' 1 ' if with some difficulty, ' 2 ' if with much difficulty and ' 3 ' if the patient is unable to perform the activity. Answers were ad- ded and divided by the number of items, giving a mean HAQ-S score ranging from ' $0^{\prime}$ (no difficulties whatsoever) to ' 3 ' (unable to do anything).

- The Self-assessed Function questionnaire (SAF) is a generic measure of function [17, 18]. The SAF comprises 4 items on physical function (severity of disease, hindrance in daily activities, physical functioning, and general health) and 5 items on psychosocial function (being able to cope with daily practical problems, psychological functioning, success in coping with disability, contacts with others, difficulty in contacts with acquaintances). Answers are given on a 5-point scale (very good, good, moderate, bad, very bad). Higher scores indicate better function.

All measures were assessed at baseline; only the locus of control scale was applied after completion of the trial. The 3 health status selfreports, the SIP, HAQ-S and the SAF, were administered in this order and completed during the baseline measurements at the hospital. The total length of time required to administer these 3 measurements was about 30 minutes. The Dutch Personality Inventory, the Multidimensional Health Locus of Control and the Loneliness Scale were completed in this order at home. Total time for administering these 3 measurements was also about 30 minutes.

\section{Statistical analysis}

Patient characteristics were summarized by mean and standard deviation (SD) or - where appropriate - by median and range. A principal 
Table 1. Characteristics of 144 participants.

\begin{tabular}{|c|c|c|c|c|}
\hline $\begin{array}{l}\text { SOCIO-DEMOGRAPHIC } \\
\text { VARIABLES }\end{array}$ & $\begin{array}{l}\text { age (years) } \\
\text { male } \\
\text { married } \\
\text { employed } \\
\text { income } 1 \text { ) } \\
\text { education } 2 \text { ) }\end{array}$ & $\begin{array}{l}\text { mean } 42.5 \\
78 \% \\
67 \% \\
72 \% \\
\text { high: } 20 ; \mathrm{mi} \\
\text { high: } 21 ; \mathrm{mi}\end{array}$ & $\begin{array}{l}\text { SD } \\
\text { 4; low: } \\
\text { 4; low: }\end{array}$ & $\begin{array}{l}26 \\
35\end{array}$ \\
\hline $\begin{array}{l}\text { DISABILITY-RELATED } \\
\text { VARIABLES }\end{array}$ & $\begin{array}{l}\text { disease duration (years) } \\
\left.\text { spinal mobility }(\mathrm{cm})^{3}\right) \\
\text { plyysician's global assessment } 4)\end{array}$ & $\begin{array}{ll}\text { median } & 4.0 \\
\text { median } & 5.5 \\
\text { mean } & 2.7\end{array}$ & $\begin{array}{l}\text { range } \\
\text { range } \\
\text { SD }\end{array}$ & $\begin{array}{l}0.32 \\
0.2-11.4 \\
0.9\end{array}$ \\
\hline $\begin{array}{l}\text { HEALTH STATUS } \\
\text { QUESTIONNAIRES }\end{array}$ & $\begin{array}{l}\text { Sickness Impact Profile } \\
\text { physical (range 0-100) } \\
\text { psychosocial (range 0-100) } \\
\text { total score (range 0-100) } \\
\text { Health Assessment Questionnaire } \\
\text { for the Spondyloarthropathies }{ }^{4} \text { ) (range 0-3) } \\
\text { Self-assessed Function } 3 \text { ) } \\
\text { physical (range 4-20) } \\
\text { psychosocial (range 5-25) }\end{array}$ & $\begin{array}{l}\text { median } 2.4 \\
\text { median } 2.1 \\
\text { median } 4.0 \\
\text { median } 0.31 \\
\text { mean } 13.2 \\
\text { mean } 19.6\end{array}$ & $\begin{array}{l}\text { range } \\
\text { range } \\
\text { range } \\
\text { range } \\
\mathrm{SD} \\
\mathrm{SD}\end{array}$ & $\begin{array}{l}0-22.6 \\
0-33.6 \\
0-24.4 \\
0-1.46\end{array}$ \\
\hline PERSONALITY TRAITS & $\begin{array}{l}\text { Dutch Personality Inventory } 3 \text { ) } \\
\text { neuroticism (range 0-42) } \\
\text { social inadequacy (range 0-30) } \\
\text { self-esteem (range 0-38) } \\
\text { Multidimensional Health Locus of Contro } 3 \text { ) } \\
\text { internal orientation (range 6-36) } \\
\text { physician orientation (range 6-36) } \\
\text { chance orientation (range 6-36) }\end{array}$ & $\begin{array}{lr}\text { median } 8.0 \\
\text { median } 8.0 \\
\text { mean } 27.4 \\
\text { mean } & 22.5 \\
\text { mean } & 17.4 \\
\text { mean } & 18.6\end{array}$ & $\begin{array}{l}\text { range } \\
\text { range } \\
\mathrm{SD}\end{array}$ & $\begin{array}{l}0-30 \\
0-27 \\
5.7\end{array}$ \\
\hline SOCIAL NETWORK & Loneliness Scale $\left.^{3}\right)($ range 0-11) & median 0 & range & $0-9$ \\
\hline
\end{tabular}

1) US dollars net per month; high: $>2000$ dollars; middle: $1000-2000$ dollars; low: $<1000$ dollars

2) Years of education (including primary school); high: $>15$ years, middle: $10-15$ years; low: $<10$ years.

3) Higher scores represent better mobility, better function, higher traits or more loneliness.

4) Lower scores represent better function.

components analysis studied the possibility of a single factor, one overall health dimension underlying the 3 health status questionnaires: a sum score was computed with items weighted according to the factor loadings [19]. When we found one overall health score, we calculated 
Table 2. Pearson correlation coefficients between 3 self-reported health status measures in 144 AS patients.

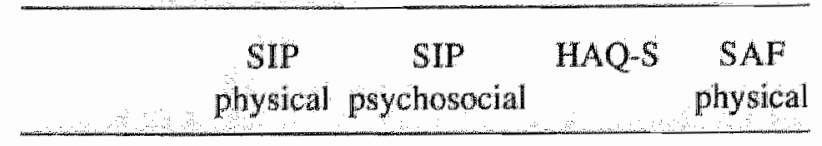

SIP

\begin{tabular}{lllll} 
psychosocial & 0.49 & & & \\
HAQ-S & 0.59 & 0.36 & & \\
SAF & & & & \\
physical & -0.47 & -0.32 & -0.60 & \\
psychosocial & -0.40 & -0.58 & -0.32 & 0.47 \\
\hline
\end{tabular}

SIP: Sickness Impact Profile. HAQ-S: Health Assessment Questionnaire for the Spondyloarthropathies. SAF: Self-assessed Function. All correlation coefficients significant, $p<0.001$.

Table 3. Factor analysis of 3 self-reported health status measures in 144 AS patients.

\begin{tabular}{lc}
\hline & OVERALL HEALTH STATUS SCORE \\
SIP physical & 0.73 \\
psychosocial & 0.67 \\
HAQ-S & 0.78 \\
SAF physical & -0.82 \\
psychosocial & -0.75 \\
\hline
\end{tabular}

SIP: Sickness Impact Profile. HAQ-S: Health Assessment Questionnaire for the Spondyloarthropathies. SAF: Self-assessed Function. Values are Pearson correlation coefficients, all significant, $\mathrm{p}<0.001$.

Pearson correlations between this derived score and the disability-related variables, personality traits and social network characteristics. Finally, we performed a stepwise regression analysis to study the relation between the derived health status score and the above-mentioned explanatory variables [19].

\section{RESULTS}

Characteristics of the participants are given in Table 1. Pearson correlation coefficients between the 3 health status questionnaires, SIP, HAQ-S and SAF, were reasonably high (Table 2). Factor analysis showed that the 3 health status questionnaires loaded highly on 1 factor, implying a single underlying score (Table 3 ). A higher factor score indicates a poorer health status. Correlations between the derived health status score and the disability-related variables, the personality traits and loneliness were significant $(\mathrm{p}<0.05)$, except for social inadequacy and physician orientation (Table 4).

As regarded the socio-demographic characteristics, a score was calculated representing the number of years of education and the level of income. Pearson correlation between this score and self-reported health status was -0.16. Better health status corresponded with a higher educational level and better economic status. However, this relation was weak and statistically non-significant. Therefore, the level of education and economic status were not used in the regression analyses.

The stepwise regression analysis with the health status score as dependent variable and the disability-related data as explanatory variables revealed 4 contributing variables (Table 5): neuroticism, physician's global assessment, inter- 
Table 4. Pearson correlation coefficients between overall health and: disability-related variables, personality traits, and social network characteristics in 144 AS patients.

\section{DISABILITY-RELATED VARIABLES}

age

$0.23 * *$

disease duration

spinal mobility 1)

$0.21 * *$

physician's global assessment ${ }^{2}$ )

$-0.32 * * *$

$0.36^{*} * *$

PERSONALITY TRAITS

Dutch Personality Inventory 1 )

neuroticism

$0.48^{* * *}$

social inadequacy

0.14

self-esteem

$-0.36^{* * * *}$

Muitidimensional Health

Locus of Control ${ }^{1}$ )

internal orientation

physician orientation

$-0.23^{* * 14}$

chance orientation

0.07

$0.17^{*}$

SOCIAL NETWORK

Loneliness Scale ${ }^{\text {() }}$

0.26 **

Higher scores for overall health indicate poorer health status. 1) Higher scores represent better mobility, better function, higher traits or more loneliness. 2) Lower scores represent better function. Significant, ${ }^{*} \mathrm{p}<0.05$, *** $\mathrm{p}<0.01$, *** $\mathrm{p}<0.001$.

nal orientation, and thoraco-lumbar mobility. When loneliness was forced into the model first, it was a significant determinant, but it explained only a small amount of variance $\left(\mathrm{R}^{2}\right.$ : $0.09, \mathrm{p}<0.05)$. However, when the personality traits were entered next, loneliness became nonsignificant, indicating that personality traits and loneliness were interrelated. This finding was also illustrated by the relatively high correlations
Table 5. Results of stepwise regression predicting self reported health status in 144 AS patients.

\begin{tabular}{llrrr} 
& & \multicolumn{2}{c}{ Multiple Change } & $\mathrm{F}$ \\
Step & Variable & $\mathrm{R}^{2}$ & $\mathrm{n} \mathbb{R}^{2}$ & ratio \\
\hline 1 & neuroticism & 0.25 & & 35.8 \\
2 & physician's global assessment & 0.33 & 0.08 & 25.2 \\
3 & internal orientation & 0.39 & 0.06 & 22.3 \\
4 & spinal mobility & 0.44 & 0.05 & 20.0 \\
\hline
\end{tabular}

All steps significant, $p<0.001$.

between loneliness on the one hand and neuroticism and self-esteem on the other $(0.43$ and -0.33 respectively, $\mathrm{p}<0.001$ ).

In another analysis the psychosocial dimension of both SIP and SAF were omitted from the factor score, because these dimensions included questions probably related to the independent variable neuroticism. Stepwise regression analysis revealed the following: 4 variables explained $64 \%$ of total variance: physician's global assessment $42 \%$, neuroticism $10 \%$, internal orientation $7 \%$, and spinal mobility $5 \%$ $(p<0.001)$. When neuroticism was forced into the model first, neuroticism explained $38 \%$ and physician's global assessment $14 \%$. Neuroticism and physician's global assessment were interrelated (Pearson correlation $0.20, \mathrm{p}=0.01$ ).

\section{DISCUSSION}

This study indicates that in AS self-reported health status is more strongly related to personality traits than to the degree of disability. 
The most important determinant of self-reported health status in AS was the level of neuroticism. Physician's global assessment of disease activity, health internality, and spinal mobility were also significant but less important determinants of health status in AS. Therefore, self-report of health status is affected favourably by balance and stability. Social aspects also contribute to self-reported health status in AS. However, scores of personality traits and loneliness overlap, as is illustrated by the high correlation.

When we reduced self-reported health status to physical aspects, physician's global assessment of disease activity was the most important determinant. However, when neuroticism was forced into the reduced model first, this trait contributed most strongly. This indicates that physician's global assessment and the degree of neuroticsm are somehow inter-related.

In this study a total of 6 questionnaires were administered. The accuracy of completion may have been reduced by the fact that the total length of time required to administer these questionnaires was about 60 minutes. To reduce the influence of fatique, boredom or repetition, we decided to administer 3 of the 6 questionnaires at home. The order of completion of the questionnaires was, however, fixed. It would have been better to randomize the order using a latin square design, to eliminate any order effects.

We must stress that the associations between self-reported health status and the measured variables do not necessarily indicate cause and effect, or directionality. For example, it is imaginable that patients who have a poor health status may as a consequence feel inadequate, or that patients who feel inadequate may develop a poor health status.

In our physical therapy trial, endpoints were particularly focused on physical factors, such as mobility and fitness [1]. In physiotherapy trials personality traits are of course no realistic targets for treatment. In view of their strong relation to self-reported health status, it is not surprising that we were unable to show any efficacy of trial treatment in this measure [1]. In the total management and assessment of AS, personality traits need closer scrutiny.

\section{REFERENCES}

1. Hidding $A$, van der Linden $S$, Boers $M$, Gielen X, Kester A, de Witte L, Dijkmans $\mathrm{B}$, Moolenburgh $\mathrm{D}$ : Is group physical therapy superior to individual therapy in Ankylosing Spondylitis? A randomized controlled trial. Arthritis Care Res 1993; 6: 117-125

2. van der Linden $S$, Valkenburg HA, Cats A: Evaluation of diagnostic criteria for Ankylosing Spondylitis: A proposal for modification of the New York criteria. Arthritis Rheum 1984; 27: 361-368

3. Miller MH, Lee P, Smythe HA, Goldsmith $\mathrm{H}$ : Measurement of spinal mobility in sagittal plane: New skin contraction technique compared with established methods. J Rheumatol 1984; 11:507-511

4. Luteyn F, Starren J, van Dijk J: Hand- 
leiding bij de Nederlandse Persoonlijkheids Vragenlijst. Amsterdam: Swets \& Zeitlinger, 1985

5. Luteyn F: De relaties tussen ABV, MMPI en NPV. Nederlands Tijdschrift voor Psychologie 1980; 35: 215-222

6. Wallston KA, Wallston BS, DeVellis R: Development of the Multidimensional Health Locus of Control (MHLC) Scales. Health Education Monographs 1978; 6: 161-170

7. Levenson $\mathrm{H}$ : Differentiating among internality, powerful others, and chance. In $\mathrm{H}$. Lefcourt (Ed.): Research with the locus of control construct (Vol. 1). New York: Academic Press, 1981

8. Sanders GS, Suls J: Social psychology of health and illness. London: Lawrence Erlbaum Associates Publishers, 1982

9. Halfens R: Locus of control: de beheersingsorientatie in relatie tot ziekte- en gezondheidsgedrag, Thesis. Maastricht: University of Limburg, 1985

10. de Jong-Gierveld $\mathrm{J}$ : Eenzaamheid: een meersporig onderzoek. Deventer: Van Loghum Slaterus, 1984

11. de Jong-Gierveld J, Kamphuis F: The development of a Rasch-type Loneliness Scale. Applied Psychological Measurement 1985; 9: 289-299

12. de Jong-Gierveld J: Developing and testing a model of loneliness. J Personality Social Psychology 1987; 53: 119-128

13. Bergner M, Bobbit RA, Kressel S, Pollard
WE, Gilson BS, Morris JR: The Sickness Impact Profille: Conceptual formulation and methodology for the development of a health status measure. Int J Hith Serv 1976; 6: $393-415$

14. Bergner $M$, Bobbitt RA, Carter WB, Gilson BS: The Sickness Impact Profile: development and final revision of a health status measure. Medical Care 1981; 19: 787-805

15. McDowell I, Newell C: Measuring health: A guide to rating scales and questionnaires. New York / Oxford: Oxford University Press, 1987

16. Daltroy HL, Larson MG, Roberts WN, Liang MH: A modification of the Health Assessment Questionnaire for the Spondylarthropathies. J Rheumatol 1990; 17: 946-950

17. de Witte LP, Tilli DJP, Ticheler AJG, Winants $\mathrm{BAC}$, van der Horst $\mathrm{FG}$, van der Linden S: Leven met een reumatische aandoening. Een onderzoek naar de ervaren kwaliteit van het leven bij 372 mensen met een reumatische aandoening. Hoensbroek: Instituut voor Revalidatie Vraagstukken, 1989

18. de Witte LP: After the rehabilitation centre. A study into the course of functioning after discharge from rehabilitation. Thesis. IRV Series in Rehabilitation Research, Volume 3. Amsterdam: Swets \& Zeitlinger, 1991

19. Norusis MJ: SPSS statistical data analysis. Chicago: SPSS Inc, 1990 


\section{CHAPTER 9}

\section{DISCORDANCE BETWEEN SELF-REPORT MEASURES AND CLINICAL OBSERVATIONS OF FUNCTIONAL DISABILITY IN ANKYLOSING SPONDYLITIS, RHEUMATOID ARTHRITIS AND FIBROMYALGIA}

Alita Hidding, Marijke van Santen, Erik de Klerk, Xandra Gielen, Maarten Boers, Rinie Geenen ${ }^{1)}$, Johan Vlaeyen ${ }^{2}$ ), Arnold Kester ${ }^{3}$ ), and Sjef van der Linden

Department of Internal Medicine, Division of Rheumatology, University Hospital Maastricht; 1) Department of Rheumatology, University Hospital Utrecht; 2) Department of Medical Psychology, 3) Department of Medical Informatics and Statistics, University of Limburg; The Netherlands

Journal of Rheumatology 1994, in press 


\section{ABSTRACT}

Objective: To study discordance between selfreport measures and clinical observations of functional disability in Ankylosing Spondylitis (AS), Rheumatoid Arthritis (RA), and Fibromyalgia.

Merhods: 35 AS patients completed 9 selected items of the Functional Index questionnaire, whereas 12 RA and 13 Fibromyalgia patients completed 7 selected items of the Arthritis Impact Measurement Scales. Five days later, all 60 patients and 4 controls actually performed the selected activities. This was recorded on video. The tapes were assessed in random order by 12 observers ( 6 occupational therapists and 6 physicians). Both patients and observers indicated functional disability on a 10 centimeter visual analogue scale (VAS).

Results: Inter-observer agreement was high (Cronbach's Alpha 0.98). All observers scored the 4 healthy controls as having 'no disability at all'. Mean discordance scores (VAS patients minus VAS observers) for the selected items were negligible in AS $(-0.17 \mathrm{~cm}(\mathrm{p}=0.30))$, moderate in RA $(+1.10 \mathrm{~cm}(\mathrm{p}=0.06))$ and high in Fibromyalgia $(+2.44 \mathrm{~cm}(\mathrm{p}<0.01))$.

Conclusion: Discordance between self-report questionnaires and observed functional disability is a feature most striking in Fibromyalgia. Validation of self-report questionnaires of functional disability requires the appropriate spectsum of theumatological diagnoses to be considered.

\section{INTRODUCTION}

In rheumatology, self-report measures of functional disability are frequently used to establish health status and to evaluate outcomes of interventions. The measurements should be valid and the instruments applicable to a variety of rheumatic diseases. Clinical observations of functional disability are usually considered to be the 'gold standard'.

In a literature search we found only 6 trials, 2 from psychological literature and 4 from rheumatological literature, comparing self-reported and clinical assessments. Two trials reported discordance between depressed patients and clinicians in psychopathology ratings such as somatization, anxiety and hostility $[1,2]$. Two studies reported discordance in Rheumatoid Arthritis (RA). In the first study clinicians tended to rate the degree of functional disability lower than the patients, whereas the second study reported the opposite $[3,4]$. The 2 remaining studies found a reasonable concordance for functional disability $[5,6]$. All 6 studies used a response format of 2 to 6 ordered response categories; 1 study additionally used a visual analogue scale. We found no studies dealing with agreement between self-reported and clinician's assessment in rheumatic diseases other than RA.

Clearly, the perceived level of functional disability for patients is influenced by patient's needs, priorities, experiences and attitudes [7]. In a recent study in Ankylosing Spondylitis 
(AS) we measured attitudes of patients towards their functional disability. AS patients tended to deny problems [8]. Therefore, the observed disability might be different from the self-reported disability. Also, the influence of patient's experiences and attitudes might vary for different rheumatic diseases. In this study we compared self-reported and clinically assessed functional disability in AS, RA and Fibromyalgia patients.

\section{METHODS}

\section{Participants and observers}

A total of 60 AS patients (modified New
York criteria [9]), who had completed a trial on group physical therapy in AS [10], were asked to participate in the study. In all, 35 patients agreed. A total of 13 female Fibromyalgia patients (ACR criteria [11]), who constituted the control group in an on-going study of the effects of fitness training in Fibromyalgia, and 12 age and sex matched RA patients (ACR 1987 criteria [12], all Steinbröcker functional class II [13]) were also included in the study. All 60 patients and 4 healthy controls gave written informed consent. All participants were unaware of the research question. Patient characteristics are given in Table 1 .

Table 1. Characteristics of the three patient groups.

\begin{tabular}{|c|c|c|c|c|}
\hline & & $\begin{array}{l}\text { Ankylosing } \\
\text { Spondylitis }(n=35)\end{array}$ & $\begin{array}{l}\text { Rheumatoid } \\
\text { Arthritis }(n=12)\end{array}$ & $\begin{array}{l}\text { Fibromyalgin } \\
(n=13)\end{array}$ \\
\hline \multicolumn{5}{|l|}{ Age (years) } \\
\hline \multicolumn{2}{|l|}{ Median } & 47 & 46 & 47 \\
\hline \multicolumn{2}{|l|}{ Range } & $24-63$ & $26-60$ & $31-60$ \\
\hline \multicolumn{5}{|c|}{ Duration of disease (years) } \\
\hline \multicolumn{2}{|l|}{ Median } & 7 & 9 & 7 \\
\hline \multicolumn{2}{|l|}{ Range } & $2-34$ & $3-32$ & $2-20$ \\
\hline \multicolumn{5}{|c|}{ Socio-demographic chanacteristics (\%) } \\
\hline \multicolumn{2}{|c|}{ female } & 17 & 100 & 100 \\
\hline \multicolumn{2}{|l|}{ married } & 69 & 92 & 92 \\
\hline \multicolumn{2}{|l|}{ employed } & 89 & 17 & 0 \\
\hline \multirow[t]{3}{*}{ income: 1) } & high & 21 & 55 & 8 \\
\hline & middle & 62 & 36 & 84 \\
\hline & low & 17 & 9 & 8 \\
\hline \multirow[t]{3}{*}{ education level: 2 ) } & high & 17 & 17 & 30 \\
\hline & middle & 60 & 58 & 39 \\
\hline & low & 23 & 25 & 31 \\
\hline
\end{tabular}

1) US dollars net per month; high: $>2000 \$$; middle: $1000-2000 \$$; low: $<1000 \$$.

2) Years of education (including primary school); high: $>15$ years; middle: $10-15$ years; low: $<10$ years. 
Six occupational therapists and 6 medical advisors (in patients on social insurance) participated in the study. These professions were chosen because of their expertise in assessing functional disability. They frequently take decisions about provisions on the basis of observed disability. Observers were not informed about the rheumatological diagnoses and they were not told about the inclusion of 4 healthy controls. Neither participants nor observers were informed about the research question.

\section{Functional self-reports}

All patients first completed a questionnaire on disability at home. The AS patients completed a questionnaire including 9 selected activities from a Dutch translation of the Functional Index. The Functional Index is a validated and reliable health status measure in AS $[14,15]$. It consists of 20 questions corresponding to physical activities of daily living that are frequently limited in AS. The RA and Fibromyalgia patients completed a questionnaire including 7 selected physical activities from the Dutch translation of the Arthritis Impact Measurement Scales (AIMS). The AIMS and its translation are validated, reliable, and sensitive questionnaires commonly applied to rheumatic diseases, particularly RA [16-24]. We selected those activities of the Functional Index and the AIMS that are regularly limited due to these diseases and are easily noted by an observer (Table 2). Functional disability was rated on a 10 centimeter visual analogue scale (VAS, $0=$ able to perform the activity without any dif-
Table 2. Activities of the Functional Index (up) and Arthritis Impact Measurement Scales (down) selected to compare self-reports of patients and observations of clinical experts in three patient groups.

9 selected activities in Ankylosing Spondylitis

CAN YOU:

1. Get out of bed.

2. Put on shoes with laces.

3. Get up from an easy chair.

4. Lie down on your back without a pillow.

5. Lie down on a bed.

6. Turn in bed.

7. Sit down in an easy chair.

8. Climb up and down 3 steps.

9. Bend over to pick up a heavy book from the floor without bending your knees.

7 selected activities in Rheumatoid Arthritis and Fibromyalgia

CAN YOU:

1. Turn a key in a lock.

2. Put a book on the floor and pick it up.

3. Sit down and get up from a chair.

4. Tie shoelaces.

5. Write.

6. Climb up and down stairs.

7. Lie down in bed and get out of bed.

ficulty, and $10=$ totally unable to perform the activity). This response format was chosen because it is more sensitive than just 2 or 3 ordered response categories of the Functional Index and the AIMS. In addition to the selected activities, the questionnaires comprised 11 other 
items of the Functional Index and 13 items of the AIMS to conceal the activities relevant for the purpose of this study.

A retest of the self-reports was done 10 days after the first self-report in RA and Fibromyalgia patients, and immediately following the recording of activities on video for the AS patients.

\section{Observed functional disability}

Five days after the self-reports, the AS patients and 2 controls actually performed the 9 selected activities of the Functional Index; the RA and Fibromyalgia patients and 2 controls performed the 7 selected activities of the AIMS. The activities were recorded on video by 2 camera operators. All patients were uniformly instructed about the activities to be performed. The operators as well as the instructors were unaware of the research question. Afterwards, the videotaped activities were assessed in random order by each of the 12 observers individually. Observers recorded their assessment of a patient's functional disability on a 10 centimeter VAS, just like the patients.

\section{Analysis}

For each activity of a patient mean scores for all observers were calculated. Within each group of patients, a paired t-test was used for each activity to test the difference between selfreports and clinical observations (mean patient's VAS score minus mean observer's VAS score). To examine whether patients and observers ordered the severity of disability in a comparable way, Cronbach's Alpha coefficients [25, 26] were calculated using the SPSS/PC procedure reliabilities [27]. Sources of discordance were studied simultaneously using the variance component approach. From the mean squares obtained in the analysis of variance, components of variance were calculated according to the proposals of Cronbach et al. $[25,26]$. These components were used to calculate, within each patient group, 3 percentages of total variance, reflecting: 1) individual differences in functional disability, 2) the difference between modes of assessment (self-report versus observation), and 3) residual variance. To assess test-retest reliability of self-reports and inter-observer agreement of clinical observations, Cronbach's Alpha coefficients were again calculated.

\section{RESULTS}

\section{Discordance between patients and observers}

Compared to observers, AS patients judged themselves significantly 'less disabled' on 3 activities ('sit down', 'climb' and 'bend'), RA patients significantly 'more disabled' on 1 activity ('turn a key'), and Fibromyalgia patients significantly 'more disabled' on all 7 activities (Table 3, Fig. 1). The mean discordance between self-reported and observed functional disability (VAS patients minus VAS observers) for all activities was $-0.17 \mathrm{~cm}$ in $A S,+1.10 \mathrm{~cm}$ in RA, and $+2.44 \mathrm{~cm}$ in Fibromyalgia. A difference of $1.0 \mathrm{~cm}$ corresponds to $10 \%$ of the total scale ranging from 'no disability' $(0 \mathrm{~cm})$ to 'totally unable to perform' $(10 \mathrm{~cm})$. Mean 
Table 3. Comparison between patients and 12 observers.

\begin{tabular}{|c|c|c|c|c|c|c|c|c|c|}
\hline & activities 1 ) & $\begin{array}{l}\text { patient } \\
\text { mean }\end{array}$ & $\mathrm{SD}$ & $\begin{array}{l}\text { obser } \\
\text { mean }\end{array}$ & $\begin{array}{l}\text { ers } \\
\text { SD }\end{array}$ & $\begin{array}{l}\text { differer } \\
\text { mean }\end{array}$ & SEM & $\mathrm{p}^{2)}$ & $\alpha^{3)}$ \\
\hline Ankylosing & 1.get out bed & 3.44 & 3.26 & 2.60 & 2.30 & +0.84 & 0.54 & 0.09 & 0.73 \\
\hline \multirow{9}{*}{ Spondylitis $(n=35)$} & 2 shoelaces & 1.75 & 2.08 & 1.58 & 2.01 & +0.16 & 0.38 & 0.66 & 0.60 \\
\hline & 3.get up & 1.49 & 1.63 & 1.35 & 1.44 & +0.15 & 0.25 & 0.52 & 0.79 \\
\hline & 4.lie & 1.53 & 1.60 & 1.47 & 1.35 & +0.05 & 0.21 & 0.80 & 0.79 \\
\hline & 5.lie down & 1.12 & 1.34 & 1.17 & 1.07 & -0.05 & 0.24 & 0.83 & 0.62 \\
\hline & 6.turn & 2.12 & 2.02 & 2.35 & 1.78 & -0.23 & 0.34 & 0.47 & 0.69 \\
\hline & 7.sit down & 0.67 & 0.79 & I. .00 & 0.96 & -0.33 & 0.15 & 0.03 & 0.69 \\
\hline & 8.climb & 0.64 & 0.84 & 1.15 & 1.24 & -0.50 & 0.20 & $<0.01$ & 0.65 \\
\hline & 9.bend & 3.35 & 3.20 & 4.39 & 3.47 & -1.05 & 0.45 & 0.02 & 0.84 \\
\hline & total & 1.76 & 1.40 & 1.93 & 1.52 & -0.17 & 0.17 & 0.30 & 0.88 \\
\hline Rheumatoid & 1.turn key & 5.97 & 2.98 & 1.99 & 1.75 & +3.97 & 1.07 & $<0.01$ & -0.47 \\
\hline \multirow[t]{7}{*}{ Arthritis $(n=12)$} & 2.bend & 5.68 & 3.63 & 3.86 & 2.96 & +1.82 & 1.39 & 0.22 & -0.16 \\
\hline & 3.chair & 2.54 & 2.46 & 1.22 & 1.10 & +1.32 & 0.66 & 0.09 & 0.41 \\
\hline & 4.shoelaces & 2.63 & 2.91 & 1.83 & 1.56 & +0.79 & 0.62 & 0.19 & 0.79 \\
\hline & 5.write & 1.20 & 1.57 & 1.09 & 1.22 & +0.11 & 0.62 & 0.85 & -0.03 \\
\hline & 6.climb & 2.83 & 3.02 & 2.73 & 2.18 & +0.10 & 0.98 & 0.92 & 0.36 \\
\hline & 7.bed & 1.90 & 2.33 & 1.97 & 1.74 & -0.07 & 0.90 & 0.94 & -0.43 \\
\hline & total & 3.24 & 1.53 & 2.14 & 1.56 & +1.10 & 0.53 & 0.06 & 0.44 \\
\hline \multirow[t]{8}{*}{ Fibromyalgia $(n=13)$} & 1.turn key & 3.09 & 3.12 & 1.20 & 1.01 & +1.89 & 0.85 & 0.04 & 0.48 \\
\hline & 2.bend & 5.59 & 3.17 & 2.43 & 2.22 & +3.16 & 0.71 & $<0.01$ & 0.76 \\
\hline & 3.chair & 3.93 & 3.25 & 2.01 & 2.06 & +1.92 & 0.88 & 0.04 & 0.60 \\
\hline & 4.shoelaces & 2.53 & 2.62 & 1.21 & 1.30 & +1.33 & 0.60 & 0.04 & 0.72 \\
\hline & 5.write & 3.84 & 3.18 & 1.09 & 1.09 & +2.75 & 0.79 & $<0.01$ & 0.48 \\
\hline & 6.climb & 5.49 & 3.67 & 2.56 & 2.40 & +2.93 & 0.87 & $<0.01$ & 0.73 \\
\hline & 7.bed & 4.78 & 3.26 & 2.39 & 2.18 & +2.40 & 0.61 & $<0.01$ & 0.84 \\
\hline & total & 4.42 & 2.73 & 1.98 & 1.68 & +2.44 & 0.58 & $<0.01$ & 0.78 \\
\hline
\end{tabular}

Values are centimeters on a VAS $(0=$ able, $10=$ unable). Positive difference indicates self-assessed disability to be mote serious than observed disability. 1) Numbers and keywords refer to corresponding items in Table 2. 2) $\mathrm{T}$-test; $\mathrm{p}$ values refer to the significance of the difference beween mean scores of patients and observers. ${ }^{3)}$ Cronbach's Alpha; $\alpha-$ values refer to the correspondence between patients and observers in scores of the severity of functional disability of patients relative to each other.

discordance was marginally significant in RA $(p=0.06)$, but highly significant in Fibromyalgia patients $(p<0.01$, Table 3$)$.

Cronbach's Alpha coefficients for all ac- tivities were high in AS (0.88) and Fibromyalgia (0.78), but moderate in RA (0.44, Table 3). Although there were differences in the level, the functional disability of patients was 
Fig. 1. Discordance between patients and observers. (* statistically significant, $\mathrm{p}<0.05$ ).
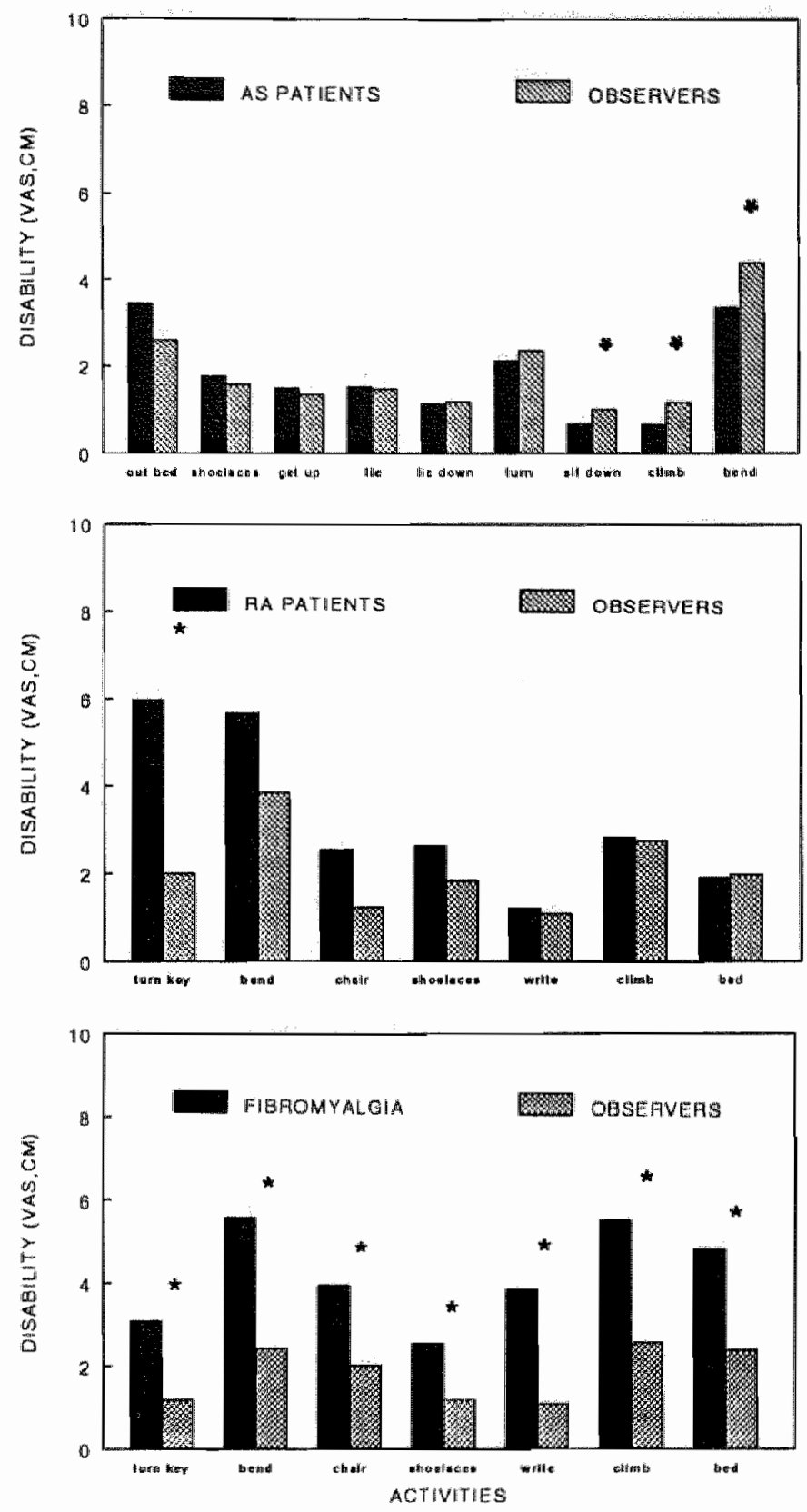
Table 4. Sources of variability in functional disability score.

\begin{tabular}{|c|c|c|c|c|c|c|}
\hline & & $\begin{array}{l}\text { sum of } \\
\text { squares }\end{array}$ & $\begin{array}{l}\text { degrees } \\
\text { of freedom }\end{array}$ & $\begin{array}{l}\text { mean } \\
\text { squares }\end{array}$ & $\begin{array}{l}\text { component } \\
\text { of variance }\end{array}$ & $\begin{array}{l}\text { percentage } \\
\text { of variance }\end{array}$ \\
\hline \multirow[t]{3}{*}{ Ankylosing Spondylitis } & patients & 122.60 & 32 & 3.83 & 1.69 & $79 \%$ \\
\hline & mode of assessment & 0.50 & 1 & 0.50 & 0.002 & $<1 \%$ \\
\hline & residual & 14.43 & 32 & 0.45 & 0.45 & $21 \%$ \\
\hline \multirow[t]{3}{*}{ Rheumatoid Arthritis } & patients & 33.52 & 11 & 3.05 & 0.67 & $24 \%$ \\
\hline & mode of assessment & 7.29 & 1 & 7.29 & 0.465 & $16 \%$ \\
\hline & residual & 18.81 & 11 & 1.71 & 1.71 & $60 \%$ \\
\hline \multirow[t]{3}{*}{ Fibromyalgia } & patients & 83.81 & 10 & 8.38 & 3.26 & $41 \%$ \\
\hline & mode of assessment & 32.79 & 1 & 32.79 & 2.812 & $36 \%$ \\
\hline & residual & 18.57 & 10 & 1.86 & 1.86 & $23 \%$ \\
\hline
\end{tabular}

mostly rated in the same direction by patients and observers in AS and Fibromyalgia, but less so in RA.

The variance component analysis showed a clear distinction between the patient groups (Table 4). The percentage of total variance explained by individual differences in functional disability between patients across modes of assessment was much more pronounced among AS patients $(79 \%)$ than among RA $(24 \%)$ or Fibromyalgia patients ( $41 \%$ ). The discrepancy between the two modes of assessment (self-report versus observation) was most pronounced in Fibromyalgia patients (36\% versus less than $1 \%$ and $16 \%$ ). Finally, more than half of the variance in RA patients was residual variance $(60 \%)$.

\section{Validity and reliability}

The test-retest reliability of all items of the self-reports was very high in AS and Fibromyalgia ( 0.94 and 0.97$)$, but moderate in RA (0.63, Table 5).

All observers scored the healthy controls as having 'no disability at all'. This supports the validity of the observation. Inter-observer agreement, i.e., the consistency of individual differences across observers, was high (0.98) ( 0.97 for occupational therapists and 0.96 for physicians). It should be noted that the extent of inter-observer agreement was inflated by the relatively large number of observers $(n=12)$ in this study. This reflects the fact that the reliability of scores tends to rise if more measurements are taken. However, when this sample-size influence was taken into account by computing intraclass correlation coefficients [25, 26, 28], the observer agreement still remained quite high $(0.73)$. 
Table 5. Test-retest reliability of self-reports of physical disability in three groups of patients.

\begin{tabular}{|c|c|c|c|c|}
\hline & & differen & & \\
\hline & activity & mean & SEM & $\alpha^{1)}$ \\
\hline Ankylosing & 1. get out bed & -0.12 & 0.18 & 0.90 \\
\hline Spondylitis & 2. shoelaces & +0.01 & 0.21 & 0.90 \\
\hline & 3. get up & +0.04 & 0.14 & 0.93 \\
\hline & 4. lie & -0.19 & 0.18 & 0.87 \\
\hline & 5. Jie down & +0.31 & 0.33 & 0.91 \\
\hline & 6. turn & +0.31 & 0.18 & 0.92 \\
\hline & 7. sit down & -0.56 & 0.11 & 0.71 \\
\hline & 8. climb & -0.04 & 0.15 & 0.69 \\
\hline & 9. bend & -0.19 & 0.44 & 0.83 \\
\hline & total & -0.05 & 0.13 & 0.94 \\
\hline Rheumatoid & 1. turn key & +2.53 & 1.51 & -0.11 \\
\hline Arthritis & 2. bend & -0.45 & 0.82 & 0.71 \\
\hline & 3. chair & -0.39 & 0.64 & 0.80 \\
\hline & 4. shoelaces & +0.40 & 0.57 & 0.90 \\
\hline & 5. write & -1.39 & 0.75 & 0.40 \\
\hline & 6. climb & -0.71 & 1.32 & 0.15 \\
\hline & 7. bed & -1.69 & 0.78 & 0.76 \\
\hline & total & -0.25 & 0.61 & 0.63 \\
\hline Fibromyalgia & 1. turn key & +0.34 & 0.31 & 0.97 \\
\hline & 2. bend & +0.63 & 0.79 & 0.81 \\
\hline & 3. chair & +1.24 & 0.64 & 0.89 \\
\hline & 4. shoelaces & -0.90 & 0.53 & 0.90 \\
\hline & 5. write & +0.20 & 0.54 & 0.93 \\
\hline & 6. climb & +0.81 & 0.48 & 0.95 \\
\hline & 7. bed & +0.29 & 0.47 & 0.93 \\
\hline & total & +0.37 & 0.31 & 0.97 \\
\hline
\end{tabular}

Values are centimeters on a visual analogue scale $(0=$ able, $10=$ unable). Positive difference indicates less disability at retesting. ${ }^{1)}$ Chronbach's Alpha.

\section{DISCUSSION}

This study showed that the difference between self-reported and observed functional disability was negligible in AS, moderate in RA, but high in Fibromyalgia patients. In other words, patients and observers agreed about the severeness of functional disability in AS, disagreed slightly in RA and disagreed strongly in Fibromyalgia. The severity of disability of patients relative to each other was rated consistently in the same direction by patients and observers in AS and Fibromyalgia, but less so in RA. Hence, patients and observers made the same distinction between high and low disability in AS and Fibromyalgia, although at a different level, whereas in RA, patients and observers ordered the severity of disability differently.

The discrepancy between self-reported and observed functional disability in Fibromyalgia was highly statistically significant. In our view, this discrepancy is also clinically relevant for a number of reasons. First, the discrepancy exceeds the $95 \%$ confidence interval of test-retest reliability in the RA patients, the most 'unreliable' group in our study (Table 5). Second, it exceeds $20 \%$, corresponding to one category on a five point scale. Third, there is support for $20 \%$ as a relevant difference. Data from the OMERACT conference indicate that rheumatologists may find $20 \%$ to be an acceptable minimum for relevant difference between treatment groups in RA trials [29]. By the same token, we view the discrepancies observed in the AS and RA patients as irrelevant. 
Clearly, in validating self-report questionnaires for functional disability the appropriate spectrum of rheumatological diagnoses should be considered. If an instrument (e.g. AIMS) is validated for one disease (RA), then validation should not be assumed for other diagnoses (for example Fibromyalgia).

What factors might contribute to relevant disagreement between self-reported and clinically observed disability? First of all, patients report their perceived disability. Observers rate the 'disease' and patients their 'illness' [30]. In self-report questionnaires patients have to judge whether they are able to perform the activity. They probably include in their judgement past experiences and how they feel about them. This contrasts with what observers see. For example, whereas Fibromyalgia patients often say that it takes much effort to perform normal activities of daily living, persons in the vicinity of the patients only observe the actual end results of these efforts and not the perceived experiences of pain, tiredness, etc.

In addition, the degree of disagreement might be related to specific tasks; despite our selection some activities may have been less suitable for observation. In RA in particular, activities which involve the use of peripheral joints, e.g. 'turn key', 'write', might be extremely painful - more painful than other activities in which more central joints are involved such as 'sit down' or 'climb stairs'. The net observed result of such activities does not reflect the effort required to obtain this result nor the concomitant pain. Differences in perceived pain might be responsible for the lower consistency in RA. Our findings underscore the need to use self-report questionnaires to assess functional disability as experienced by patients in daily life along with clinically assessed measures of health status.

In summary, self-reports of AS patients highly coincide with observations of clinical experts; this is less so in RA patients. There is clear disagreement in Fibromyalgia patients. The effort to perform everyday activities and the concomitant pain may contribute to disagreement between self-reports and clinical observations of functional disability. Validation of an instrument for one disease does not imply validation for other rheumatic diseases.

\section{REFERENCES}

1. Prusoff BA, Klerman GL, Paykel ES: Concordance between clinical assessments and patient's self-report in depression. Arch Gen Psychiatry 1972; 26: 546-552

2. Kass F, Charles E, Klein DF, Cohen P: Discordance between the SCL-90 and therapist's psychopathology ratings. Implications for clinical assessment. Arch Gen Psychiatry 1983; 40: 389-393

3. Spiegel IS, Hirshfield MS, Spiegel TM: Evaluating self-care activities: Comparison of a self-reported questionnaire with an occupational therapist interview. $\mathrm{Br} \mathrm{J}$ Rheum 1985; 24: 357-361

4. Kwoh K, O'Connor GT, Regan-Smith MG, Olmstead EM, Brown LA, Burnett 
JB, Hochman RF, King K, Morgan GJ: Concordance between clinician and patient assessment of physical and mental health status. J Rheumatol 1992; 19: 103》-1037

5. McDaniel LK, Anderson KO, Bradley LA, Young LD, Turner RA, Agudelo CA, Keefe FJ: Development of an observation method for assessing pain behavior in Rheumatoid Arthritis patients. Pain 1986; 24: $165-184$

6. Jacobs JWG, Oosterveld FGJ, Deuxbouts $\mathrm{N}$, Rasker JJ, Taal $\mathbb{E}$, Dequeker J, Uytterhoeven R: Opinions of patients with Rheumatoid Arthritis about their own functional capacity: how valid is it? Ann Rheum Dis 1992: 51 ; 765-768

7. Blalock SJ, DeVellis BM, DeVellis RF et al: Psychological well-being among people with recently diagnosed rheumatoid arthritis. Do self-perceptions of abilities make a difference? Arthritis Rheum 1992; 35: $1267-1272$

8. Hidding $A$, van der Linden $S$, Boers $M$, Gielen X, Kester A, Vlaeyen J: Fake good test-taking attitude in Ankylosing Spondylitis. Abstract. Arthritis Rheum 1992; 35 (suppl): S244

9. van der Linden S, Valkenburg HA, Cats A: Evaluation of diagnostic criteria for Ankylosing Spondylitis: A proposal for modification of the New York criteria. Arthritis Rheum 1984; 27: 361-368

10. Hidding $A$, van der Linden $S$, Boers $M$, Gielen X, Kester A, de Witte L, Bijkmans $\mathrm{B}$, Moolenburgh D: Is group physical ther- apy superior to individualized therapy in Ankylosing Spondylitis? A randomized controlled trial. Artritis Care Res 1993; 6: 117-125

11. Wolfe F, Smythe HA, Yunus MB, Bennett RM, et al: The American College of Rheumatology 1990 criteria for classification of Fibromyalgia. Arthritis Rheum 1990; 33: 160-172

12. Arnett FC, Edworthy SM, Bloch DA, Mcshane DJ, Fries JF, Cooper NS: The American Rheumatism Association 1987 revised criteria for classification of Rheumatoid Arthritis. Arthritis Rheum 1988; 31: 315-324

13. Steinbrocker $\mathrm{O}$, Traeger $\mathrm{CH}$, Batterman RC: Therapeutic criteria in Rheumatoid Arthritis. J Am Med Association 1949; 140: 659-662

14. Dougados $M$, Guegen A, Nakache JP, Nguyen M, Mery C, Amor B: Evaluation of a Functional and Articular Index in Ankylosing Spondylitis. I Rheumatol 1988; 15: 302-307

15. Dougados $M$, Guegen A, Nakache JP, Nguyen M, Mery C, Amor B: Evaluation of a Functional Index for patients with Ankylosing Spondylitis. J Rheumatol 1990; 17: 1254-1255

16. Meenan RF, Gertman PM, Mason JH: Measuring health status in arthritis. The Arthritis Impact Measurement Scales. Arthritis Rheum 1980; 23: 146-152

17. Meenan RF: The AIMS approach to health status measurement: Conceptual back- 
ground and measurement properties. J Rheumatol 1982; 9:785-788

18. Meenan RF, Gertman PM, Mason JH, Dunaif R: The Arthritis Impact Measurement Scales. Further investigations of a health status measure. Arthritis Rheum 1982; 25: 1048-1053

19. Mason $J \mathrm{H}$, Weener JL, Gertman PM, Meenan RF: Health status in chronic disease: A comparative study of Rheumatoid Arthritis. J Rheumatol 1983; 10: 763-768

20. Meenan RF, Anderson JJ, Kazis LE et al: Outcome assessment in clinical trials. Evidence for the sensitivity of a health status measure. Arthritis Rheum 1984; 27 : 1344-1352

21. Potts MK, Brandt KD: Evidence of the validity of the Arthritis Impact Measurement Scales. Arthritis Rheum 1987; 30: 93-96

22. Alberti JM, Perlman SG, Connell K, Robinson M, Conlon P: Validation of the AIMS psychological scales. Abstract. Arthritis Rheum 1987; 30 (suppl): S 101

23. Anderson JJ, Firschein HE, Meenan RF: Sensitivity of health status measure to short-term clinical changes in Arthritis. Arthritis Rheum 1989; 32: 844-850

24. Taal E, Jacobs JW, Seydel ER, Wiegman
O, Rasker JJ: Evaluation of the Dutch Arthritis Impact Measurement Scales (Dutch-AIMS) in patients with Rheumatoid Arthritis. Br J Rheum 1989; 28: 487-491

25. Cronbach LJ: Essentials of psychological testing. New York: Harper \& Row, 1984

26. Cronbach LJ, Gleser GC, Nanda H, Rajaratnam N:The dependability of behavioral measurements: Theory of generalizability for scores and profiles. New York: John Wiley, 1972

27. Norusis MJ: SPSS statistical data analysis. Chicago: SPSS Inc, 1990

28. Kramer MS, Feinstein AR: Clinical biostatistics. The biostatistics of concordance. Clin Pharmacol Therapy 1981; 29: 111-123

29. Goldsmith $\mathrm{CH}$, Boers $\mathrm{M}$, Bombardier $\mathrm{C}$, Tugwell $P$, for the OMERACT committee: Criteria for clinically important changes in outcomes: development, scoring and evaluation of Rheumatoid Arthritis patients and trial profiles. J Rheumatol 1993; 20: 561565

30. Liang MH, Cullen K, Larson M: In search of a more perfect mousetrap (health status or quality of jife instrument). J Rheumatol 1982; 9: 775-779 
CHAPTER 10

GENERAL DISCUSSION 
The general topic of this thesis is the efficacy of group physical therapy for patients suffering from Ankylosing Spondylitis (AS). AS is a chronic systemic inflammatory disorder of unknown etiology, affecting mainly the axial skeleton [1]. Sacroiliac joint involvement (sacroiliitis) is its hallmark. The most common and early complaints of AS are chronic inflammatory low back pain and stiffness. In the Netherlands the prevalence of AS is about $0.1 \%$ [2], implying that at least 15000 persons in this country have AS. There is currently no cure for AS, but most patients can be adequately managed. The aim of treatment of AS is maintaining or improving general functioning and quality of life [3]. Nonsteroidal anti-inflammatory drugs can reduce pain, while regular exercises and physical therapy are thought to improve mobility, strength and fitness [3]. The common policy of rheumatologists in the Netherlands is that patients diagnosed as having AS usually first receive a course of supervised individualized physical therapy. Afterwards, the patients are expected to exercise daily at home. Although the effects of group physical therapy are unproven, some patients have added group physical therapy in supervised gym classes and pool sessions to their individualized physical therapy, intending to enhance the effects of the exercises at home. Patients frequently initiate group physical therapy themselves. Group physical therapy has already existed for several years in many places in the Netherlands. The Dutch Society of Ankylosing Spondylitis patients has stimulated rheumatologists to study scientifi- cally the therapeutic effects of group physical therapy. Finally, the study was funded by the Health Insurance Executive Board of the Netherlands (Investigation on Medicine or 'Ontwikkelingsgeneeskunde' grant Nr. OG90018). The study was carried out at the Department of Internal Medicine, Division of Rheumatology of the Maastricht University Hospital from 1990 until 1992. This thesis is the result of this study.

A total of 333 patients with AS, fulfilling the modified New York criteria [4], were recruited from 2 outpatient rheumatology clinics in Leiden and Alkmaar. These 2 cities were chosen because group physical therapy did not yet exist in these places. A total of $163(49 \%)$ subjects agreed to participate in the study and gave written informed consent. The participants were examined by one rheumatologist to check for the inclusion and exclusion criteria. A total of 19 patients were excluded, 9 of them stating they were unable to exercise daily. Hence, 144 patients (mean age 43 years, 112 males) were available for the study.

To begin with, all patients received supervised individualized therapy for 6 weeks, in order to standardize their pretreatment condition and to better reflect clinical practice (chapter 3 ). Subsequently, in order to study the effects of group physical therapy, patients were randomized into 2 groups. One group had to perform daily unsupervised exercises at home for 9 months; the other group did the same plus weekly group physical therapy (chapter 4). The question whether continuation of group physical 
therapy is necessary was studied by organizing a 9-month extension period (chapter 5). Patients who had received group physical therapy during the first 9-month experimental period were randomized again into 2 groups for another 9 months: daily unsupervised exercises at home (discontinuation group) or the same plus weekly group physical therapy (contimuation group).

This thesis reports on both objective and subjective outcomes of group physical therapy. Mobility and fitness were clinician assessed measures. Assessment of change in global health and health status questionnaires, such as Sickness Impact Profile (SIP) [5 - 7], Health Assessment Questionnaire for the Spondyloarthropathies (HAQ-S) [8], and Functional Index $[9,10]$ were patient reported.

The present state of group physical therapy in AS in the Netherlands, including targets and organization, is described in chapter 2. A high level of agreement was found among the Dutch therapists regarding the targets of group physical therapy in AS. However, the opinions about the organization or the way in which these targets should be accomplished varied considerably. This means that any standardization of group physical therapy in AS would require particular emphasis on organizational aspects.

For methodological reasons [11], the intervention studied in this thesis was protocolized in detail $[12-18]$. Before the study all physical therapists received instruction and training in group physical therapy from an expert and they were also supervised during the study.

The relation between the therapeutic effects of supervised individualized physical therapy and duration of disease is described in chapter 3. Measured outcomes for the 144 AS patients were: patient's assessment of change in global health, spinal mobility (thoraco-lumbar flexion and extension [19], chest expansion [20, 21], cervical rotation), fitness (maximum load in ergometry $[22,23]$ ), and function (Sickness Impact Profile (SIP) [24 - 26], Health Assessment Questionnaire for the Spondyloarthropathises (HAQ-S) [27], and Functional Index [28, 29]). After 6 weeks patients had improved in all endpoints, but only significantly so in cervical rotation ( 8 degrees), fitness ( 6 watts) and SIP (0.6). A mean improvement in global health of $1.1 \mathrm{~cm}(22 \%)$ on a visual analogue scale was reported by the patients. In the analysis the population was divided into 2 groups, with the median duration of disease as the cut-off point (median 4 years, range $0-33$ ). No relevant difference in improvement was found between the 'short duration' and 'long duration' groups $(p>0.05)$. Neither was any relevant correlation found between change scores and disease duration ( $p>0.01$ ). These findings indicate that the magnitude of improvement is about the same in recently diagnosed as in longstanding AS.

It should be noted that the study described in chapter 3 was not a 'blinded' randomized controlled trial, but an uncontrolled 'before-after' study. A control group would have provided a definite background with which to compare the patients' response to therapy. Therefore, it is impossible to decide whether the positive short term effects of supervised individu- 
alized therapy are due to this therapy or attributable to other factors. For example, one cannot exclude psychological factors unconsciously influencing the patient's wish to please the therapist. To decrease any such effects assessments were not made by the physiotherapist, but by an independent assessor. Another methodological problem of this trial is that mobility and fitness assessments should ideally have been collected by an observer who was 'blinded'. This blinding is necessary to avoid bias due to the expectations of the observer [10]. Blinding is less critical in self-assessments such as SIP. Furthermore, the reported mean improvement of $22 \%$ in global health self-assessment after treatment is important, because it reflects patients' values and priorities, irrespective of possible assessor bias. More importantly, the weak methodological design of the study described in chapter 3 does not influence the question of the possible influence of disease duration on the beneficial therapeutic effects of short term supervised individualized physical therapy.

The fact that the participation rate for the whole study was low (144 [43\%] of 333 AS patients completed the study) leaves open the question whether a selection bias in favour of motivated and willing patients took place. A comparison between the participants and the non-participants revealed that they differed with regard to disease duration (an average of 9 years and 12 years, respectively), but they did not differ significantly with regard to the socio-demographic characteristics marriage, employment and education level. Therefore, it would be wise not to generalize the results to all AS patients, but only to apply them to well motivated individuals.

The reasons given for not participating in the group physical therapy included: personal circumstances $(47 \%)$, being opposed to therapy in groups (21\%), therapy being too demanding $(21 \%)$, and not enough (16\%) or too many (10\%) complaints of AS. A comparison of health-related orientation between participants and non-participants showed a lower internal and doctor orientation, and a significantly higher chance orientation in non-participants than in participants $(\mathrm{p}<0.05)$. Non-participants, who had a longer average disease duration, may consider their disease to be less controllable by their own behavior and by doctors and, therefore, may be less willing to participate in group physical therapy.

The effects of adding supervised group physical therapy to unsupervised individualized therapy in AS are described in chapter 4. Outcome measures were the same as in chapter 3. Patient's assessment of change in global health improved by $0.3(6 \%)$ after home exercises, and by $1.7(34 \%)$ after group physical therapy. Thoraco-lumbar flexion and extension increased by an average of $0.5 \mathrm{~cm}$ after home exercises, and by $0.9 \mathrm{~cm}$ after group physical therapy. Maximum load in ergometry decreased by 2 watts after home exercises, but increased by 7 watts after group physical therapy. These 3 differences were statistically significant $(p<0.05)$. There were no significant differences in chest expansion, cervical rotation or self-as- 
sessment of function (SIP, HAQ-S and Functional Index). Therefore, our randomized controlled trial showed that adding group physical therapy to unsupervised individualized therapy caused an additional improvement of 0.4 $\mathrm{cm}(7 \%)$ for thoraco-lumbar flexion and extension, of 9 watts (5\%) for fitness, and of $28 \%$ on global health. Although three outcomes improved significantly, one might asked whether these effects are clinically relevant as well.

Clinical relevance refers to the importance of outcomes to patients, and is usually described in terms of the magnitude of a result [11]. One might ask whether the improvements we have shown in this study regarding spinal mobility and fitness are indeed large enough to justify putting patients through the rigors of intensive physical therapy programs. It might be argued that from the point of view of the patients an extra improvement of $28 \%$ in global health is definitely clinically important.

A related question would be: how long should relevant effects persist to be clinically meaningful in the long term? What is the relevance of a follow-up period of only 9 months for a chronic disease like AS? In a slowly progressive chronic disease a considerably longer study period would be more appropriate for ascertaining long term consequences of an intervention on relevant outcomes such as spinal deformities, occupational disability and physical, social and emotional function. Clearly, the ideal study on the effect of group therapy should include many years of follow-up [30-33].

Supervised individualized therapy before randomization was provided to standardize the patients' pretreatment condition (chapter 3). A disadvantage is that supervised individualized physical therapy may already have taken away some room for improvement by group physical therapy.

The question whether continuation of group physical therapy is necessary in AS is investigated in chapter 5 . The results indicated that patients who continued group physical therapy improved further with regard to patient's assessment of change in global health (mean improvement $1.6(32 \%)$ ) and SIP score (dysfunctioning decreasing from 1.6 to 1.2 [range of scale 0 - 52]). Scores for thoraco-lumbar mobility and HAQ-S did not change very much, whereas chest expansion decreased by $0.6 \mathrm{~cm}$, cervical rotation by 13 degrees, fitness by 5 watts. At the same time the Functional Index deteriorated slightly, from 4.8 to 5.3 . The patients who discontinued group physical therapy improved only marginally $(0.2(4 \%))$ in global health, whereas all other outcomes deteriorated: thoraco-lumbar mobility by $0.4 \mathrm{~cm}$, chest expansion by $0.7 \mathrm{~cm}$, cervical rotation by 13 degrees, fitness by 6 watts, SIP from 3.4 to 3.7, HAQ-S from 0.28 to 0.36 , and Functional Index from 5.6 to 7.0. Only for global health and HAQ-S were the differences statistically significant in favour of the continuation group $(\mathrm{p}<0.05)$.

It should be stressed that the study described in this chapter is a 9-month extension of the study described in chapter 4 . As many patients had already improved considerably before 
this extension period, room for further improvement during the second 9 -month study period was small. 'Ceiling' and 'bottom' effects may also have played a role. For example, patients who have no remaining limitations will obviously not improve any further. For both studies combined the total mean improvement in function was rather impressive, viz., a decrease in dysfunction from 2.6 to $1.2 \mathrm{SIP}$ score. Also, the total mean improvement in global health was striking: $66 \%$ on a visual analogue scale. These improvements in functioning and global health after the study as a whole were irrefutable, clinically important changes. Data from a consensus conference on outcome measures in Rheumatoid Arthritis clinical trials (OMERACT) indicate that experienced clinicians as well as clinical investigators may find $20 \%$ to be an acceptable minimum for a relevant difference between treatment groups in trials in Rheumatoid Arthritis patients [34].

Measurements of spinal mobility only improved in the first 9-month period and decreased in the 9-month extension period. Hence, much of the benefit of group therapy may have resulted from the conditioning effects of sustained exercise. It must be stressed that compliance with group therapy in the studies described in chapters 4 and 5 declined over time. The average attendance to group therapy decreased from $74 \%$ in the first 9 -month period to $62 \%$ in the second. Surprisingly, no relation was found between the effects of group therapy and attendance. This suggests that the effective- ness of group therapy is relatively independent of the degree of attendance. This raises the question which factors are in fact responsible for the beneficial effects of group therapy. Over the entire study, compliance with unsupervised exercises at home decreased as well, from an average of 2.2 hours per week during the first 9 months to 1.8 hours per week in the second 9 months. However, the amount of time spent exercising at home was significantly higher in the continuation group (1.9 hours per week, mean value) than in the discontinuation group (1.2 hours per week, $\mathrm{p}<0.05$ ). Peer pressure, as applied by the group, as well as the added stimulus of the supervisor, probably encouraged compliance, and by inference, benefits. The benefits of group therapy may thus not be directly related to compliance with weekly group therapy sessions, but are possibly more directly related to the amount of time spent doing exercises at home.

To study the financial implications of the group physical therapy intervention, costs were recorded during the first 9-month experimental period (chapter 6). Group physical therapy itself cost $\$ 531$ per patient per year. Direct medical costs for patients receiving group physical therapy were reduced by $\$ 122$ per patient per year. After 9 months, group physical therapy produced an extra improvement of $7 \%$ in spinal mobility, of $5 \%$ in fitness and of $28 \%$ in patient's assessment of change in global health. Hence, the beneficial effects of group physical therapy cost $\$ 409$ per AS patient on a yearly basis or about $\$ 10$ per weekly therapy session. 
A question that had to be answered was: is group physical therapy in AS really cost-effective? Doubilet et al. [35] have pointed out that cost-effectiveness of a treatment should be related to the cost-effectiveness of alternative treatments. Weekly supervised individualized therapy in $\mathbf{3 0}$ minute sessions is more expensive than 3 hours of weekly group physical therapy ( $\$ 575$ and $\$ 531$ per 40 sessions per patient per year respectively). It might be argued that a $28 \%$ increase in global assessment is worth its price (\$409) from a point of view of clinical relevance. This could be supported by the fact that $75 \%$ of the patients wanted to continue group physical therapy and were willing to pay for it. Because of the proven efficacy of group physical therapy, recommending this therapy to patients with $\mathrm{AS}$ and requesting health insurers to reimburse the costs would seem to be justified $[36,37]$.

It must be stressed that this study was done in the Netherlands. The financial findings are therefore most relevant to countries with comparable health care systems in so far as the costs are concerned.

A complete cost-effectiveness analysis of group physical therapy for a chronic disease like AS requires measurement of direct as well as indirect costs, e.g. decreased earnings by the patients [38]. It must be stressed that in a slowly progressive chronic disease a longer study period than 9 months may be more appropriate to ascertain long term consequences. In addition, it might be desireable to value not only disability-related, but also more personal- ity-related effects, e.g. feelings of inadequacy or positive effects on the patient's health locus of control [39].

Chapters 7,8 and 9 describe the subjective evaluation of group physical therapy in more detail. In chapter 7 attention is paid especially to the patient's global assessment. Global assessment was measured by asking the patient to describe his or her perceived change in general functioning on a visual analogue scale. The relative contributions of several health status factors to this assessment were determined. At baseline explanatory variables were obtained for patients receiving group physical therapy during the first 9-month period. The following variables were studied: duration of disease, changes in spinal mobility (thoraco-lumbar flexion and extension, chest expansion and cervical rotation), fitness (maximum work capacity in ergometry), function (SIP, HAQ-S and Functional Index), pain, stiffness, and articular and enthesis indices [31]. Other explanatory variables were personality traits (degree of neuroticism, social inadequacy, self-esteem $[40,41]$, health locus of control [42-45]), and loneliness [46481). Correlations between changes in global health and all explanatory variables were only significant for self-esteem (0.27), improvement in chest expansion (0.31), fitness (0.32), HAQ$S(0.29)$, and stiffness $(0.33, p<0.05)$. A regression analysis showed improvement in fitness and stiffness to contribute significantly to self-reported change in global health $(p<0.001)$. This means that beneficial effects of group physical therapy were partly mediated by 
increasing fitness and relief from stiffness. Physical exercises are intended to improve fitness, while medications, such as NSAIDs, are expected to reduce stiffness and pain. Because both fitness and relief from stiffness contribute to improvement in global health, both physical exercises and the use of medications seem important in the treatment of AS.

Improvement in fitness and relief from stiffness together, however, explained only a relatively low proportion (27\%) of the variance in global health. In other words, $73 \%$ of the total variance in self-reported change in global health is due to other - as yet unknown sources.

It is worth stressing that the correlations between self-esteem and changes in global health were reasonably high. In the analysis the patient population was divided into 2 groups, with the median score of self-esteem as the cutoff point. This median value of 27 corresponds with the usual level of self-esteem in patients with somatic diseases [40]. A significant difference in global health improvement was found between the 'low self-esteem group' and the 'high self-esteem group' (mean improvement in global health, $2.3(46 \%)$ and $1.3(26 \%)$, respectively, $\mathrm{p}<0.01$ ). These findings underscore that group physical therapy is most successful in patients with a lower self-esteem. It seems possible that in such patients it is the following factors in particular which contribute to the beneficial effects of group therapy: the opportunity to draw comparisons with other - sometimes more disabled - patients, mutual encourage- ment, reciprocal motivation and companionable contact with peers in similar circumstances [18].

Chapter 8 elaborates on the health status questionnaires used in this thesis. In AS, selfreported health status is strongly associated with disability-related variables such as duration of disease and loss of spinal function. It seems possible, however, that other factors, such as personality traits and social network variables, also contribute to the health status. Therefore, the relative contributions of disability-related variables as well as personality traits and social network variables to self-reported health status were measured. This analysis used the same explanatory variables as chapter 7 . These were cross-sectionally assessed at baseline in all 144 patients. Health status was measured by 3 selfreports: SIP, HAQ-S and Self-assessed Functioning [49]. These 3 instruments were used to compute one common health score by means of factor analysis. In a stepwise regression analysis the degree of neuroticism explained $25 \%$ of total variance, while the physician's global assessment explained an additional $8 \%$, internal orientation an additional $6 \%$ and spinal mobility an additional $5 \%$. The AS patients showed a mean neuroticism score of 10 (SD 7). This value falls within the 'normal range' of healthy people as well as that of patients with somatic diseases [40]. The regression analysis showed that self-reported health status was more strongly related to personality traits than to the degree of disability. In physical therapy trials, personality traits are not specific targets for treatment. Hence, personality traits 
must be taken into account in the total management of AS. It must be stressed that the determinants of self-reported health status were studied cross-sectionally in this chapter. It might be argued that these determinants are probably less important in self-reported changes in health status due to interventions.

When designing the trial, health status questionnaires were chosen to detect clinically important changes in function. However, generic questionnaires such as the SIP might not be sensitive enough to detect relevant changes in patients with AS. The SIP instrument showed baseline scores of 'no disability at all' in one fourth of the patient population. This meant that any further improvement of function was impossible for these patients. Generic selfreports are probably not sensitive enough to detect relevant changes due to physical therapy.

The present trial included a population which was heterogeneous with respect to duration of disease and physical disability. A solution for dealing with this heterogeneity would have been stratifying individuals with major differences in disease duration and activity and identifying particular subgroups in order to answer specific questions. Using small subgroups, however, would decrease the generalizability of the results and reduce statistical power. In this trial we deliberately chose to include patients with a variable duration of disease, making them representative of the target population. Small sample sizes might also be a problem in detecting clinically important changes in health status. Therefore, it would have been wise to increase (if possible) the sample size in this study in order to detect more precisely any differences in function after individualized and group therapy. The sample size of 68 (n/group) used in this study allowed detection of a true difference of 1.6 in the SIP (range of the scale $0-52$ ) with a power of $90 \%$ $\left(\alpha=0.05, \beta=0.1, \mathrm{SD}_{\text {SIP }}\right.$ change $=2.8$ ). However, stratifying these 68 individuals into smaller subgroups would have reduced statistical power to such a degree that detection of relevant changes would have become impossible.

In view of the strong relation between selfreported health status and personality traits, as well as the relatively low dysfunction scores at baseline, it was perhaps not very surprising that it was impossible to show the efficacy of group physical therapy by applying the rather generic health status questionnaires used in this study.

It has been suggested that AS patients tend to deny their problems [50]. Therefore, the attitudes of AS patients towards their functional disability were measured. If AS patients do indeed deny problems, self-reported disability may be different from observed disability. This possible difference was the subject of the next study.

Chapter 9 compares self-reported and clinically assessed functional disabilities in AS, Rheumatoid Arthritis (RA) and Fibromyalgia patients. A total of 35 AS patients, randomly chosen from the study population, completed a questionnaire on 9 selected items relating to physical activities. These items were chosen from the Functional Index questionnaire [9, 
10], a disease specific questionnaire for AS. A total of 12 RA and 13 Fibromyalgia patients completed 7 selected items of the Arthritis Impact Measurement Scales (AIMS) [51 - 57]. Five days later, all 60 patients and 4 controls actually performed the selected activities. This was recorded on video. The tapes were assessed in random order by 12 observers $(6$ occupational therapists and 6 physicians). Both patients and observers indicated functional disability on a 10 centimeter visual analogue scale (VAS). Inter-observer agreement was high (Cronbach's Alpha $=0.98$ ). All observers scored the 4 healthy controls as having 'no disability at all'. Mean discordance scores (VAS patients minus VAS observers) for the selected items were negligible in AS $(-0.17 \mathrm{~cm}, 2 \%$, $\mathrm{p}=0.30)$, moderate in RA $(+1.10 \mathrm{~cm}, 11 \%$, $\mathrm{p}=0.06)$ and high in Fibromyalgia $(+2.44 \mathrm{~cm}$, $24 \%, \mathrm{p}<0.01)$. This study therefore showed that average differences between self-reported and observed functional disability were negligible in AS but not in RA, while discordance between self-report questionnaires and observed functional disability was a striking feature in Fibromyalgia. Based upon these findings it is proposed that validation of self-report questionnaires of functional disability should include consideration of the appropriate spectrum of rheumatological diagnoses. If an instrument (e.g. AIMS) is validated for one disease (RA) then validity should not be assumed for other diagnoses (for example Fibromyalgia or AS).

What factors might contribute to a relevant disagreement between self-reported and clini- cally observed disability? Firstly, patients report their perceived disability. Observers rate the 'disease', while patients rate their 'illness' [58]. In self-report questionnaires patients have to judge whether they are able to perform a particular activity. Their judgement probably includes experiences from the past and how they feel about them. This might contrast with what observers rate. Secondly, the observers' scores may bear a closer relation with the physical 'deformity' of the patients due to their disease than with the physical 'disability' of the patients. The physicians might be impressed by the anatomical deformations observable in RA and in AS, which are less obvious in Fibromyalgia.

The findings described in chapter 9 underscore the need for using self-report questionnaires to assess functional disability as experienced by patients in daily life, along with clinically assessed measures of health status. The self-reports of AS patients largely coincide with observations by clinical experts.

In summary, the following conclusions can be drawn from the investigations presented in this thesis:

- Short term supervised individualized physical therapy during 6 weeks has slight but positive effects on spinal mobility, fitness and function. Moreover, a major improvement in global health was reported by the patients. The magnitude of improvement is about the same in recently diagnosed as in longstanding AS.

- Weekly group physical therapy during 9 months has a genuine surplus value over exer- 
cises at home as regards the patient's assessment of change in global health, spinal mobility and fitness. The improvement in global health definitely seems clinically relevant.

To maintain improvement, group physical therapy should be continued after 9 months. The benefits of group therapy do not seem to be directly related to compliance with weekly group therapy sessions, but are probably also related to the amount of time spent doing exercises at home. Group physical therapy may motivate patients to more intensive sporting activities and home exercises.

- Group physical therapy is cost-effective, because the improvement in global health ( $28 \%)$ would seem to be clinically relevant and worth its price (\$409). This is supported by the fact that $75 \%$ of the patients wanted to continue group physical therapy and were willing to pay for it themselves.

- The beneficial effects of group physical therapy are partly mediated by increased fitness and relief from stiffness. This supports the view that both physical exercises and the use of medications, such as NSAIDs, are important in the treatment of AS.

- Self-reported health status is more strongly related to personality traits than to the degree of disability. In physical therapy trials personality traits are not specific targets for treatment. Personality traits must be taken into account in total management.

- Contrary to our hypothesis, AS patients do not take an unduly favourable view of their functional capacity. Self-reports of functional disability by AS patients largely coincide with observations by clinical experts.

\section{REFERENCES}

1. Khan MA, van der Linden S: Ankylosing Spondylitis and other Spondylarthropathies. Rheum Dis Clin North America $1990 ; 16: 551-578$

2. van der Linden $S$, Valkenburg HA, de Jongh BM, Cats A: The risk of developing Ankylosing Spondylitis in HLA-B27 positive individuals. A comparison of relatives of Spondy-litis patients with the general population. Arthritis and Rheum 1984; 27 : 241-249

3. Spring H: Funktionsorientierte Gymnastik und Sport bei der Spondylitis Ankylosans. In: Spondylitis Ankylosans. Bern: Verlag Hans Huber, 1989; 117-132

4. van der Linden S, Valkenburg HA, Cats A: Evaluation of diagnostic criteria for Ankylosing Spondylitis: A proposal for modification of the New York criteria. Arthritis Rheum 1984; 27: 361-368

5. Bergner M, Bobbit RA, Kressel S, Pollard WE, Gilson BS, Morris JR: The Sickness Impact Profile: Conceptual formulation and methodology for the development of a health status measure. Int J Hith Serv 1976; 6: 393-415

6. McDowell I, Newell C: Measuring health: A guide to rating scales and questionnaires. New York / Oxford: Oxford University Press, 1987 
7. de Bruin AF, de Witte LP, Stevens FCJ, Diederiks JPM: De bruikbaarheid van de Sickness Impact Profile als generieke maat voor functionele toestand. Tijdschr Soc Gezondheidsz 1992; 70: 160-170

8. Daltroy HL, Larson MG, Roberts $\mathrm{WN}$, Liang MH: A modification of the Health Assessment Questionnaire for the Spondylarthropathies. I Rheumatol 1990; 17: 946950

9. Dougados M, Gueguen A, Nakache JP, Nguyen M, Mery C, Amor B: Evaluation of a Functional and an Articular Index in Ankylosing Spondylitis. J Rheumatol 1988; 15: 302-307

10. Dougados M, Gueguen A, Nakache JP, Nguyen M, Mery C, Amor B: Evaluation of a Functional Index for patients with Ankylosing Spondylitis. J Rheumatol 1990; 17: 1254-1255

11. Sackett DL, Haynes RB, Guyatt GH, Tugwell P: Clinical epidemiology. A basic science for clinical medicine. Second edition. Boston / Toronto / London: Little, Brown and Company, 1991

12. Abspoel M, Obbens HJM: Fysiotherapeutische interventies bij Spondylitis Ankylopoëtica, Ned Tijdschr Fysiother 1987; 97 : 234-239

13. Fischer B, Wagenhäuser FJ: Tägliche Bechterew-gymnastik. Rheumaklinik und Institut für physikalische Therapie. Universitätsspital Zürich, 1973

14. Göhring $\mathrm{H}$ : Krankengymnastische Möglichkeiten zur Verbesserung und Erhaltung der Thoraxbeweglichkeit und der Atembewegungen bei Morbus Bechterew. Zeitschr Krankengym- nastik 1989; 41: 47-53

15. Mucha C, Mucha E, Rosenstock G: Durchführungskriterien einer ambulanten krankengymnastischen Gruppentherapie bei Patienten met ankylosierender Spondylitis. Zeitschr Krankengymnastik 1986; 2: 100113

16. Spring H: Funktionsorientierte Gymnastik und Sport bei der Spondylitis Ankylosans. In: Spondylitis Ankylosans. Bern: Verlag Hans Huber, 1989; 117-132

17. Fellmann N: Die rheumatischen Spondylitiden und ihre Bewegungstherapie. Krankengymnastik $1984 ; 1: 16-31$

18. Baumberger H: Schweizerische Vereinigung Morbus Bechterew: eine PatientenSelbsthilfeorganisation. Schweiz Rundschau Med 1991; 80: 644-649

19. Miller MH, Lee P, Smythe HA, Goldsmith $\mathrm{H}$ : Measurement of spinal mobility in sagittal plane: New skin contraction technique compared with established methods. J Rheumatol 1984; 11:507-511

20. Moll JMH, Wright V: An objective clinical study of chest expansion. Ann Rheum Dis $1972 ; 31: 1-8$

21. Roberts W, Larson M, Liang M, Harrison R, Barefoot J, Clarke A: Sensitivity of anthrometric techniques for clinical trials in Ankylosing Spondylitis. Br J Rheum 1988; 28: $40-45$

22. Astrand PO, Rodahl K: Textbook of work physiology. Physiological bases of exer- 
cise. McGraw-Hill Book Company, 1977

23. Jones NL, Makrides L, Hitchoock C, Chypchar T, McCartney N: Normal standards for an incremental progressive cycle ergometer test. Am Rev Respir Dis 1985; 131: 700-708

24. Bergner M, Bobbit RA, Kressel S, Pollard WE, Gilson BS, Morris JR: The Sickness Impact Profile: Conceptual formulation and methodology for the development of a health status measure. Int J Hlth Serv 1976; 6: 393-415

25. McDowell I, Newell C: Measuring health: A guide to rating scales and questionnaires. New York / Oxford: Oxford University Press, 1987

26. de Bruin AF, de Witte LP, Stevens FCJ, Diederiks JPM: De bruikbaarheid van de Sickness Impact Profile als generieke maat voor functionele toestand. Tijdschr Soc Gezondheidsz 1992; 70: 160-170

27. Daltroy HL, Larson MG, Roberts WN, Liang MH: A modification of the Health Assessment Questionnaire for the Spondylarthropathies. J Rheumatol 1990; 17: 946950

28. Dougados $M$, Gueguen A, Nakache JP, Nguyen M, Mery C, Amor B: Evaluation of a Functional and an Articular Index in Ankylosing Spondylitis. J Rheumatol 1988; 15: 302-307

29. Dougados $M$, Gueguen A, Nakache JP, Nguyen M, Mery C, Amor B: Evaluation of a Functional Index for patients with Ankylosing Spondylitis. J Rheumatol

\section{$1990 ; 17: 1254-1255$}

30. Kraag G, Stokes B, Groh J, Helewa A, Goldsmith C: The effects of comprehensive home physiotherapy and supervision on patients with Ankylosing Spondylitis. A randomized controlled trial. J Rheumatol $1990 ; 17: 228-233$

31. Mander M, Simpson IM, McLellan A, Walker D, Goodacre JA, Dick WC: Studies with an enthesis index as a metod of clinical assessment in Ankylosing Spondylitis. Ann Rheum Dis 1987; 46: 197-202

32. Obbens HJM, Abspoel M: Onderzoek naar het effect van fysiotherapeutische interventies bij Spondylitis. Ned Tijdschr Fysiother 1987; 97: 240-247

33. Oosterveld FGJ, Ruesink A, Rasker JJ: Fysiotherapie bij patiënten met Spondylitis Ankylopoëtica. Een pilot study. Ned Tijdschr Fysiother 1987; 97: 116-122

34. Goldsmith $\mathrm{CH}$, Boers $\mathrm{M}$, Bombardier $\mathrm{C}$, Tugwell $P$, for the OMERACT committee: Criteria for clinically important changes in outcomes: development, scoring and evaluation of Rheumatoid Arthritis patients and trial profiles. J Rheumatol 1993; 20: 561565

35. Doubilet $\mathrm{P}$, Weinstein MC, McNeil BJ: Use and misuse of the term "cost effective" in medicine. N Engl J Med 1986; 314: 253 256

36. Hidding $\mathrm{A}$, de Witte $\mathrm{L}$, van der Linden $\mathrm{S}$, et al: Het oefenen in groepen: een uilkomst. Een onderzoek naar de effecten van groepsoefentherapie voor Bechterew-patiënten. 
Academisch Ziekenhuis Malastricht, 1993

37. Hidding $A$, de Witte $L$, van der Linden $S$, et al: Groepsoefentherapie bij Spondylitis Ankylopoëtica. Een gerandomiseerde studie. Onderzoeksverslag Ziekenfondsraad. Academisch Ziekenhuis Maastricht, 1993

38. Meenan RF, Yelin EH, Henke CJ, Curtis DL, Epstein WV: The costs of Rheumatoid Arthritis: A patient-oriented study of chronic disease costs. Arthritis Rheum $1978 ; 21: 827-833$

39. Lawrence VA, Tugwell P, Gafni A, Kosuwon W, Spitzer WO: Acute low back pain and economics of therapy: The iterative loop approach. J Clin Epidemiol 1992; 45: $301-311$

40. Luteyn F, Starren J, van Dijk J: Handleiding bij de Nederlandse Persoonlijkheids Vragenlijst. Amsterdam: Swets \& Zeitlinger, 1985

41. Luteyn F: De relaties tussen ABV, MMPI en NPV. Ned Tijdschr Psychol 1980; 35: 215-222

42. Wallston KA, Wallston BS, DeVellis R: Development of the Multidimensional Health Locus of Control (MHLC) Scales. Health Education Monographs 1978; 6: $161-170$

43. Levenson H: Differentiating among internality, powerful others, and chance. In $\mathrm{H}$. Lefcourt (Ed.): Research with the locus of control construct (Vol. 1). New York: Academic Press, 1981

44. Sanders GS, Suls J: Social psychology of health and illness. London: Lawrence
Erlbaum Associates Publishers, 1982

45. Halfens R: Locus of control: de beheersingsorientatie in relatie tot ziekte- en gezondheidsgedrag. Thesis. Maastricht: University of Limburg, 1985

46. de Jong-Gierveld J: Eenzaamheid: een meersporig onderzoek. Deventer: Van Loghum Slaterus, 1984

47. de Jong-Gierveld J, Kamphuis F: The development of a Rasch-type Loneliness Scale. Appl Psychol Measurement 1985; 9 : 289-299

48. de Jong-Gierveld J: Developing and testing a model of loneliness. J Pers Soc Psychol. 1987; 53: 119-128

49. de Witte LP: After the rehabilitation centre. A study into the course of functioning after discharge from rehabilitation. IRV Series in Rehabilitation Research, Volume 3. Amsterdam: Swets \& Zeitlinger, 1991

50. Hidding A, van der Linden S, Boers $M$, Gielen X, Kester A, Vlaeyen J: Fake good test-taking attitude in Ankylosing Spondylitis. Abstract. Arthritis Rheum 1992; 35 (suppl): S244

51. Meenan RF, Gertman PM, Mason JH: Measuring health status in arthritis. The Arthritis Impact Measurement Scales. Arthritis Rheum 1980;23: 146-152

52. Meenan RF: The AIMS approach to health status measurement: Conceptual background and measurement properties. J Rheumatol 1982; 9: 785-788

53. Meenan RF, Gertman PM, Mason JH, Dunaif $R$ : The Arthritis Impact 
Measurement Scales. Further investigations of a health status measure. Arthritis Rheum 1982; 25: 1048-1053

54. Mason JH, Weener JL, Gertman PM, Meenan RF: Health status in chronic disease: A comparative study of Rheumatoid Arthritis. J Rheumatol 1983; 10: 763-768

55. Meenan RF, Anderson JJ, Kazis LE et al: Outcome assessment in clinical trials. Evidence for the sensitivity of a health status measure. Arthritis Rheum 1984; 27: 1344-1352
56. Potts MK, Brandt KD: Evidence of the validity of the Arthritis Impact Measurement Scales. Arthritis Rheum 1987; 30:93-96

57. Anderson JJ, Firschein HE, Meenan RF: Sensitivity of health status measure to short-term clinical changes in Arthritis. Arthritis Rheum 1989; 32: 844-850

58. Liang MH, Cullen K, Larson M: In search of a more perfect mousetrap (health status or quality of life instrument). J Rheumatol 1982; 9: 775-779 


\section{SUMMARY}


The general topic of this thesis is the efficacy of group physical therapy for patients suffering from Ankylosing Spondylitis (AS). In the Netherlands the prevalence of AS is about $0.1 \%$, implying that at least 15000 persons in this country have AS. The most common and early complaints of AS are chronic inflammatory low back pain and stiffness. There is currentDy no cure for AS, but most patients can be adequately managed. The aim of treatment of AS is to maintain or improve general functioning and quality of life. Nonsteroidal anti-inflammatory drugs can reduce pain, while regular exercises and physical therapy are thought to improve mobility, strength and fitness. Three kinds of physical therapy for AS can be distinguished: supervised individualized therapy, unsupervised self-administered individualized therapy or exercises at home, and supervised group therapy. In the Netherlands, patients diagnosed as having AS usually first receive a course of supervised individualized physical therapy. Afterwards, the patients are expected to exercise daily at home. Some patients have added group physical therapy to their individualized therapy in supervised gym classes and pool sessions, with the intention to enhance the effects of the individual exercises. Patients frequently initiate group physical therapy themselves. However, the effects of group physical therapy are as yet unknown.

In chapter 2 the present state of group physical therapy in AS in the Netherlands is described. This chapter studies the targets and or- ganization of group physical therapy. The results show a degree of consensus among therapists in the Netherlands regarding the specific aims or targets of group physical therapy in AS. There was, however, greater diversity in the opinions about the way in which these aims should be accomplished. The organization, including group size, constituent components and duration of therapy varied considerably between therapists.

Chapter 3 describes the therapeutic effects of supervised individualized physical therapy in a 'before-after' study. The results indicate that short term supervised individualized physical therapy during 6 weeks has slight but positive effects on spinal mobility, fitness, functioning, and global health. The magnitude of improvement is about the same in recently diagnosed as in longstanding AS.

Chapter 4 discusses the effects of adding supervised group physical therapy to unsupervised individualized therapy in AS. Outcome measures are global health, spinal mobility, fitness, and functioning. After 9 months, group physical therapy is superior to individualized therapy in improving thoraco-lumbar mobility and fitness, and has an important effect on global health reported by the patients.

Chapter 5 investigates the question whether continuation of group therapy is necessary in AS. After cessation of group therapy, patients decrease in all outcomes. After a 9-month extension period with group therapy, global health and functioning are sustained or even show 
further improvement, but mobility and fitness decrease. Group therapy has a positive influence on exercises performed at home.

In chapter 6 the cost-effectiveness of supervised group therapy is compared with that of exercises at home in AS patients. Compared to therapy at home, group therapy produces an extra increase of $7 \%$ in spinal mobility and of $5 \%$ in fitness, and an extra improvement of $28 \%$ in global health at a cost of $\$ 531$ per year, while reducing direct medical costs by $\$ 122$ per year. Hence, the beneficial effects of group therapy cost $\$ 409$ per AS patient on a yearly base or about $\$ 10$ per weekly therapy session (40 sessions per year).

In chapter 7 attention is paid to the factors related to self-reported change in global health after group therapy. Global health is related to the outcomes fitness and stiffness.

Chapter 8 describes the determinants of self-reported health status in AS patients. In AS, self-reported health status is more strongly related to personality traits such as neuroticism than to the degree of disability.

Chapter 9 discusses the discordance between self-report measures and clinical observations of functional disability in AS, Rheumatoid Arthritis (RA), and Fibromyalgia patients. Discordance is a feature most striking in Fibromyalgia. The self-reports of AS patients largely coincide with observations of clinical experts.

Chapter 10 provides a general discussion of the study described in this thesis. 
SAMENVATTING 
Het onderwerp van dit proefschrift is de effectiviteit van groepstherapie bij patiënten met Spondylitis Ankylopoetica (SA). De prevalentie van SA in Nederland is ongeveer $0,1 \%$. Dit houdt in dat er minstens 15.000 patiënten met $\mathrm{SA}$ in Nederland zijn. De belangrijkste symptomen van SA zijn chronisch inflammatoire lage rugpijn en stijfheid. Op dit moment bestaat er geen afdoende behandeling voor SA. Toch kunnen de meeste patiënten met een symptomatische behandeling redelijk goed geholpen worden. Het doel van de behandeling bij SA is het op peil houden of verbeteren van het algemeen dagelijks functioneren en de kwaliteit van leven. Nonsteroïdale anti-inflammatoire medicijnen helpen de pijn te verminderen. Regelmatig oefenen is nodig om mobiliteit, kracht en fitheid op peil te houden, danwel te verbeteren. In Nederland kent men 3 vormen van oefentherapie voor een patiënt met SA: begeleide individuele therapie, niet begeleide individuele therapie oftewel de oefeningen thuis en begeleide groepstherapie. In Nederland is het gebruikelijk dat patiënten met SA, bij wie de diagnose recent gesteld is, eerst een serie begeleide individuele behandelingen krijgen. Daarna dienen zij thuis zelfstandig te blijven door oefenen. Sommigen sluiten zich, meestal op eigen initiatief, aan bij oefengroepen met het doel om de motivalie om te oefenen en de intensiteit van het oefenen op peil te houden. Het effect van groepstherapie bij SA is echter tot op heden nog niet bekend.

In hoofdstuk 2 van dit proefschrift wordt een beschrijving gegeven van de huidige gang van zaken met betrekking tot groepstherapie bij $\mathrm{SA}$ in Nederland. Er bestaat een grote mate van overeenstemming tussen therapeuten in Nederland met betrekking tot de doelstellingen van groepstherapie bij SA. Echter, over de uitwerking van deze doelstellingen in de praktijk lopen de meningen nogal uiteen. De organisatie van ce therapie, zoals de groepsgrootte, de diverse onderdelen en de duur, is duidelijk verschillend bij de diverse groepen.

In hoofdstuk 3 worden de therapeutische effekten van begeleide individuele oefentherapie bij SA in een 'before-after' studie behandeld. De resultaten laten zien dat 6 weken begeleide individuele oefentherapie geringe maar positieve effecten heeft op de spinale mobiliteit, de fitheid, het functioneren en de globale gezondheid. De mate van verbetering is vrijwel hetzelfde bij zowel relatief recent gediagnostiseerde als bij reeds lang bestaande SA.

In hoofdstuk 4 gaat het over de meerwaarde van begeleide groepsoefentherapie boven niet begeleide individuele therapie bij SA. Effectmaten zijn: globale gezondheid, spinale mobiliteit, fitheid en functioneren. $\mathrm{Na} 9$ maanden is groepstherapie effectiever dan individuele therapie ten aanzien van de thoraco-lumbale mobiliteit en de fitheid. Tevens rapporteren de patiënten dat groepstherapie een belangrijk positief effect heeft op de globale gezondheid.

In hoofdstuk 5 wordt de vraag beantwoord of het zinvol is groepsoefentherapie bij SA te continueren. Wordt de groepstherapie stop gezet dan verslechteren de patiënten op alle effectmaten. Wanneer men de groepstherapie met 9 
maanden verlengt blijven de globale gezondheid en het functioneren stabiel of verbeteren nog licht. Groepstherapie heeft bovendien een positieve invloed op het doen van oefeningen thuis.

In hoofdstuk 6 wordt de kosten-effectiviteit van groepstherapie besproken. Vergeleken met thuis oefenen levert groepstherapie na 9 maanden een extra verbetering van $7 \%$ in spinale mobiliteit, $5 \%$ extra verbetering in fitheid en $28 \%$ extra verbetring in globale gezondheid voor een bedrag van 1001 gulden per jaar. De directe medische kosten worden met 230 gulden per jaar gereduceerd. De effecten van groepstherapie kosten dus 771 gulden per jaar, oftewel bijna 20 gulden per wekelijkse therapiesessie ( 40 sessies per jaar).

In hoofdstuk 7 worden de factoren die samenhangen met de verandering in de globale gezondheid na groepstherapie bij SA besproken. Globale gezondheid blijkt gerela-teerd aan andere effectmaten, zoals de mate van fitheid en stijfheid.

In hoofdstuk 8 worden de determinanten van de ervaren gezondheidstoestand bij SA besproken. Het blijkt dat de mening over het eigen functioneren sterker gerelateerd is aan persooniijkheidskenmerken zoals neuroticisme, dan aan de mate van aktiviteit van de ziekte.

In hoofdstuk 9 worden de verschillen beschreven tussen zelf-rapportage en klinische observatie van het functioneren van patiënten met SA, Rheumatoïde Arthritis (RA) en Fibromyalgie. Het verschil tussen zelfrapportage en klinische observatie is het meest uitgesproken bij Fibromyalgie patiënten. De zelfrapportages van de SA patiënten stemmen in hoge mate overeen met de observaties van de clinici.

In hoofdstuk 10 worden enkele kanttekeningen geplaatst bij de studie beschreven in dit proefschrift. 


\section{CURRICULUM VITAE}

27-12-1960 geboren te Groningen

Opleidingen

1973 - 1980 Atheneum

Gomaruscollege, Groningen

1980 - 1984 Fysiotherapie

Academie voor Fysiotherapie,

Leeuwarden

1984 - 1987 Bewegingswetenschappen

Rijksuniversiteit Groningen

Werkzaamheden

1986 - 1988 Fysiotherapeut

Afdeling Interne Geneeskunde

Academisch Ziekenhuis

Groningen

1988 - 1989 Fysiotherapeut

Praktijk voor Fysiotherapie in

Landgraaf

1990 - 1993 Wetenschappelijk Medewerker

Afdeling Interne Geneeskunde

Werkgroep Reumatologie

Academisch Ziekenhuis

Maastricht

1993 - heden Opleidingscoördinator

Netherlands Institute for Health

Sciences, Erasmus Universiteit

Rotterdam

en

Netherlands School of Public

Health, Utrecht 